KfK 5102

Februar 1993

\title{
MHD Flow in Multichannel U-Bends: Screening Experiments and Theoretical Analysis
}

J. Reimann, S. Molokov, I. Platnieks, E. Platacis Institut für Angewandte Thermo- und Fluiddynamik

Projekt Kernfusion

\section{Kernforschungszentrum Karlsruhe}





\title{
KERNFORSCHUNGSZENTRUM KARLSRUHE \\ Institut für Angewand te Thermo- und Fluiddynamik Projekt Kernfusion
}

\section{KIK 5102}

\begin{abstract}
MHD Flow in Multichannel U-Bends: Screening Experiments and Theoretical Analysis
\end{abstract}

\author{
đ. Reimann. S. Molokov, I. Platnieks*, E. Platacis* \\ * Latvian Academy of Sciences, Institute of Physics, Salaspils, Latvia
}

Kernforschungszentrum Karlsruhe GmbH, Karlsruhe 
Als Manuskript gedruckt

Für diesen Bericht behalten wir uns alle Rechte vor

Kernforschungszentrum Karlsruhe $\mathrm{GmbH}$

Postfach 3640, 7500 Karlsruhe 1

ISSN 0303-4003 


\section{ABSTRAC'T}

In electrically coupled multichannel ducts with a U-bend geometry magnetohydrodynamic effects are expected to cause strongly ununiform distributions of flow rates $\mathrm{Q}_{\mathrm{i}}$ and pressure drops $\Delta \mathrm{p}_{\mathrm{i}}$ in the individual channels. A multichannel $\mathrm{U}$ bend geometry is part of the KfK self-cooled $\mathrm{Pb}-17 \mathrm{Li}$ blanket design (radialtoroidal-radial channels), however, inserts are proposed which isolate electrically the radial channels (not the toroidal ones).

To investigate the multichannel effect (MCE), screening experiments were performed at LAS, Riga, Latvia with different flow channel geometries and channel numbers between 1 and 5 and using InGaSn as liquid metal. These experiments were carried out with either $\Delta \mathrm{p}_{\mathrm{i}} \approx$ const or $\mathrm{Q}_{\mathrm{i}} \approx$ const. Hartmann Numbers were varied between 0 and $\approx 1600$ (maximum magnetic field strength: $4.1 \mathrm{~T}$ ) and Interaction Parameters between 0 and 10000 .

For experiments with electrically conducting walls between the channels, the volume flow rates in the outer channels are significantly larger than those in the inner channels in the experiments with $\Delta \mathrm{p}_{\mathrm{i}} \approx$ const. For $\mathrm{Q}_{\mathrm{i}} \approx$ const., this tendency is reversed, with the highest pressure drop in the middle channel and the lowest in the outer channels. No significant difference is observed between conducting and nonconducting outside walls. There is also no marked difference between the multichannel $\mathrm{U}$ bend and the multichannel $90^{\circ}$ bend. An inclination of the magnetic field of $12^{\circ}$ in the plane of the toroidal channels does not effect remarkable the volume flow rate and the pressure distribution.

The flow geometry with electrically separated radial channels, similar to the KfKdesign result in a fairly even flow rate and pressure drop distribution. The single channels behave approximately like electrically separated channels; no marked MCE occurrs.

A theoretical analysis was carried out to describe the MCE for the multichannel U-bend with thin electrically conducting outside walls. This analysis is based on the Core Flow Approximation (CFA), valid for infinitely large Interaction Parameters and Hartmann Numbers. The theory predicts correctly all tendencies observed for the pressure measurements. Moreover, the method is able to describe in detail the flow structure in the toroidal channel. The most essential result is that the flow rate in the layer close to the First Wall increases significantly with increasing channel number. This tendency is very benificial for heat transfer in a fusion blanket. 


\section{MHD-Strömung in Mehrkanal-U-Umlenkungen: Screening Experimente und theoretische Analysen}

\section{Zusammenfassung}

In elektrisch gekoppelten Mehrkanal-Strömungsführungen mit U-förmiger Geometrie erwartet man aufgrund magnetohydrodynamischer Effekte eine stark ungleichförmige Verteilung der Durchsätze $Q_{i}$ und der Druckverluste $\Delta \mathrm{p}_{i}$. Eine solche U-förmige Strömungsführung wird bei dem vom KfK-vorgeschlagenenen selbstgekühlten $\mathrm{Pb}$-17Li Blanket Konzept verwendet (radiale-toroidale-radiale Kanäle). Allerdings werden dabei Einsätze verwendet, die die radialen Kanäle (nicht die toroidalen) voneinander elektrisch isolieren.

Zur Untersuchung des Vielkanaleffektes (VKE) wurden in Riga, Lettland Screening-Experimente mit InGaSn durchgeführt mit verschiedenen Kanalgeometrien und Kanalzahlen 1 bis 5 . In den Versuchen wurde entweder $\Delta \mathrm{p}_{\mathrm{i}}$ oder $\mathrm{Q}_{\mathrm{i}}$ konstant gehalten bei Variation der Hartmannzahlen zwischen 0 bis 1600 (maximale magnetische Feldstärke 4.1 T) und Interaktionsparameter zwischen 0 und 10000 .

Bei Verwendung von elektrisch leitenden Wänden zwischen den Kanälen zeigt sich für $\Delta \mathrm{p}_{\mathrm{i}} \approx$ const., daß die Volumenströme in den äußeren Kanälen wesentlich höher sind als in den inneren Kanälen. Bei $Q_{\mathrm{i}} \approx$ const ist die Tendenz umgekehrt: hier treten die höchsten Druckverluste im inneren Kanal auf und die niedrigsten in den Außenkanälen. Zwischen Kanälen mit elektrisch leitfähigen oder nichtleitenden Außenwänden ist kein ausgeprägter Unterschied vorhanden. Nur geringfügige Unterschiede ergeben sich auch beim Vergleich einer mehrkanaligen Uförmigen Strömungsführung mit einem mehrkanaligen $90^{\circ}$ Krümmer. Eine Neigung des Magnetfeldes um $12^{\circ}$ in der Ebene der toroidalen Kanäle bewirkt keine signifikante Änderung der Volumenstrom- und Druckverlustverteilungen.

Die Strömungsgeometrie, die ähnlich wie der KfK Entwurf mit elektrisch isolierten Radialkanälen ist, bewirkt eine recht gleichmäßige Verteilung in bezug auf Durchfluß und Druckverlust. Die einzelnen Kanäle verhalten sich in erster Näherung wie elektrisch separate Kanäle, es wurde kein ausgeprägter VKE beobachtet.

Eine theoretische Analyse wurde durchgeführt, um den VKE für die Mehrkanalgeometrie mit leitenden Außenwänden zu beschreiben. Die Analyse basiert auf der sog. Core Flow Approximation, gültig für unendlich große Interaktionsparameter und Hartmannzahlen. Die Theorie beschreibt korrekt alle bei den Druckmessungen beobachteten Tendenzen. Darüberhinaus ist das Verfahren in der Lage, die Strömungsstruktur im toroidalen Kanal detailliert zu beschreiben. Das wesentlichste Ergebnis ist, daß mit zunehmender Kanalzahl der Volumenstrom in der Schicht nahe der Ersten Wand erheblich zunimmt. Diese Tendenz ist sehr günstig in bezug auf die Wärmeabfuhr in einem Blanket. 


\section{Contents}

Seite

\section{ABSTRACT \\ ZUSAMMENFASSUNG}

1. INTRODUCTION 1

2. MULTICHANNEL EFFECTS 4

2.1 Phenomena 4

2.2 The Madarame Model $\quad 7$

3. EXPERIMENTS 13

3.1 Test Sections 13

$\begin{array}{ll}3.2 \text { Measurement Systems } & 16\end{array}$

3.2.1 Measurement of Flow Rates $\quad 16$

$\begin{array}{ll}3.2 .2 \text { Determination of Leakage Flows } & 19\end{array}$

3.2.3 Measurement of Differential Pressures $\quad 20$

3.2.4 Data Acquisition System 23

$\begin{array}{ll}3.3 \text { Test Matrix } & 26\end{array}$

4. THEORETICAL ANALYSIS AND ESSENTIAL RESULTS 32

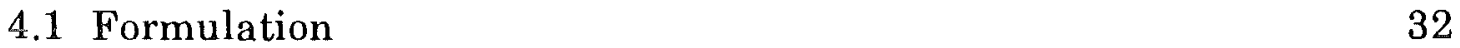

4.2 Flow Analysis at Large Hartmann Numbers 35

$\begin{array}{ll}4.3 \text { Numerical Algorithm } & 36\end{array}$

$\begin{array}{ll}4.4 \text { Essential Results } & 37\end{array}$

5. EXPERIMENTAL RESULTS 42

$\begin{array}{ll}5.1 \text { General Tendencies } & 42\end{array}$

5.2 Volume Flow Rate Distribution for $\Delta \mathrm{p}_{\mathrm{i}} \approx$ const.

5.2.1 Dependence on Hartmann Number and Interaction
Parameter

5.2.2 Dependence on Channel Geometry and Channel Number k 55

5.3 Pressure Distribution $\quad 57$

5.3.1 Single Channel Pressure Drop 57

5.3.2 Multichannel Duct: Dependence on Interaction Parameter 59

5.3.3 Comparison of Different Channel Geometries at high $N$ and $Q_{i} \approx$ const. $\quad 66$

5.4 Effect of Inclination $\quad 68$

5.4.1 Single Channel U-bend 68

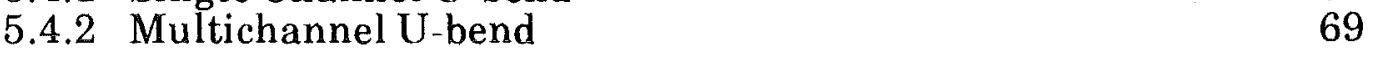

6. CONCLUSIONS

ACKNOWLEDGEMENT

REFERENCES

APPENDIX 


\section{INTRODUCTION}

Magnetohydrodynamic (MHD) pressure drop is thoncritical issue for self-cooled liquid metal blankets for fusion reactors. The knowledge of MHD flows was insufficient to predict satisfactorily all flow geometries of interest.

In the design proposed by KfK (Malang et al. [1-3]) one important example for this is the radial-toroidal-radial multichannel geometry as shown in Fig. 1.1, from [1]. Parallel toroidal first wall cooling channels where the main component of the magnetic field is aligned with the flow direction are connected with parallel radial inlet and outlet channels where the magnetic field is perpendicular to the flow direction. Therefore, this geometry corresponds to a multichannel U-bend. Compared to a single-channel U-bend large electrical currents may be induced across the radial channels which can result in prohibitively high pressure drops if no measures are taken against the induction of these currents. In the KfK design, flow channel inserts (FCI's) are used in the radial channels (for details see [3]), which should reduce significantly these currents. However, the remaining pressure drop, predicted by an electrical network method (for details see [3]), was still about $1 \mathrm{MPa}$ which is about one third of the total pressure drop of the blanket.

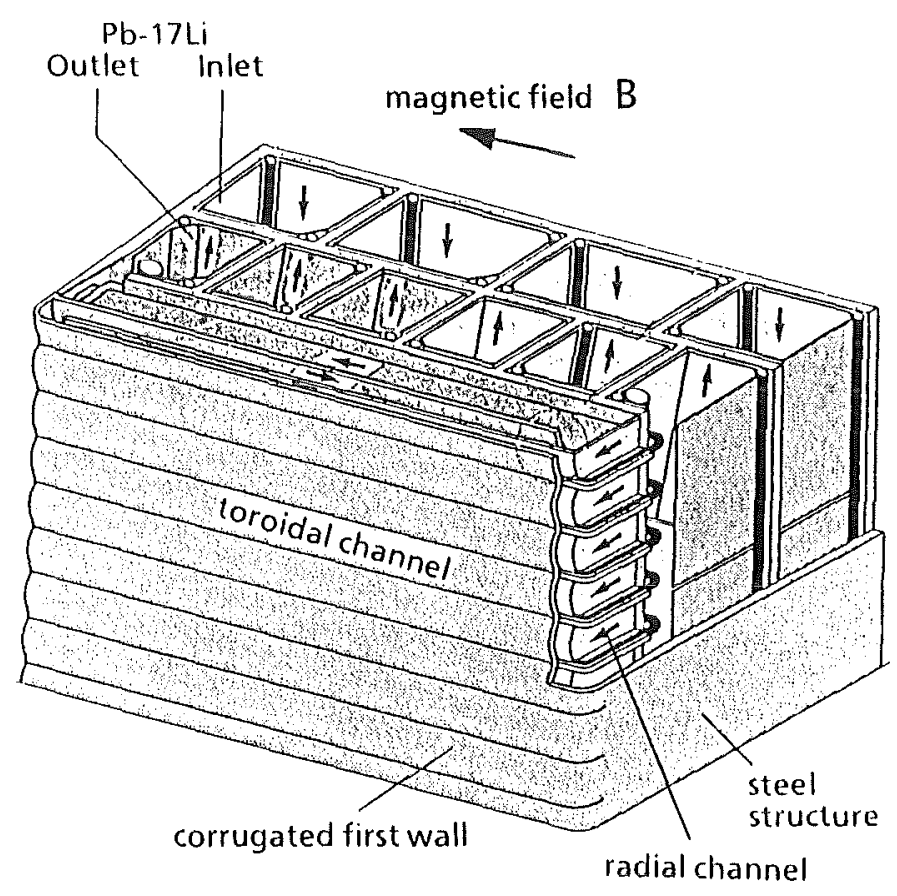

Fig. 1.1: Cross-section of a self-cooled $\mathrm{Pb}$-17Li blanket segment for DEMO (Malang et al [1]). 
The pressure drop due to this multichannel effect (denominated with MCE) is so important for the present design that specific experiments have to be carried out and more accurate prediction methods have to be developed.

The MCE effect was first investigated theoretically by Madarame [4] using strongly simplifying assumptions with respect to the velocity distribution in the liquid metal. Although this model cannot be applied quantitatively for the present geometry, it shows the significant tendencies. Therefore, this model is discussed in more detail in the next section.

In order to investigate in more detail the MCE, both experimental and theoretical work is underway. Experimentally, two types of experiments were planned:

A) Screening tests: The aim is to obtain in a short period of time information on the essential effects. Therefore, the experimental set-up should be simple, however, should include the variation of flow geometries. The measurements should be limited to the measurements of the most important parameters, which are the volume flow rates and pressure drops in the single channels and the magnetic field strength.

In order to vary easily the flow geometries a liquid metal which does not react chemically with air or humidity is advantageous because it allows opening of the test section and exchanging parts without a big effort of safety measures. Such a liquid metal is the alloy InGaSn which is used since many years in the MHD laboratory of the Institute of Physics (IP) of the Latvian Academy of Sciences (LAS) in Salaspils close to Riga, Latvia. In this institute a powerful supraconducting magnet can be operated (MAGDA magnet; $\mathrm{B}_{\max }=4,5 \mathrm{~T}$ ). In the frame of a joint cooperation the screening tests were performed there and the discussion of the corresponding results is the subject of this report.

B) Detailed Experiments: Here the aim is to provide data for code validation. The efforts in manufacturing of the test section are much larger compared to A) and the detailed measurement of local quantities such as potentials at the test section surface and pressures at many locations is required. These experiments will be performed with $\mathrm{NaK}$ as liquid metal in the MEKKA facility of the Institute of Applied Thermo- and Fluid Dynamics (IATF) of the Kernforschungszentrum Karlsruhe (KfK). Presently, this test section is manufactured; the experiments are planned to start in the end of 1992. 
The theoretical work concentrates on the use of asymptotic solutions for both fully developed flow and three-dimensional flow. 


\section{MULTICHANNEL EFFECTS}

\subsection{Phenomena}

In a straight duct with parallel conducting channels and a magnetic field perpendicular to the flow direction but aligned with the front plane of the duct (see Fig. 2.1a (from [4]), the eddy currents induced in the coolant flow back through the ribs. There is no current from one channel to another channel, therefore, a MCE does not exist.

If the magnetic field is perpendicular to the front plane, see Fig. $2.1 \mathrm{~b}$ then the electrical currents in the outside wall of the outside channels is different from the current in the inside walls (even if the rib is twice as thick as the other walls which means that each channel has equal wall thickness on all sides). The electrical current flows to a larger degree in the outside wall than in the rib because the current direction from the neighboring channel is opposite which has the consequence that a larger portion of the current is flowing through the Hartmann wall. This asymmetry results in an electrical current across the channels in the side walls with the result that pressure drops and velocity distributions are no longer identical for each channel. Fig. 2.2, calculated with the code developed by Molokov [5], shows schematically the velocity distribution for three connected channels, assuming equal flow rates through the channels which results in a higher pressure drop in the middle channel compared to the outside channels. The electrical currents in this flow situation are purely two-dimensional. Therefore, this is designated in the following with 2d MCE.

The MCE may be increased for the flow geometry shown in Fig. 2.1c. Here, the electric currents induced in the radial channels close to the bend can flow back in the first wall, the second wall and in the liquid metal in the toroidal region. Therefore, an additional $3 \mathrm{~d}$ MCE occurs.

This 3d MCE can be even stronger for the double bend (U bend) geometry, shown in Fig. 2.1d. Due to the opposite flow direction in the second bend, the induced current in the entrance region has an opposite direction and the global currents may even flow from one bend to the other.

The MCE for the flow situation in Fig. 2.2 only occurs if the Hartmann and channel side walls are electrically conducting. For the geometries Fig. 2.1c) and d) the MCE also exists for conducting ribs but nonconducting outside walls. (In the following the rib is also designated as dividing wall). 


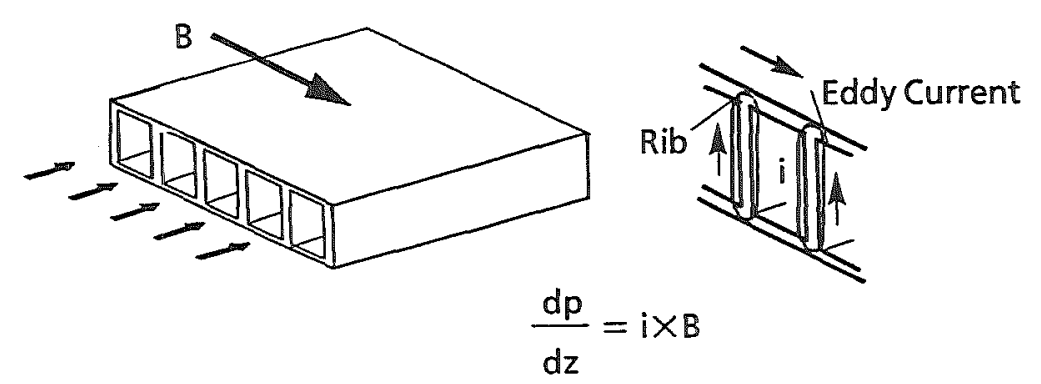

no multichannel effect (MCE)

a) straight multichannel duct; magnetic field parallel to front plate

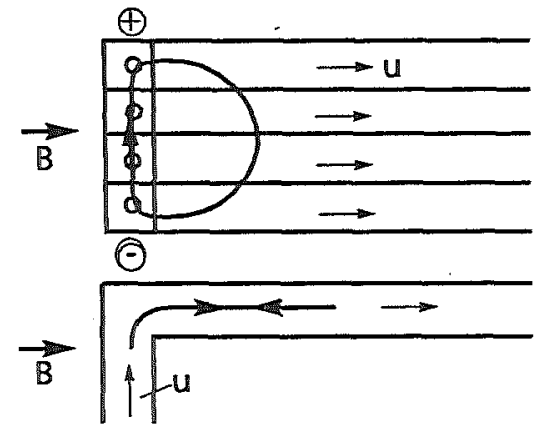

$2 \mathrm{~d}+3 \mathrm{~d} \mathrm{MCE}$

c) multichannel single bend

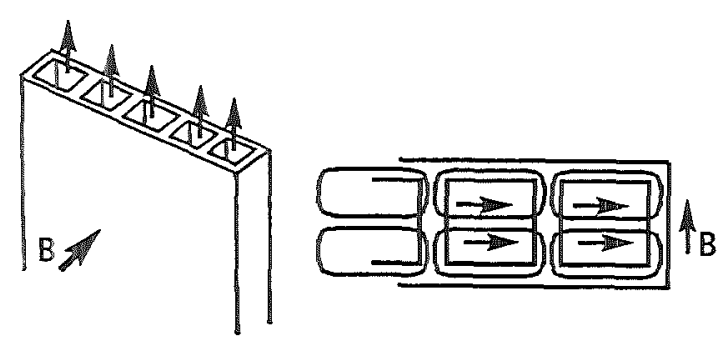

2d MCE

b) straight multichannel duct: magnetic field perpendicular to front plate

d) multichannel $U$ bend

Figure 2.1 Multichannel flow situations in a magnetic field 


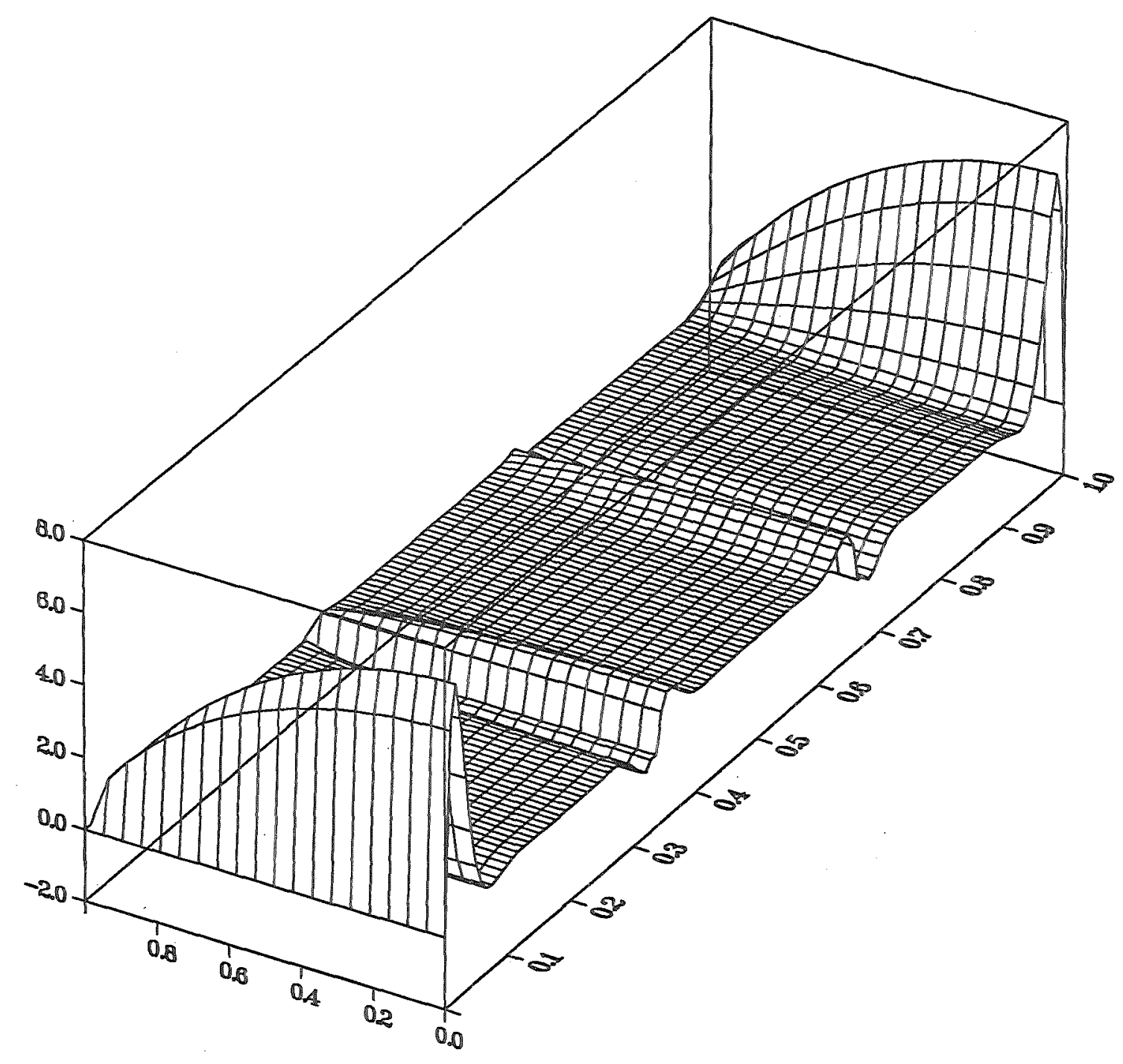

Figure 2.2 Velocity distribution in parallel channels with a magnetic field perpendicular to the front plate (Molokov [5]) 
For the self-cooled blanket the MCE is, of course, very undesired due to the increased pressure drop. An effective method to decrease the MCE is to prevent the development of electrical currents in the radial channels close to the bends using a nonconducting dividing wall. This method, already proposed very early [4] is also realized in the KfK design by the use of the flow channel inserts, compare Section 1.

\subsection{The Madarame Model}

The flow geometry Madarame [4] used in his analyses is a U-bend as shown in Fig. 2.3a. In contrast to the KfK design the length of the radial channels (orifices) is very small (corresponding to the thickness of the second wall). For our considerations this difference is of minor importance. The most important assumption is, however, that the eddy currents only flow in the plane of the outlet of the orifices and that they only can form a closed circuit in the second wall. This assumption might be justified for a large thickness of the second wall but not for other conditions (thin or electrically nonconducting second wall).

Figure 2.3b shows the geometrical parameters. In a first approach the thickness of the dividing walls is neglected, the electrical conductivities, $\sigma$, of liquid metal and wall material are assumed to be the same and the velocity, $\mathrm{w}_{\mathrm{b}}$, is constant in the plane of the second wall.

'The generation of eddy currents, and hence MHD pressure drop, depends on two factors: the presence of an EMF "driving term" and the presence of a closed circuit for currents to flow.

The coolant flowing across the magnetic field in the area between $x=0$ and $x=a$ creates a y-directional electromotive force. If a closed circuit exists, an eddy current will flow in the y direction.

Part of the current flows back through the neighborhood of $x=a$. The current flows in an elliptic circuit around the point $\mathrm{x}=\mathrm{a}$ and $\mathrm{y}=0$ elongated in the $\mathrm{y}$ direction. The other part of the current reaches the orifices at the other end of the module. Since the direction of the electromotive force is opposite at the other end, the current flows in the opposite direction and returns. The circuit narrows near the edge of the blanket. The current intensity is not uniform; therefore the distribution of the current intensity must be considered. 


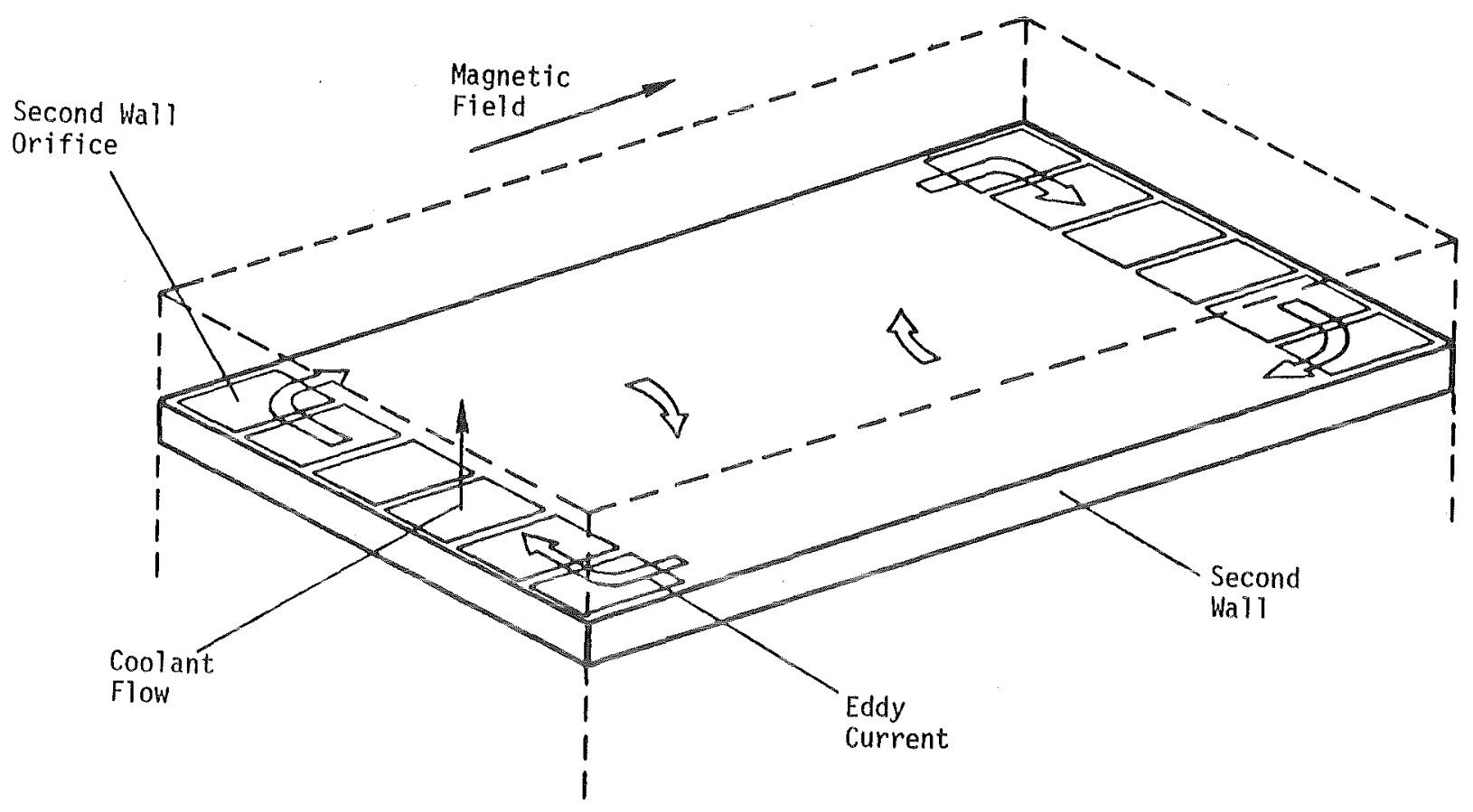

a) Eddy current induced in second wall orifices

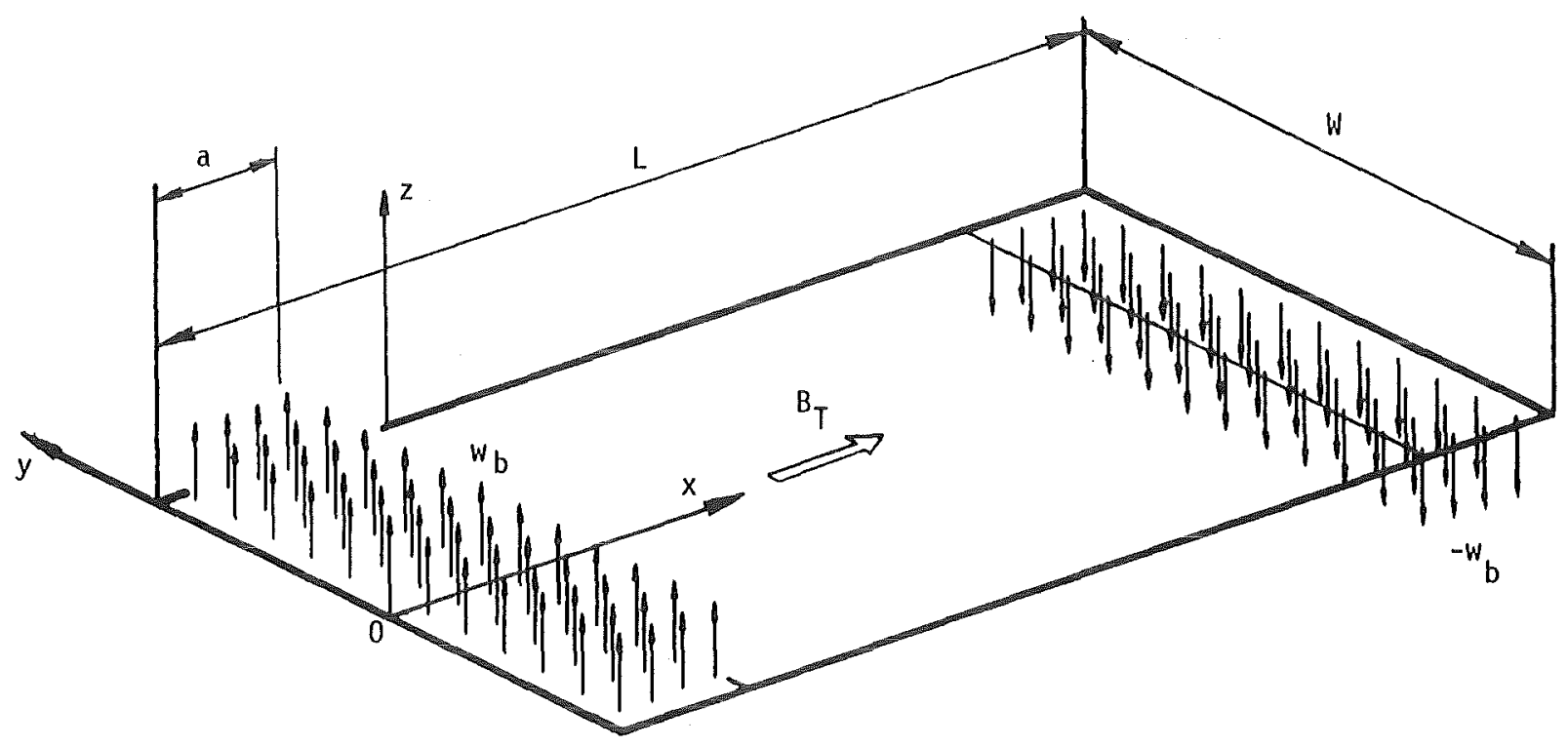

b) Slug flow model

Fig. 2.3: Madarame's model assumptions (from [4]) 
The conductivity of the path depends on the current flow pattern. Therefore, the poloidal component of the current intensity $i_{p}$ in the orifices is taken into account by a factor $\overline{\mathrm{C}}$ :

$$
\mathrm{i}_{\mathrm{p}}=\overline{\mathrm{C}} \sigma \mathrm{B} \mathrm{w}_{\mathrm{b}}
$$

where $B$ is the magnetic field strength and $\bar{C}$ is a function of $W / a$, and the location in the opening $(\mathrm{x} / \mathrm{a}, \mathrm{y} / \mathrm{W})$.

\section{MHD Pressure Drop}

Eddy currents in the magnetic field generate electromagnetic forces in the coolant. The force usually impedes the flow, thus an MHD pressure drop arises in the coolant. The averaged pressure drop in the orifices is expressed as follows:

$$
-\frac{d p}{d z}=\bar{C} \sigma B^{2} w_{b}
$$

Figure 2.4 shows the value $\bar{C}$ in the case of $a=b$ and $L / a=10$. The poloidal width of the blanket module $\mathrm{W}$ is $\mathrm{k}_{\max }$ times the poloidal width of the orifice $\mathrm{b}$, where $\mathrm{k}_{\max }$ is the number of inlet or outlet orifices. The MHD pressure drop increases with increasing number of orifices, but $\overline{\mathrm{C}}$ never exceeds unity. When there are several orifices, the pressure drop is high in the central orifices and is relatively low in orifices near the poloidal ends of the blanket module. Figure 2.5 shows the value of $\bar{C}$ in the middle orifice when there are many orifices. It is a function of W/a and L/a. If W/a is larger than $100, \bar{C}$ is unity regardless of the value of $\mathrm{L} / \mathrm{a}$.

The current flow pattern changes greatly if there are any obstructions in the plane. An insulating partition parallel to the magnetic field in the opening of the second wall distorts the circuit and increases resistance. Figure 2.6 shows the eddy current distribution in the case of $\mathrm{W} / \mathrm{a}=10$ and $\mathrm{L} / \mathrm{a}=10$. There are insulating partitions of length $l_{p}$ between each orifice of poloidal width $b$. Both $l_{p}$ and $b$ are equal to $a$ in the figure. Since there is no insulation between $x=a$ and $x=L-a$, the multichannel effect still remains. But the flow pattern in each orifice is similar to the pattern in the single orifice case. Figure 2.7 shows the effect of the insulating partitions between the orifices on the MHD pressure drop in the case of $W / a=10$, $L / a=10$ and $b / a=1$. Insulating partitions of length $l_{p}=a$ decrease the pressure drop greatly. 


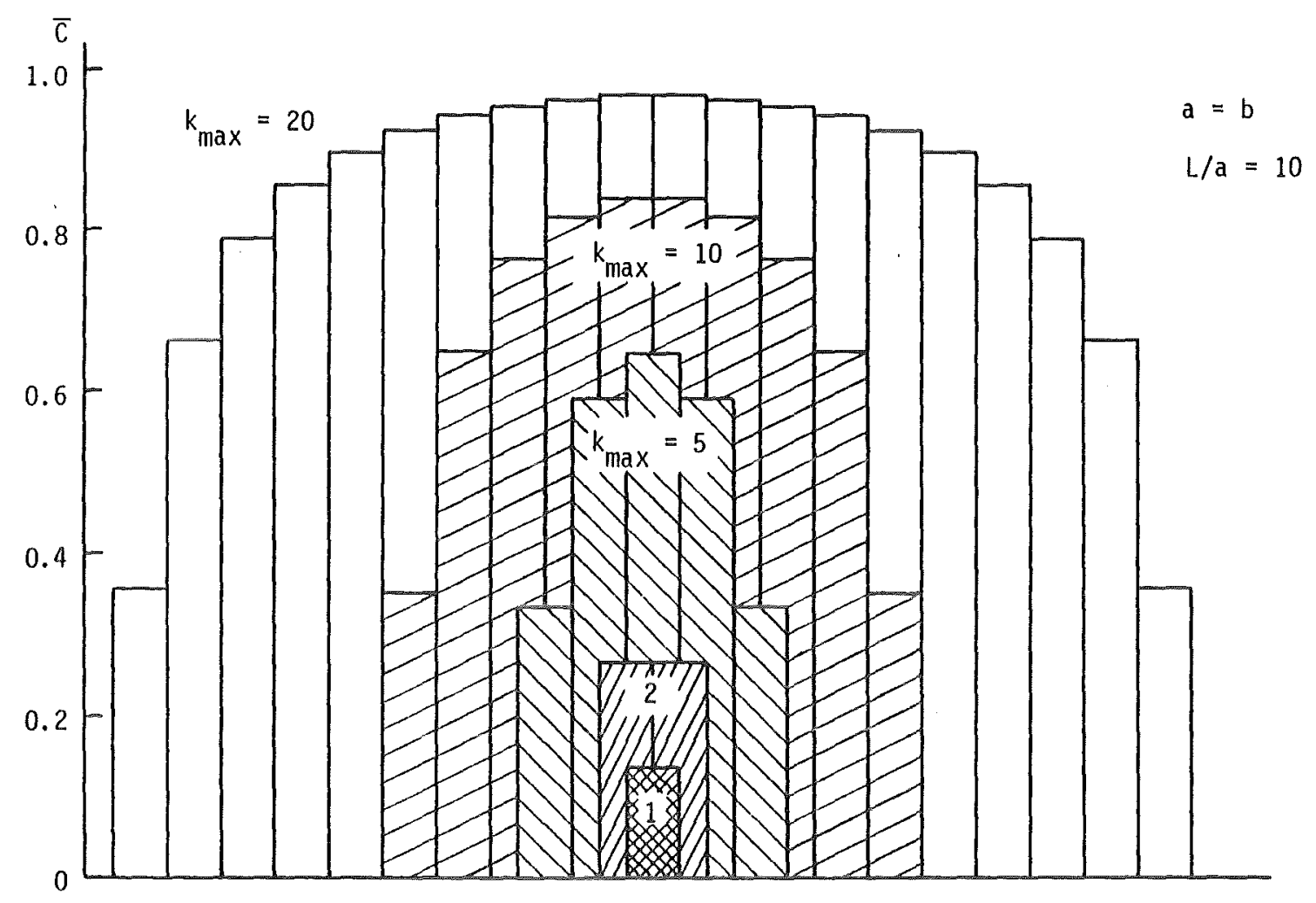

Fig. 2.4: Average pressure drop coefficient in each orifice (from [4])

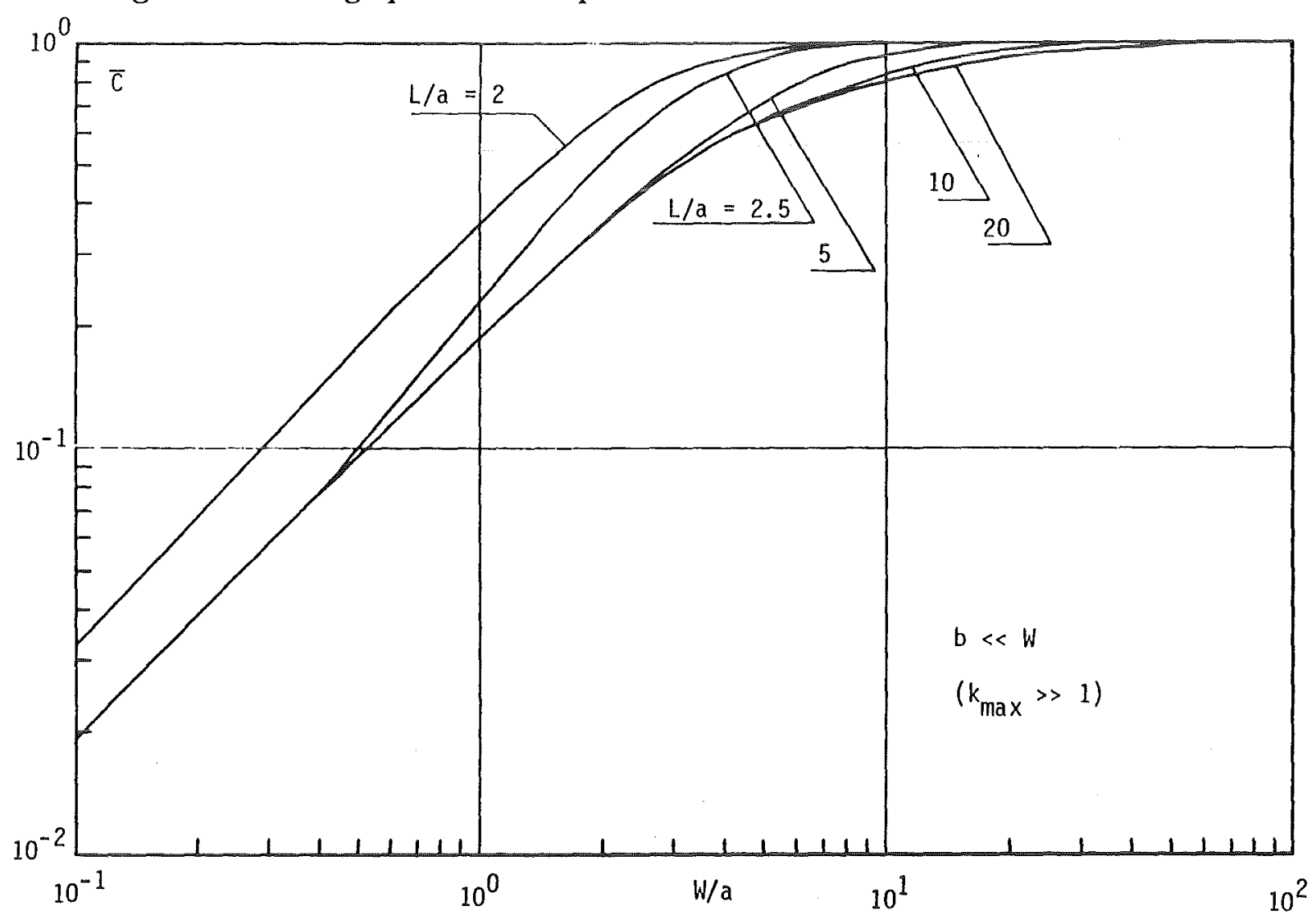

Fig. 2.5: Average pressure drop coefficient in middle orifice (from [4]) 


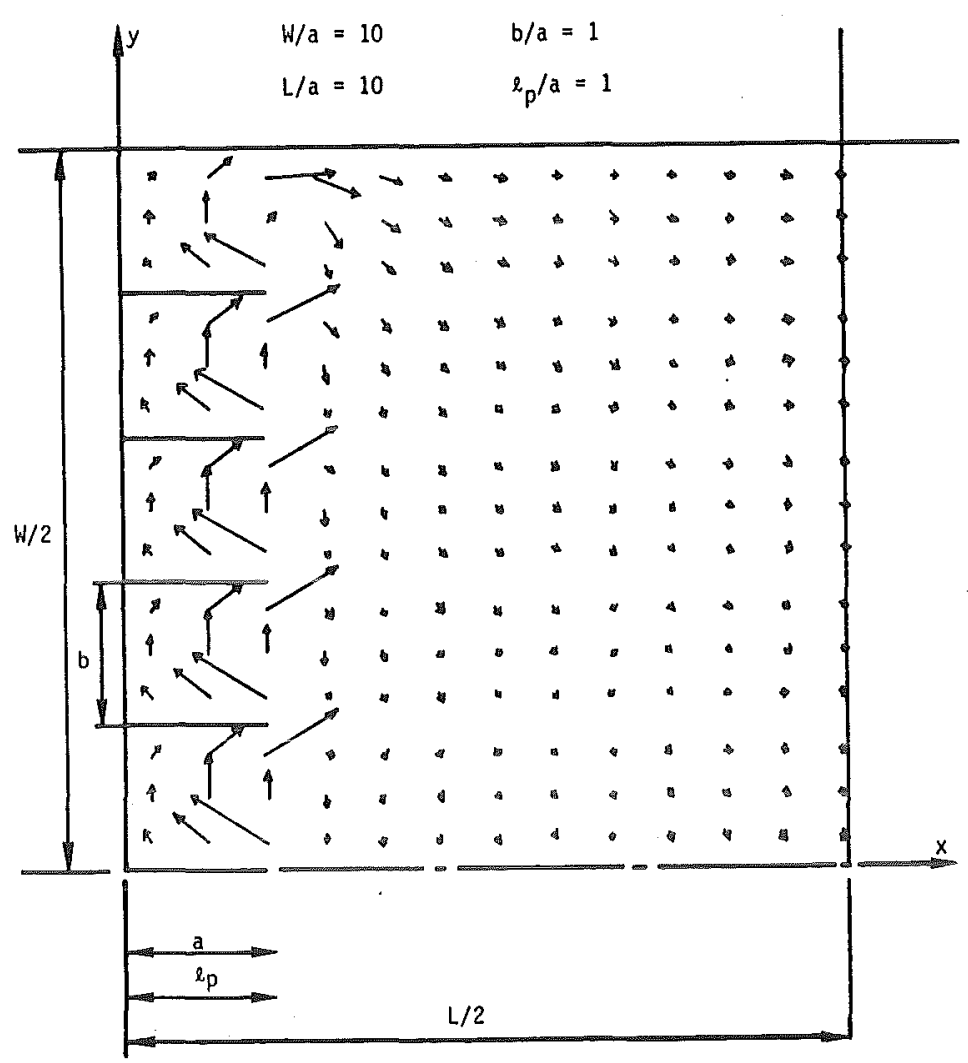

Fig. 2.6: Eddy current distribution with insulator in radial direction (from [4])

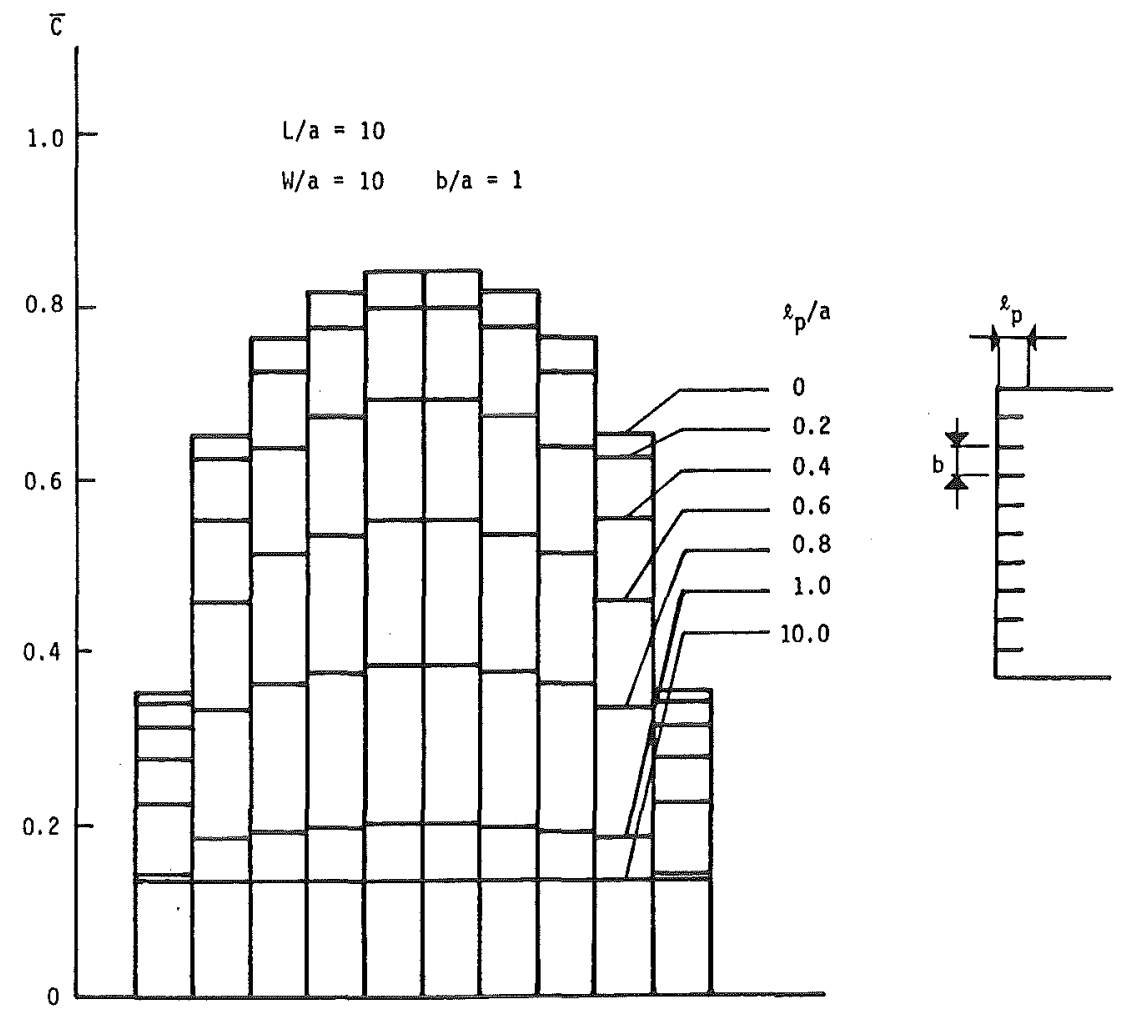

Fig. 2.7: Effect of insulator length on pressure drop (from [4]) 
In order to obtain values for the pressure drop the thickness of the second wall is used for $\mathrm{dz}$ in $\mathrm{Eq}$ (1). This is certainly not a good choice concerning the real flow situation. Madarame has also considered more realistic flow profiles in the orifice plane and the influence of the thickness of the dividing walls. However, the assumption is still used that the currents flow only in the plane of the second wall. 


\section{EXPERIMENTAL, SE'T-UP}

\subsection{Test Sections}

The experiments were performed in the MHD laboratory of the IP using the supraconducting MAGDA magnet with a cylindrical volume of the homogeneous magnetic field of $400 \mathrm{~mm}$ in diameter and $600 \mathrm{~mm}$ in length.

The total test loop was mounted on a vehicle and the test section could be introduced in the magnet.

Figure 3.1 shows schematically the main part of the test loop (storage vessel, purge gas and vacuum system not shown). A test section with 5 parallel channels was used. The volume flow rate of each channel was measured with an electromagnetic flowmeter $Q_{1}-Q_{5}$; the total volume flow rate was additionally measured with the flowmeter $Q_{0}$. The liquid metal was circulated by means of an electromagnetic pump; the flow direction could be reversed.

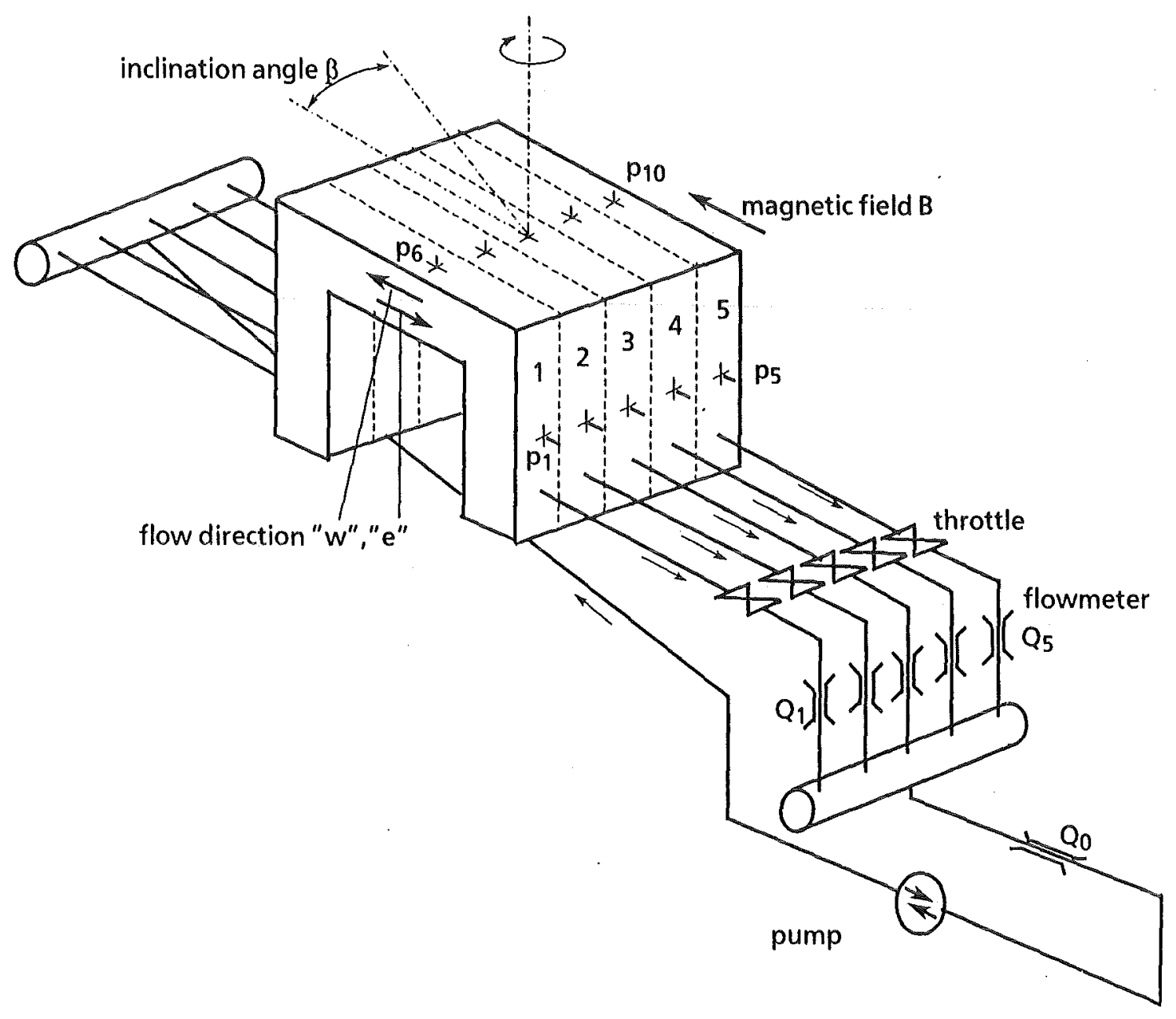

Fig. 3.1: Schematic figure of test loop 


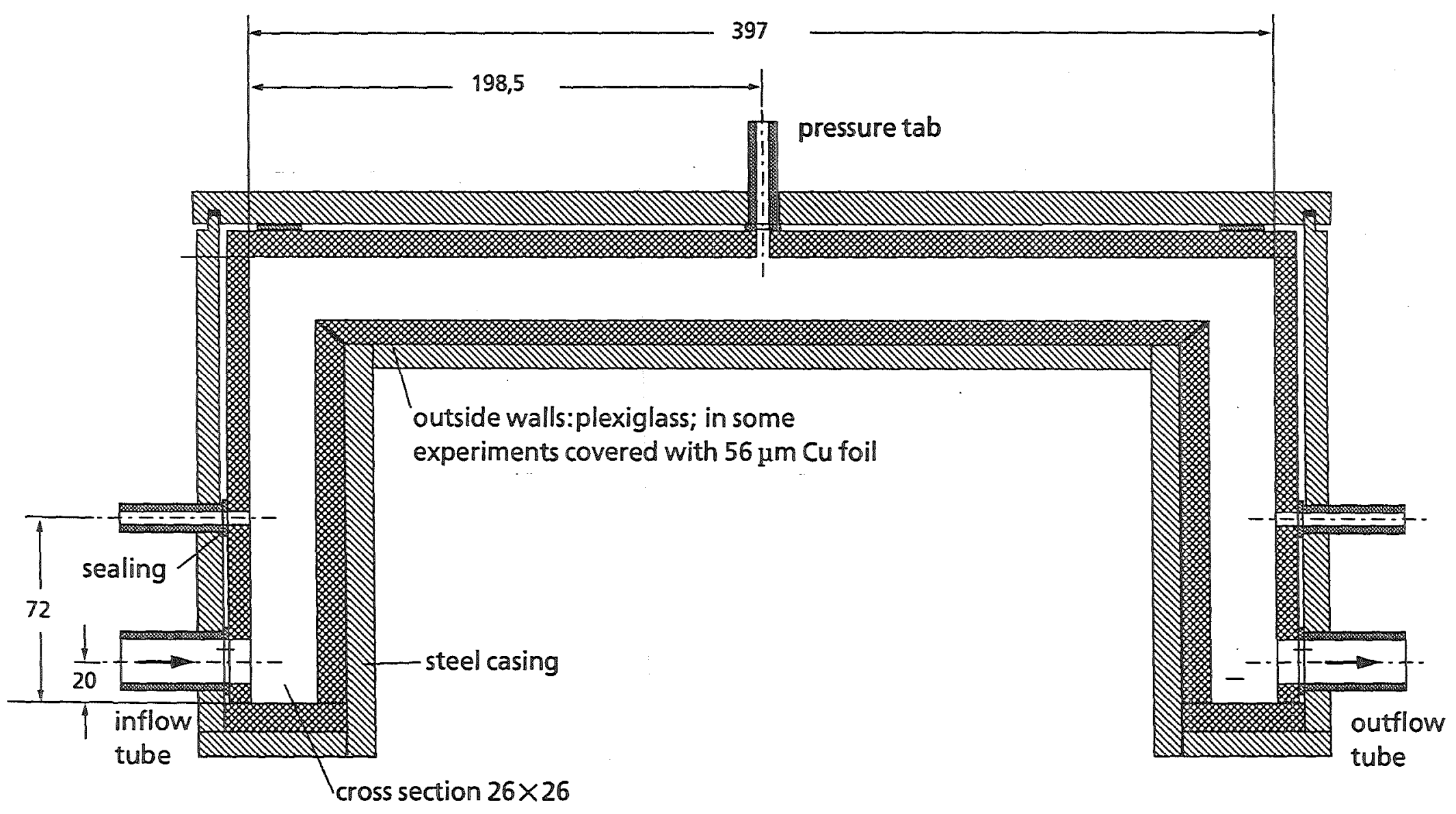

Figure 3.2 Test section 

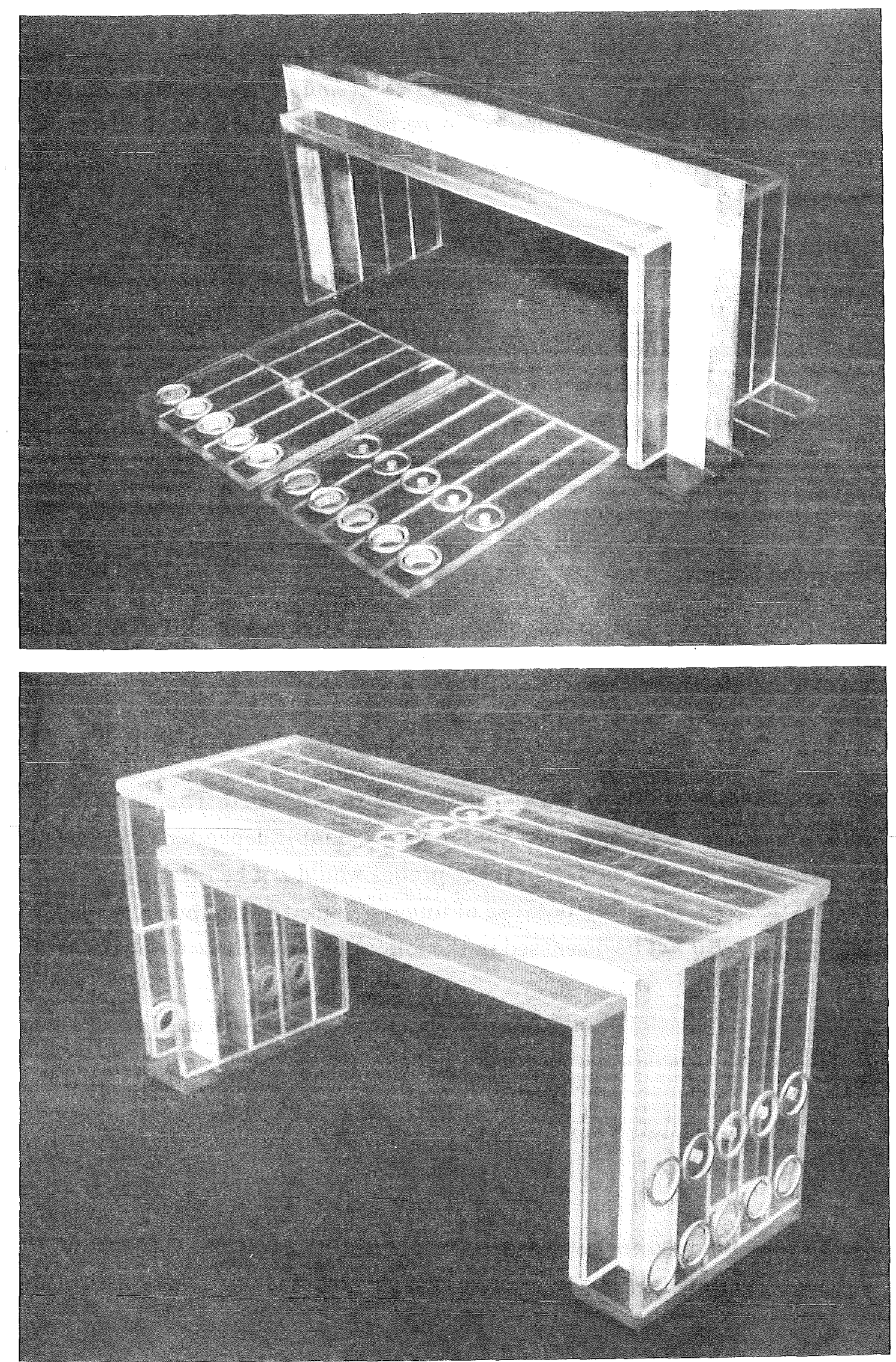

Figure 3.3 Photographs of inserts 
The test section was connected with flexible plastic tubes with the downstream reservoir and with the stainless steel tubes upstream of the throttles. Due to this flexible connection the test section could be turned around a vertical axis in the middle of the test section by $\pm 12^{\circ}$. Throttling of the throughput was performed by squeezing the plastic tubes.

Figure 3.2 shows a drawing of the test section. A steel casing with a removable top plate contained the exchangeable parts of the test section. The outside walls consisted of plexiglass plates with grooves in which the U-type inserts which divided the channels (dividing walls) were slided. The sides of the plexiglass walls facing to the liquid metal could be covered with a $100 \mu \mathrm{m}$ thick copper foil to simulate thin conducting outside walls. Between steel casing and plexiglass walls rubber sealings existed at the flow inlet and outlet tube and the pressure tabs to secure that no leakage flows occurred. Figure 3.3 shows photographs of the inserts outside the housing.

The pressure differences were measured between positions in the channels perpendicular to the B field (the "radial" channels) and the middle of the channels aligned with the B field (the "toroidal" channels).

In the second set of radial channels, electrodes were located. The idea was to use the voltage difference $\Delta E_{i}$ for flow rate measurement independent from the flowmeters. However, the signals from these probes would not be interpreted in terms of mean flow rates, probably because of uneven velocity distributions. These signals, therefore, will not be discussed in the following.

The different conditions of outside walls and dividing walls used in the experiments will be discussed in Section 3.3.

\subsection{Measurement Systems}

\subsubsection{Measurement of Flow Rates}

Table 3.1 shows the calibration constants for the different flowmeters for a calibration curve of the type

$$
Q_{i}(l s)=A+B K^{*} Q_{i}(V)
$$

where $\mathrm{K}^{*}$ is the correction for the influence of the magnetic field, see below 


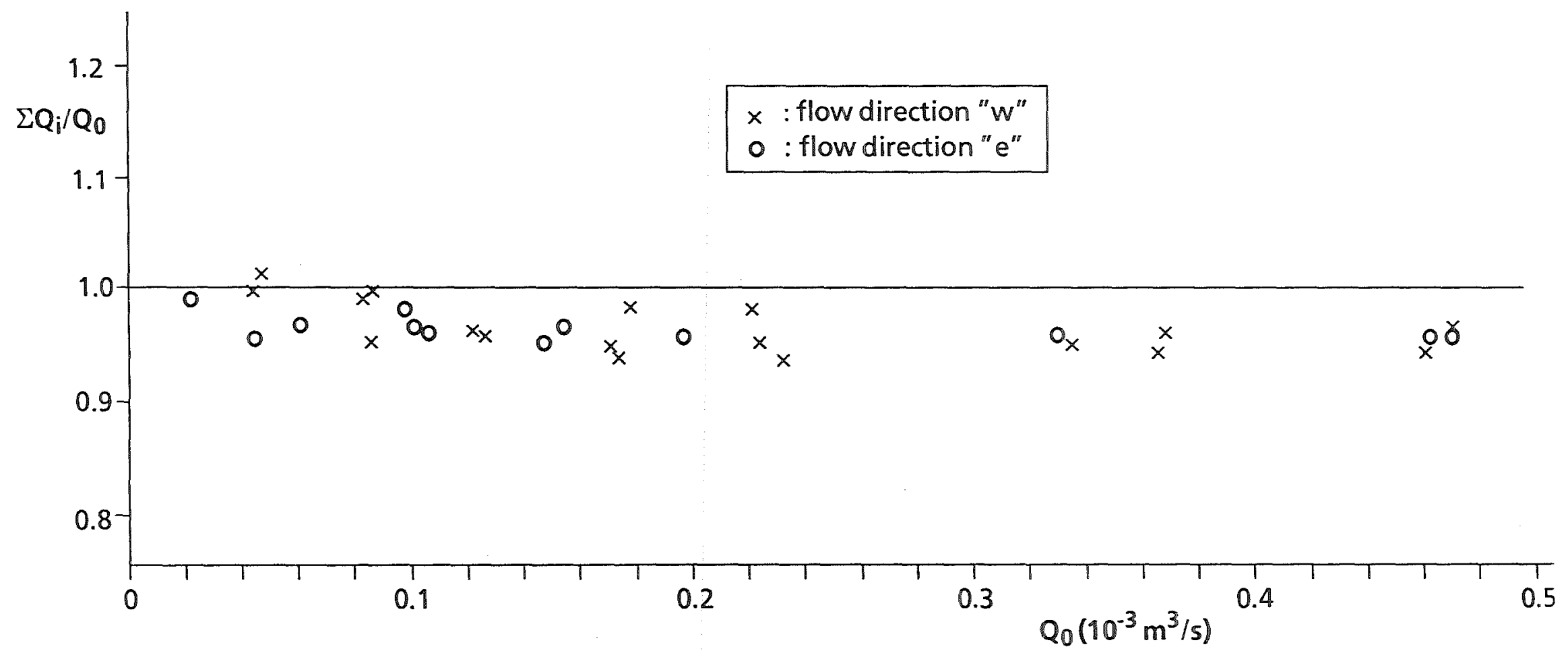

Figure 3.4 Flow rate ratio $\left(Q_{1}-Q_{5}\right) / Q_{0}$ as a function of $Q_{0}$ for $B=0 T$ 
Table 3.1 Flowmeter calibration constants

\begin{tabular}{|c|c|c|c|c|c|c|}
\hline Channel Nr. & 0 & 1 & 2 & 3 & 4 & 5 \\
\hline $\mathrm{A}$ & 0 & \pm 10 & \pm 3 & \pm 4 & \pm 6 & \pm 13 \\
\hline $\mathrm{B}$ & 0.0974 & 0.0514 & 0.0686 & 0.0807 & 0.0848 & 0.0562 \\
\hline \\
$\mathrm{m}-$ " for flow direction "er flow direction " $\mathrm{w}$ "
\end{tabular}

Figure 3.4 shows the ratio of the sum of the flow rates $Q_{1}-Q_{5}$ to the measured flow rate $Q_{0}$ for experiments with $B=0 \mathrm{~T}$. This figure contains results obtained during the total measurement campaign. The agreement for the total measurement range is quite satisfactory. There is a fairly constant error of about $-5 \%$ for these measurements which are performed after the tests with Test Section Configuration III, see APPENDIX. There are indications that the reason for this is a change of the calibration constant of flowmeter $Q_{0}$ during the experimental campaign. This change could be accounted for. However, such a correction was not applied in the data presented in Section 4.

For the experiments with magnetic field there is a small measurement uncertainty due to the influence of the magnetic field on the individual flowmeters. By shielding the flowmeters by an iron plate it was assumed that the magnetic field of the MAGDA magnet did no longer influence the magnetic field generated by the electromagnets of the single flowmeters. After the performance of the experiments some measurements of the resulting magnetic field in the vicinity of the measurement volumes of the flowmeters were carried out. Figure 3.5 shows the resulting magnetic field in the gap of flowmeter $Q_{1}$ as a function of the magnetic field of the MAGDA magnet. At $B=4$ ' $T$ the resultant magnetic field is decreased by about $30 \%$ and with this the measured flow rate $Q_{1}$.

The curve in Fig. 3.5 can be used to establish a correction curve for the flowmeter $Q_{1}$ as shown in Figure 3.6. Unfortunately, corresponding measurements were not performed for the other flowmeters. However, two local measurements were made for $\mathrm{B}_{\mathrm{MAGDA}}=4 \mathrm{~T}$ for each flowmeter shown in Table 3.2. Using the mean value of the two measurements and assuming the same type of dependence as for $\mathrm{Q}_{1}$, correction curves were developed, also shown in Figure 3.6. The influence of $B_{\text {MAGDA }}$ is not very large for $Q_{2}-Q_{5}$. The flowmeter measurement $Q_{0}$ is not used for comparison in the data analyses because this flowmeter is the less shielded by the iron plate.The data presented in Section 4 were evaluated using the calibration con- 
Table 3.2: Magnetic field near flowmeters at $\mathrm{B}=4 \mathrm{~T}$

\begin{tabular}{|l|c|c|c|c|c|}
\hline \multicolumn{1}{|c|}{ Channel Nr. } & 1 & 2 & 3 & 4 & 5 \\
\hline Meas. Position "left" $(\mathrm{mV})$ & 10.1 & 5.0 & 5.6 & 4.6 & 2.5 \\
\hline Meas. Position "right" $(\mathrm{mV})$ & 7.8 & 5.0 & 4.3 & 4.0 & 7.5 \\
\hline
\end{tabular}

stants according to Table 3.1 and the correction curve according to Fig. 3.6.

\subsubsection{Leakage Flows}

The design of the test section may allow leakage flows between the individual channels if the pressures in the individual channels are different.

The stainless steel inserts are positioned in grooves in the plexiglass inserts. This arrangement does not guarantee leak tightness between the single channels. There is a gap of about $0.3 \mathrm{~mm}$ between the outer vertical plexiglass inserts and steel casing and also between the horizontal top walls due to the rubber rings, compare Fig. 3.2. These gaps can contribute to leakage flows if additional gaps exist between the different plexiglass inserts or between inserts and steel casing.

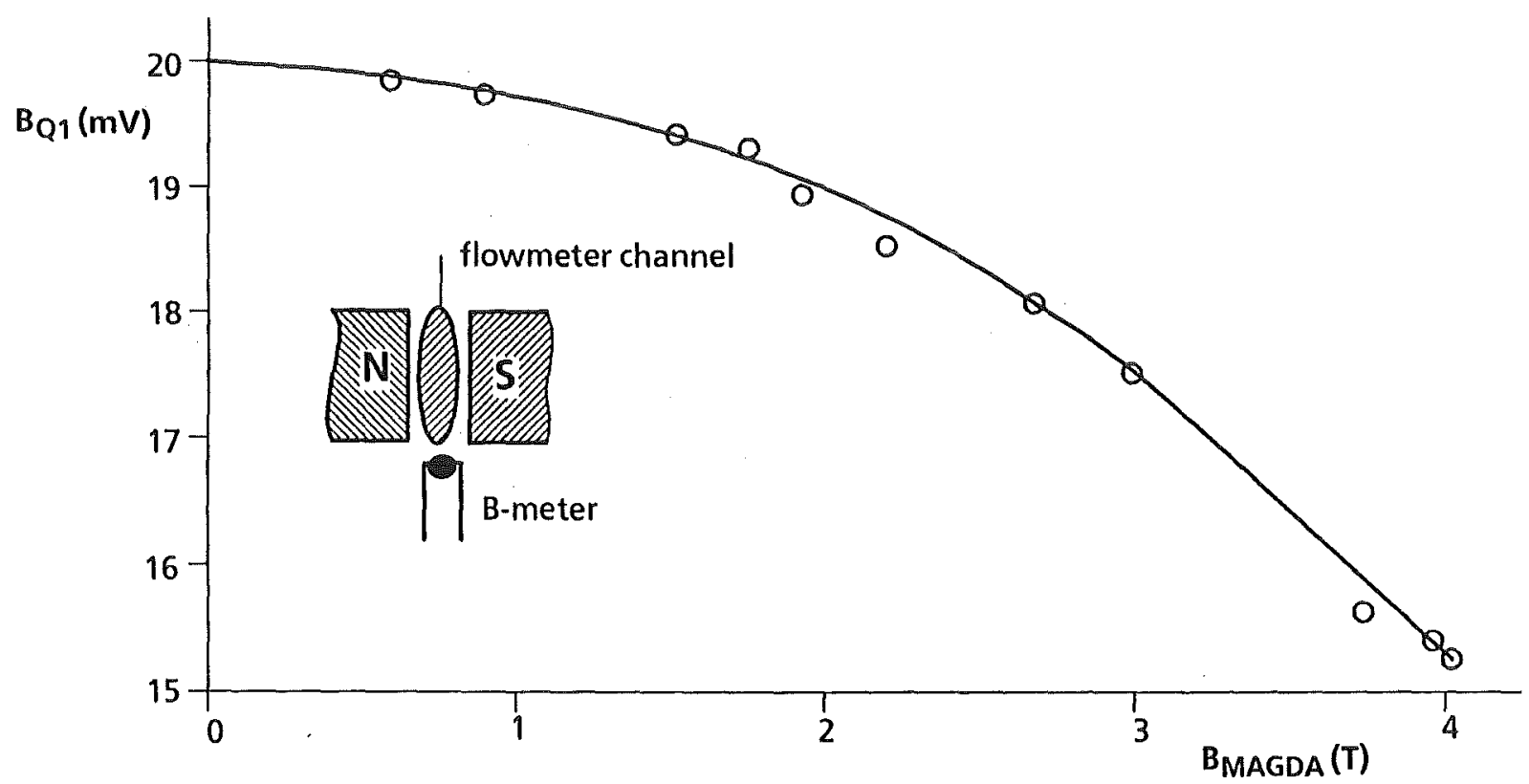

Fig. 3.5: Influence of magnetic field B of MAGDA magnet on flowmeter magnetic field BQ1 


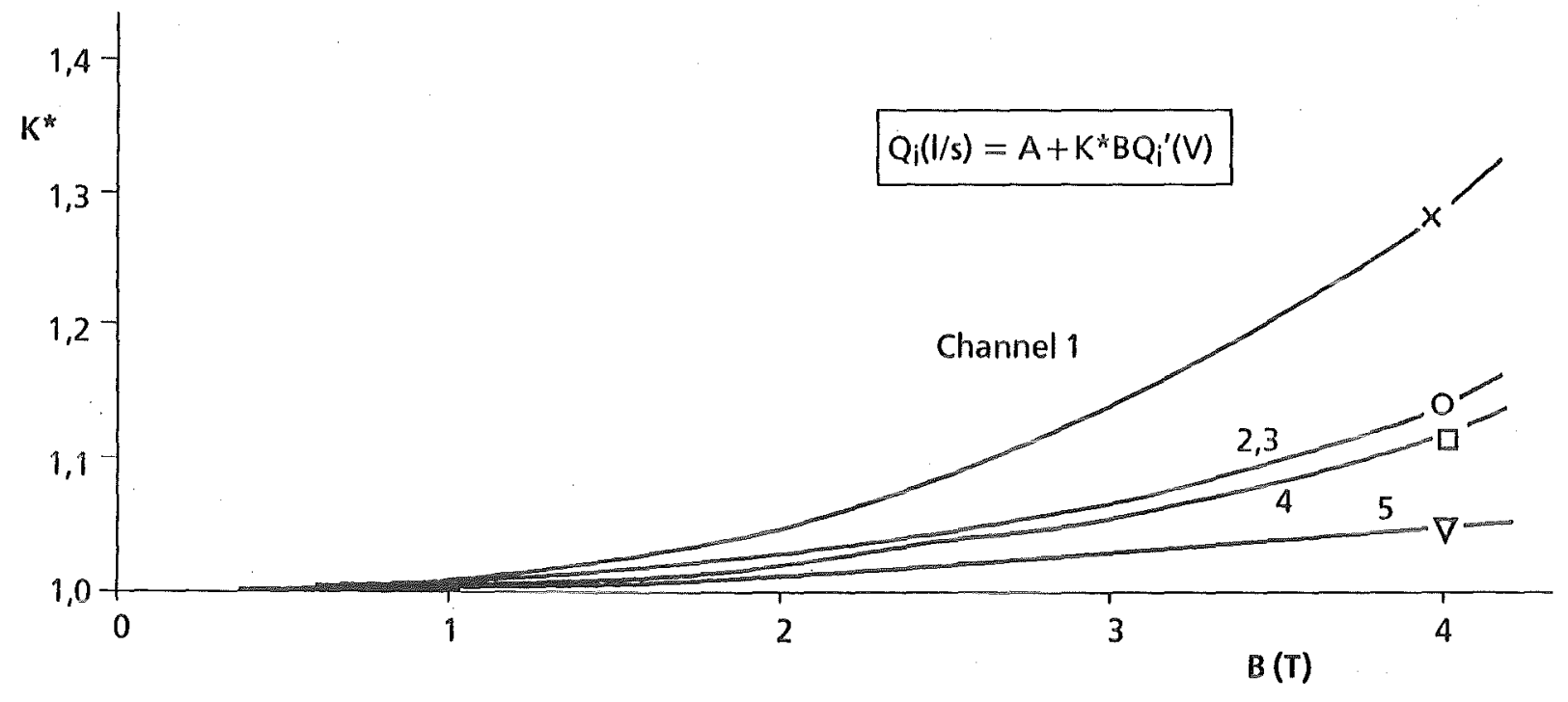

Fig: 3.6: Flowmeter correction coefficient for influence of magnetic field

Leakage flow tests outside of the magnet were performed in such a way that the liquid metal could only flow into the test section through one channel and was forced to flow into the neighbouring channels because the piping of this channel was closed downstream. With this arrangement, considerable pressure differences between the channels were generated which were fairly constant over the whole channel length. Typical flow rates from one channel to the next one were $0.025 \mathrm{l} / \mathrm{s}$ for a pressure difference of about 0.25 bar. The effect of leakage flows in the experiments with magnetic field will be discussed in Section 4.1.

\subsubsection{Measurement of Differential Pressures}

The measurement of one differential pressure per channel was planned. Conventionally, this is achieved by using one differential pressure transducer (or two transducers for absolute pressures) in each line or in total one differential pressure transducer (or two absolute pressure transducers) and a system to open and close corresponding impulse lines using many valves or a reliable commutator. 
For the present experiments a new method was developed which requires only one transducer for absolute pressure and avoids the use of many valves or the commutator. This method requires a standard data acquisition system consisting of a personal computer and an appropriate multiplexer. Both components are conventional units of present data acquisition systems (DAS). The method is shown schematically in Fig. 3.7. The fluid system where the pressures are to be measured is called Primary System (P.S.). There is a Secondary System (S.S.), conventionally filled with gas. Both systems are separated by membranes equipped with sensors to indicate the position of the membranes as shown in Fig. 3.8. The S.S. contains the pressure transducer and an apparatus to pressurize and depressurize this system (gas bottle and two valves with fixed throttles).

The pressures are measured in the following way: At first the pressure in the S.S., $\mathrm{p}_{\mathrm{SS}}$, is kept lower than the lowest pressure in the PS., $\mathrm{p}_{\mathrm{PS}}$. In this case, all membranes are on position "closed". Then, the pressure pSS. is slowly increased. When at a distinct membrane $p_{s s}$ is about $p_{p s}$, this membrane opens and gives a corresponding signal to the data acquisition system. The actual pressure in the S.S. at the moment of the opening of the membrane $i$ is equal to the pressure in the P.S. at pressure measurement location $\mathrm{i}$. When all membranes are open, the pressure psS is decreased slowly and a second measurement of all pressures is performed. If differential pressure measurements are desired, the corresponding differences are evaluated by the computer. This method requires quasi-steady-state conditions in the P.S. The pressure change psS with time has to be so small that it is negligible during that time which is needed by the DAS to perform one or more measurement cycles, compare Section 3.23.

Figure 3.8 shows details of the unit containing the membranes, used first in the present experiments. The rubber membranes were glued in the plexiglass housing. Small copper discs were glued on the membrane centers

i) to close an electrical circuit for the two contact pins for measuring the membrane closing/opening.

ii) to ensure that big pressure differences between S.S and P.S do not damage the membrane. 


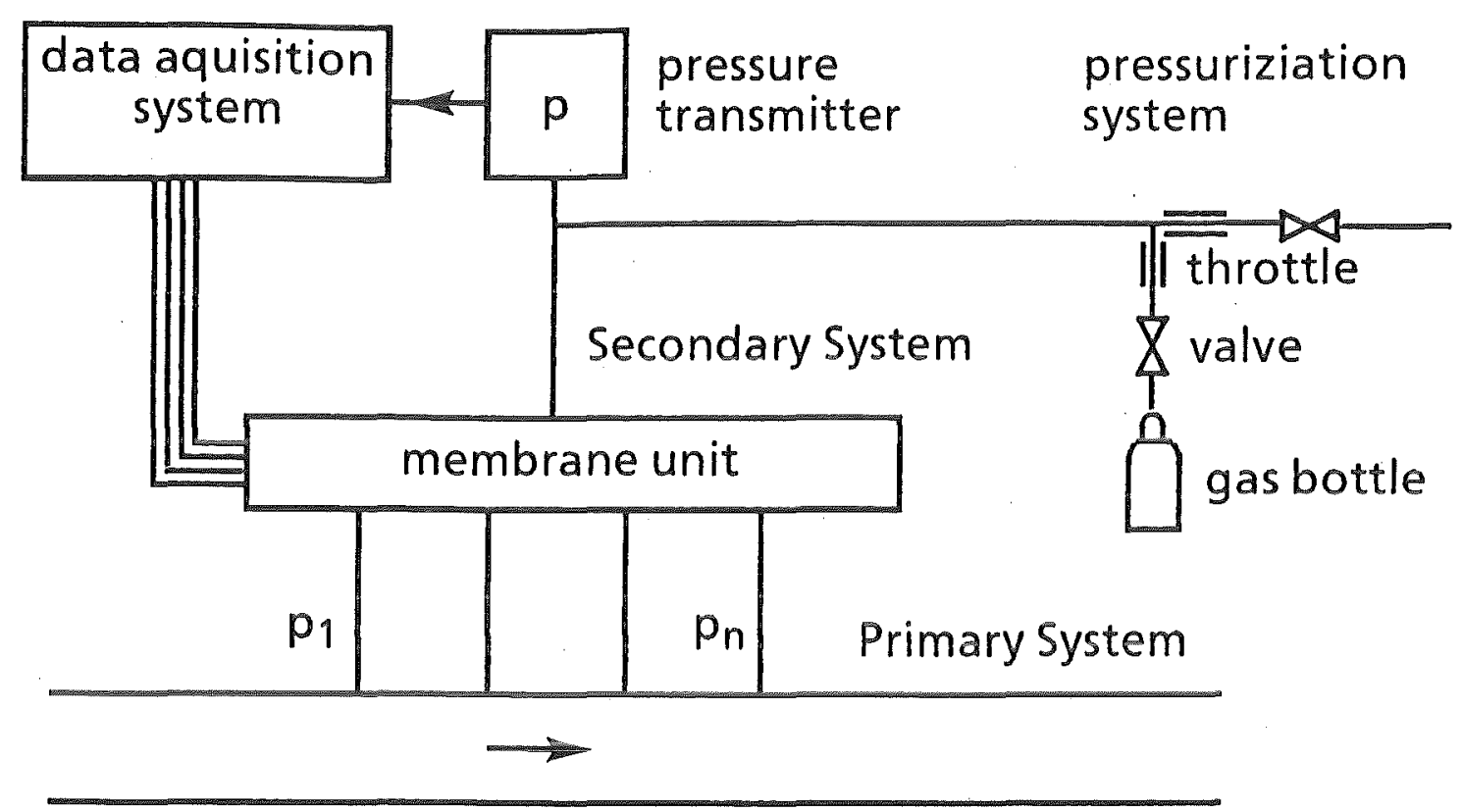

Fig: 3.7: Principle of new pressure measurement technique

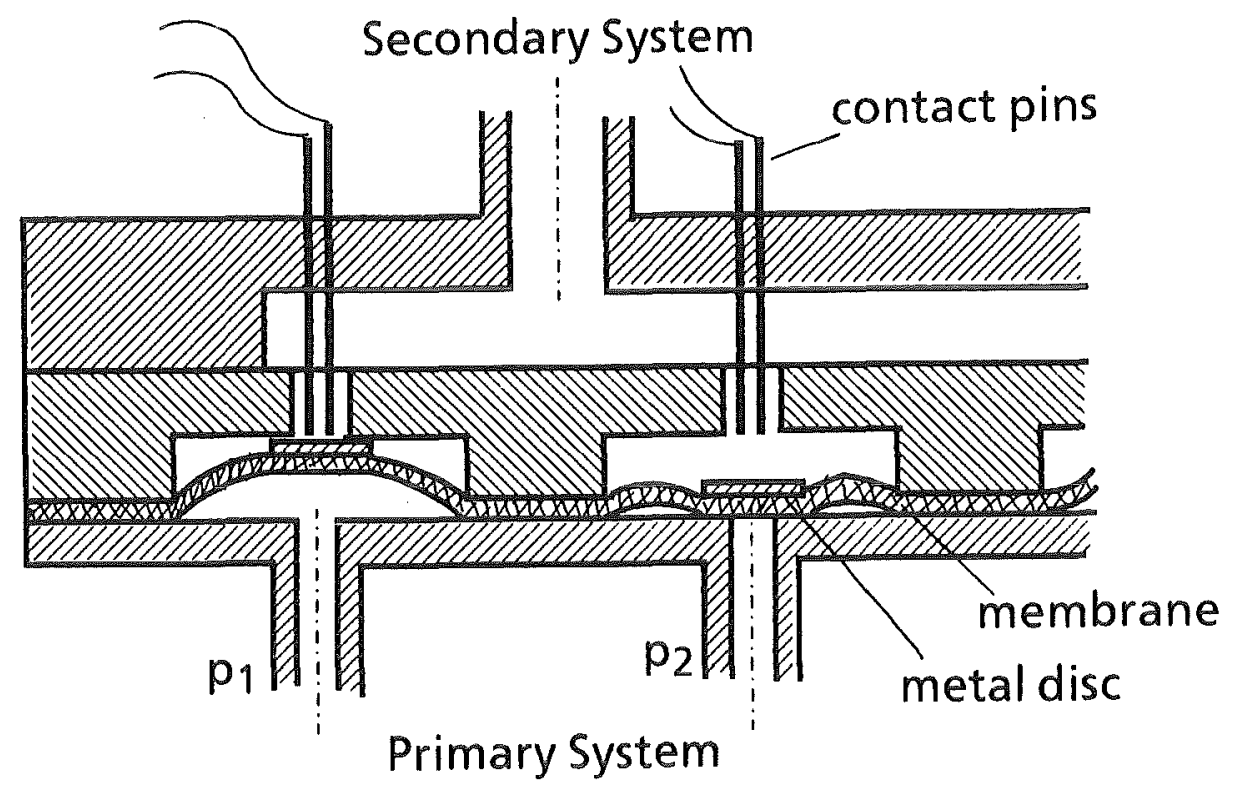

Fig: 3.8: Membrane unit 
If a membrane has a prestress then a certain pressure difference is required, which could cause a measurement error. However, this effect can be eliminated by calibration experiments.

Two membrane housings were used; one for the pressure tabs in the radial channels the other for the tabs in the toroidal channel. Both housings were mounted in such a way that the geodetical height was about $54 \mathrm{~mm}$ which results in a geodetical pressure difference of 34 mbar.

Figure 3.9 shows pressure difference measurements for the case that the test section was filled with stagnant liquid metal. The figure shows that there are small systematic deviations from the expected value for the geodetical pressure difference. If mean values are used, the scatter is about \pm 2 mbar which is small compared to values obtained in the experiments which went up to several hundred mbars.

Figure 3.9 shows results for pressure increase in the S.S. (membrane opening). Similar experiments for pressure decrease (membrane closing) showed larger deviations. Here, some membranes seemed to stick sometimes in the lower position. However, this sticking effect disappeared during the following experiments.

It proved that this new measurement technique was very reliable. The advantages of this technique increase with increasing number of measurement positions compared to conventional techniques requiring a large number of transducers or remote controlled valves. This method should easily find other applications especially in industrial areas.

\subsubsection{Data Acquisition System}

The voltages from the flowmeters, pressure transducer and the $\mathrm{B}$ field measurement were amplified and recorded by an IBM PC-AT 286. The stored data were printed out at the end of the experiments. The actual data could be observed on a monitor screen in the vicinity of the test section. For pressure measurements the measuring time for one channel was about $1 \mathrm{~ms}$. Therefore, the 10 positions were measured in about $10 \mathrm{~ms}$. To eliminate electrical noise on the signals, 20 cycles were taken and an arithmetic average was used. 


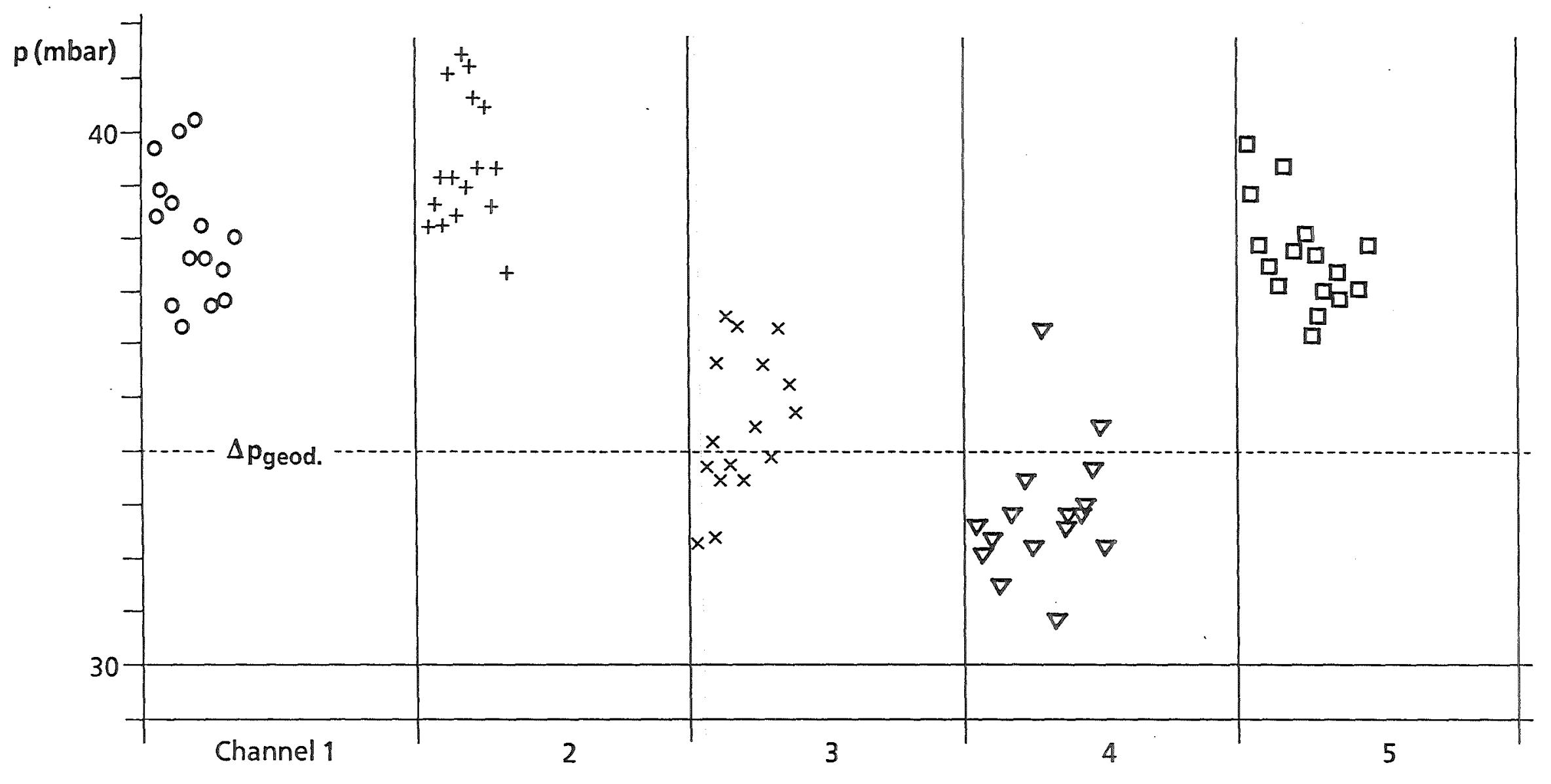




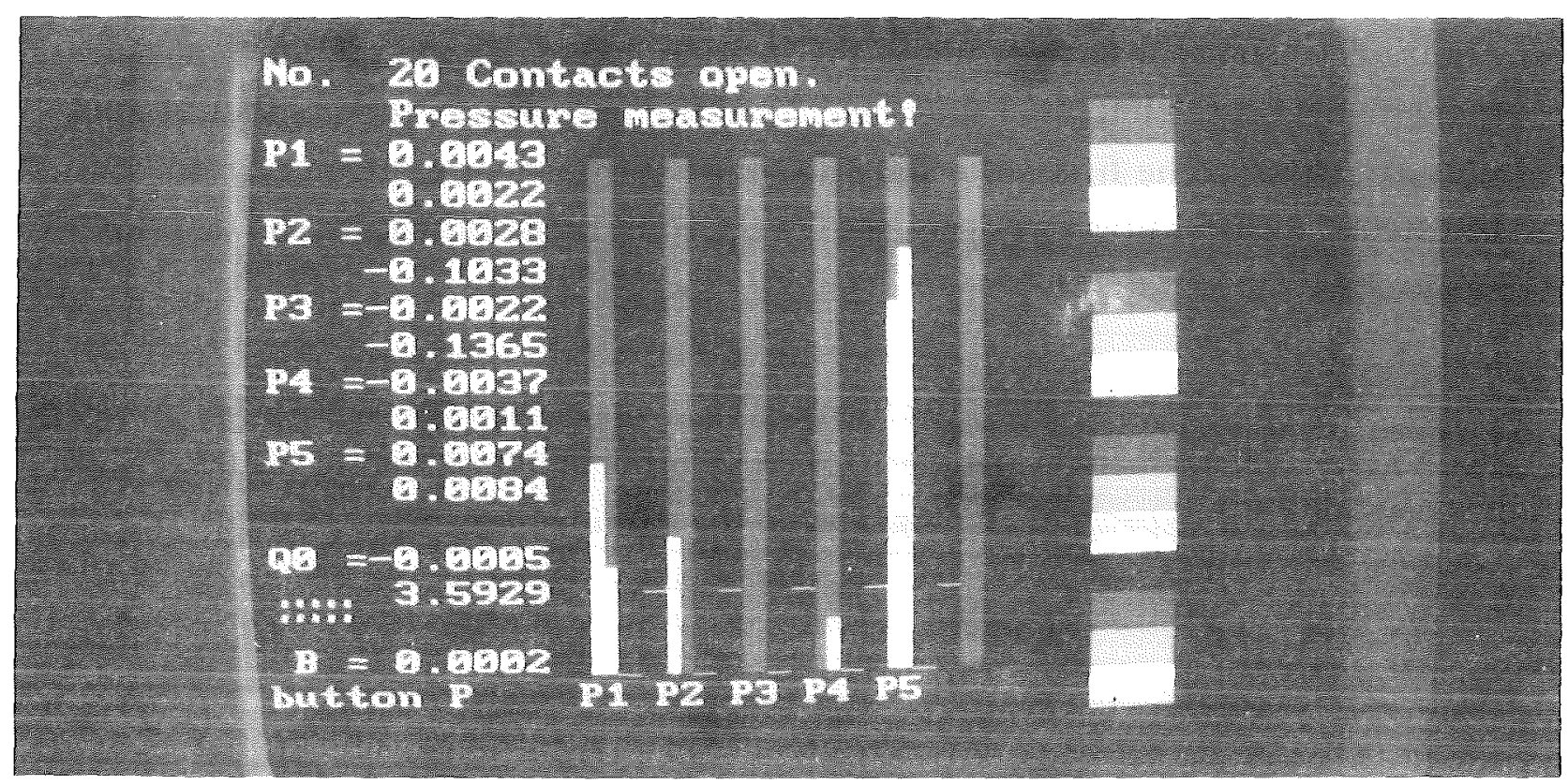

Figure 3.10 Graph of pressure measurement data on monitor screen

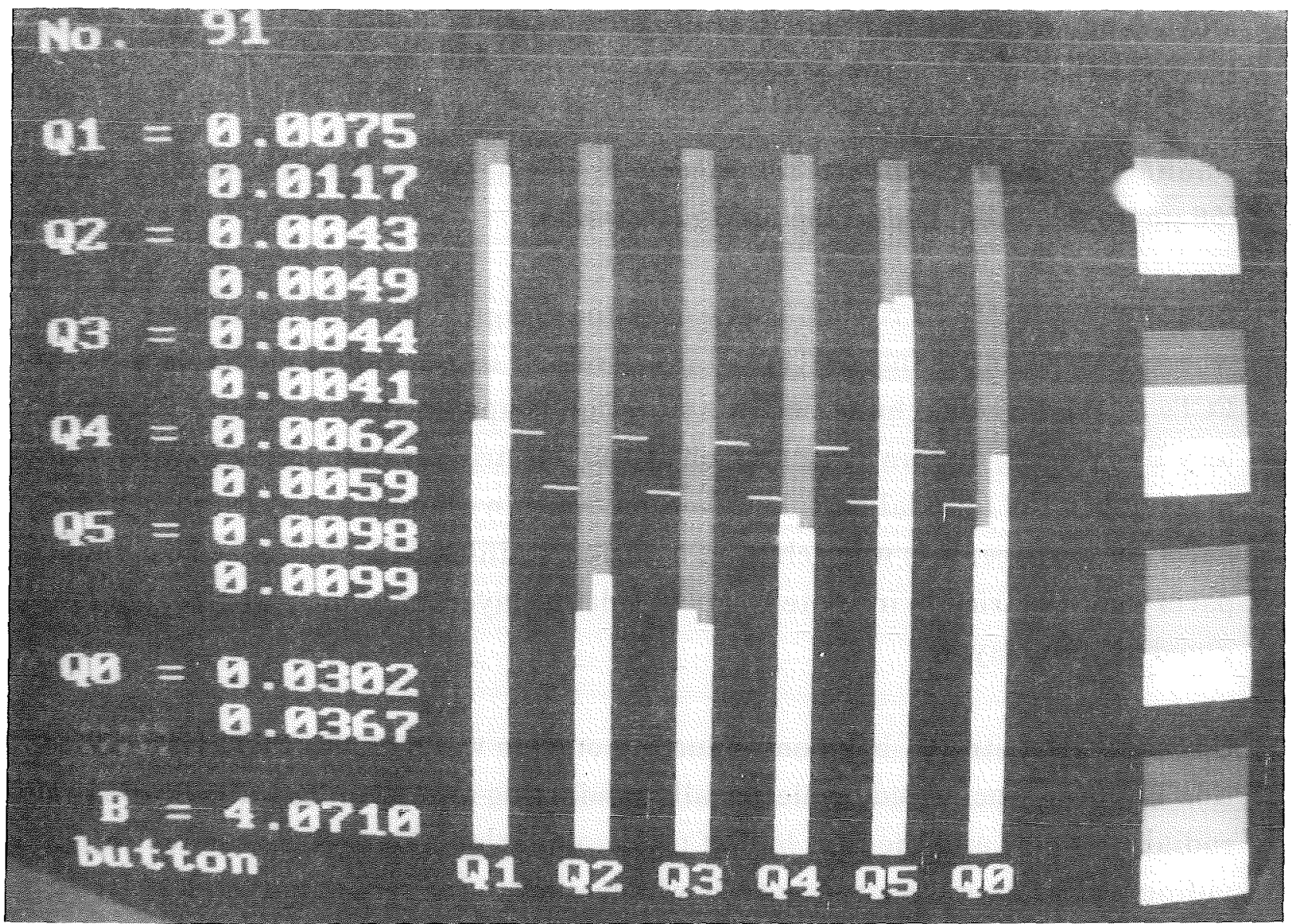

Fig: 3.11: Graph of volume flow rate measurement data on monitor screen 
Figure 3.10 shows a photograph of the monitor screen for the pressure measurement mode. On the left hand side the differential pressures of the individual channels are shown. The first values are obtained with pressure increase in the S.S., the second ones for pressure decrease. On the right these values are shown graphically.

In the volume flow rate mode, the measuring time for each channel was about 100 $\mathrm{ms}$. Three measurement cycles were taken to form mean arithmetic values. Figure 3.11 shows a corresponding photograph on the monitor screen.

\subsection{Test Matrix}

Four different channel geometries were investigated, as shown in Fig. 3.12 for the case of 5 parallel channels of the same type $(k=5)$.

Channel Geometry I is characterized by nonconducting outside walls (plexiglass) and a conducting dividing wall (stainless steel inserts). For a single channel of this type $(\mathrm{k}=1)$ all walls consisted of plexiglass.

Channel Geometry II differs from Geometry I by having conducting outside walls (56 $\mu \mathrm{m}$ copper foil glued on the plexiglass walls).

Channel Geometry III resembles the most the design of the KfK reference blanket where flow channel inserts (FCI's) are foreseen in the radial channels, but no FCI's in the toroidal channels. This situation is approached in Channel Geometery III by using dividing walls which are not electrically conducting in the radial parts but in the toroidal part; however, have a thin conducting layer in the radial parts. In practice, this was achieved by using stainless steel inserts whose radial parts were electrically insolated on both sides by layers of lacquer with copper foils glued on these layers.

Channel Geometry IV has nonconducting outside walls and in the total test section but is characterized by electrically conducting and dividing walls in the first radial channels and the first half of the toroidal channels and nonconducting dividing walls (stainless steel covered with laquer) in the second half of the test section. This geometry is characteristic for a multichannel single bend geometry be 
cause electric currents through the dividing walls can only flow in the first part of the test section.

An important parameter of these investigations is the channel number $k$, for a given channel geometry. For the Channel Geometries $I$ and $\Pi$, besides $k=5$, other values of $k$ were also investigated. Using always the test section with five channels, this was realized by the use of nonconducting dividing walls (inserts made of plastic material) with - if required - a copper foil glued on one or two sides.

In total, six different test section configurations were investigated as shown in Fig. 3.13. The 'Tables A1 - A6 in the Appendix contain the details of the experimental procedure. In general, the volume flow rate was varied in three steps by adjusting three different values of the electric current $I_{p u}$ of the EMF pump Ipu = $10 ; 15$ and $21 \mathrm{~A}$. 'The flow direction was either from the flow meters to the test section (designated as "west" =w) or the other way ("east"=e). It was anticipated to perform experiments with either equal pressure drops in the single channels $\left(\Delta p_{i}\right.$ $=$ const) or equal flow rates $\left(Q_{i}=\right.$ const $)$. Due to the limited time available for the experiments with the superconducting magnet, the first mode was approximated by using completely opened throttles. For " $Q_{i}=$ const" the throttles had to be adjusted in a corresponding manner. Due to the time consuming procedure, only a few experiments were performed in this mode.

The anticipated experimental procedure was as follows: Starting with $B=0$ Tesla the magnetic field strength $B$ was increased up to a maximum value of about $B=4$ Tesla. 'The signals of the volume flow rate and pressure measurements were recorded for stepwise alternating values of the EMF pump power. During these experiments the flow direction was not changed, the throttles were completely open and the inclination angle was $\beta=0^{\circ}$. At the maximum magnetic field strength, measurements at three power levels were then performed for the mode "all throttles open" with $\beta=0^{\circ}$ and $\beta=12^{\circ}$ and for the mode " $Q_{i}=$ const" for $\beta=0^{\circ}$. Then the flow direction was reversed and data were taken for fully opened throttles during the decreasing $B$ field for different power levels and $\beta=0^{\circ}$.

The tables show that there are some deviations from this anticipated procedure, e.g. for Test Section Configurations 4 and 5 data were also taken at a constant magnetic field at $B=3$ Tesla. 


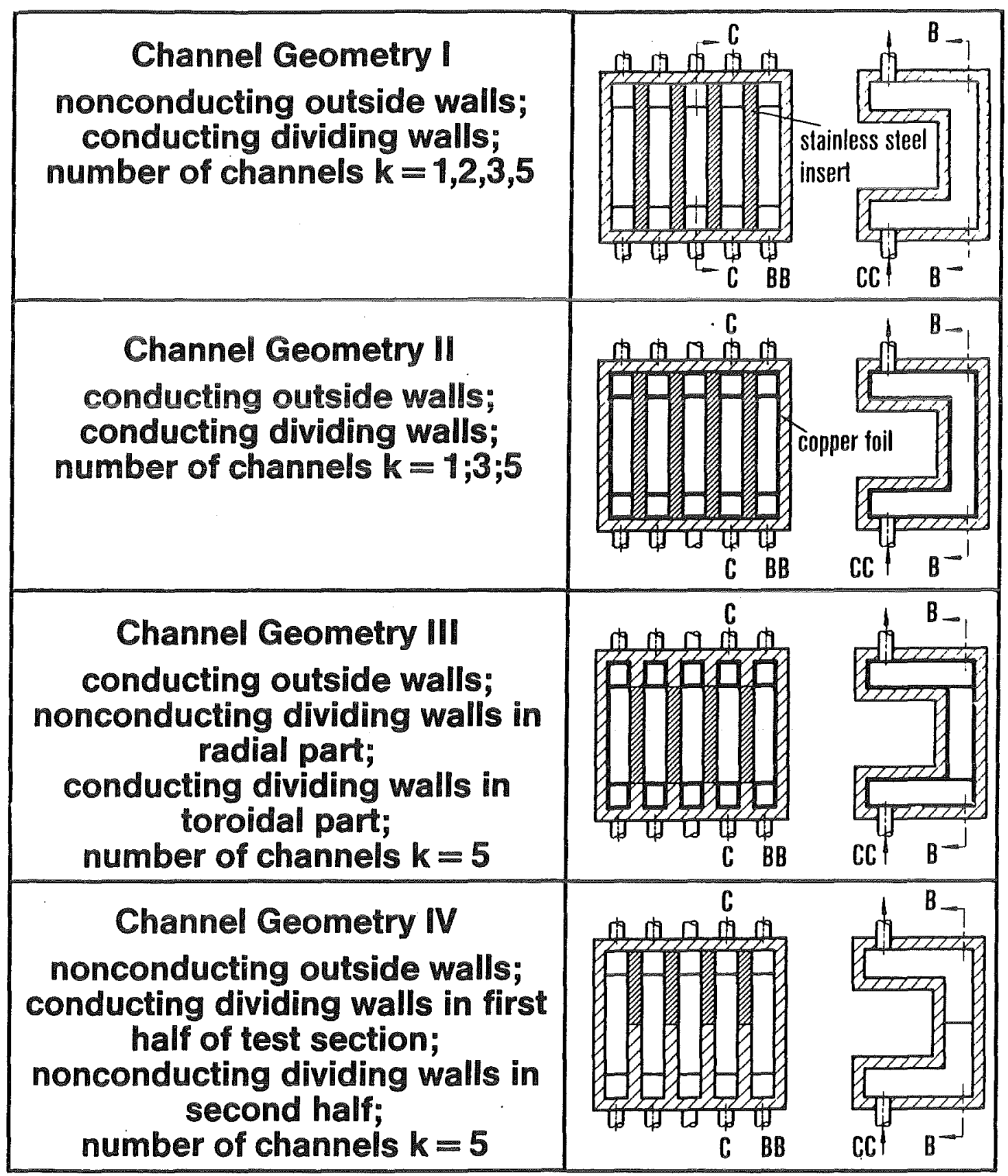

Figure 3.12 Flow channel geometries (shown for $k=5$ ) 


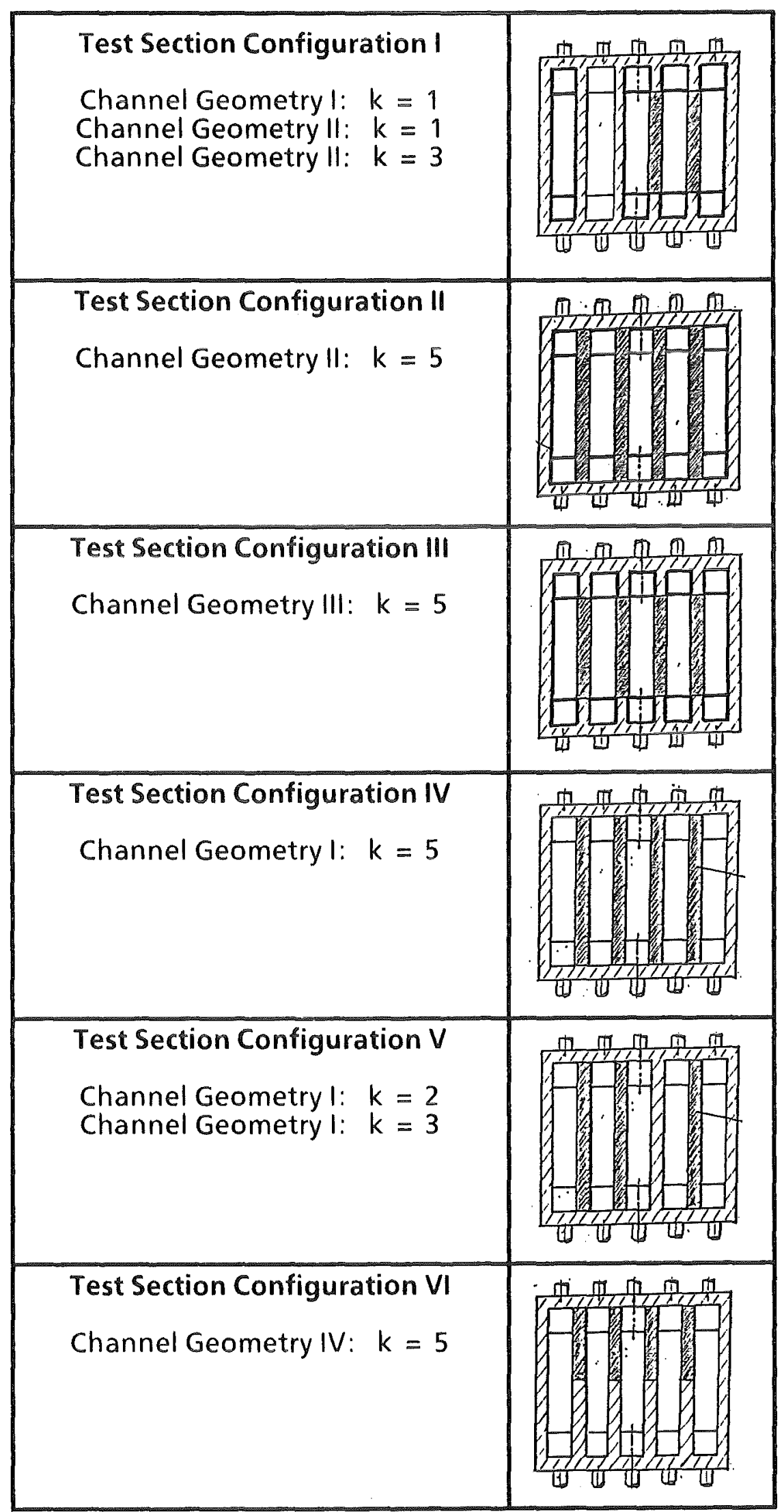

Figure 3.13 Test section configurations used in the present experiments 
In MHD flows three non-dimensional numbers are of prime interest, the Hartmann Number M, the Interaction Parameter (or Stuart Number N) and the wall conduction ratio $\mathrm{C}$, defined as

$$
\begin{gathered}
M=a B(\sigma /(\rho v))^{1 / 2} ; \\
N=a B^{2} \sigma /(\rho u) \\
C=\sigma_{w} t_{w} /(\sigma a) ;
\end{gathered}
$$

where $a$ is the half width of the single channel; $\sigma, \rho, v$ are the electrical conductivity, density, kinematic viscosity of the liquid metal InGaSn , $u$ is the mean velocity in a channel and $\sigma_{w}$ and $t_{w}$ are the electrical conductivity and wall thickness of the channel wall.

With the values for the present experiments $\left(\mathrm{a}=1.3 \cdot 10^{-3} \mathrm{~m}, \sigma=3.64 \cdot 10^{6} \mathrm{~A} / \mathrm{Vm}\right.$, $\rho=6360 \mathrm{~kg} / \mathrm{m}^{3}, \mathrm{v}=6.25 \cdot 10^{-5} \mathrm{~m} 2 / \mathrm{s}, \sigma_{\mathrm{w}}=5.8 \cdot 10^{7} \mathrm{~A} / \mathrm{Vm}$ and $\left.\mathrm{t}_{\mathrm{w}}=56 \cdot 10-6 \mathrm{~m}\right)$ the following values are obtained

$$
\begin{array}{ll}
C=0.069 & \text { for conducting outside walls } \\
C=0 & \text { for nonconducting outside walls }
\end{array}
$$

The stainless steel inserts had a thickness of $2 \mathrm{~mm}$ with a conductivity of $\sigma_{\mathrm{SS}}=$ $1.16 \cdot 10^{6} \mathrm{~A} / \mathrm{Vm}$.

Figure 3.14 shows the parameter range of $B$ and $u$, and $M$ and $N$, respectively, for Channel Geometry I with $\mathrm{k}=5$. This figure shows that with increasing $\mathrm{M}$ also $\mathrm{N}$ increased. These curves are similar for the other test section geometries, however, the maximum values of $\mathrm{N}$ differ; e.g. for Channel Geometry II the maximum value is $\mathrm{N} \approx 10000$. 


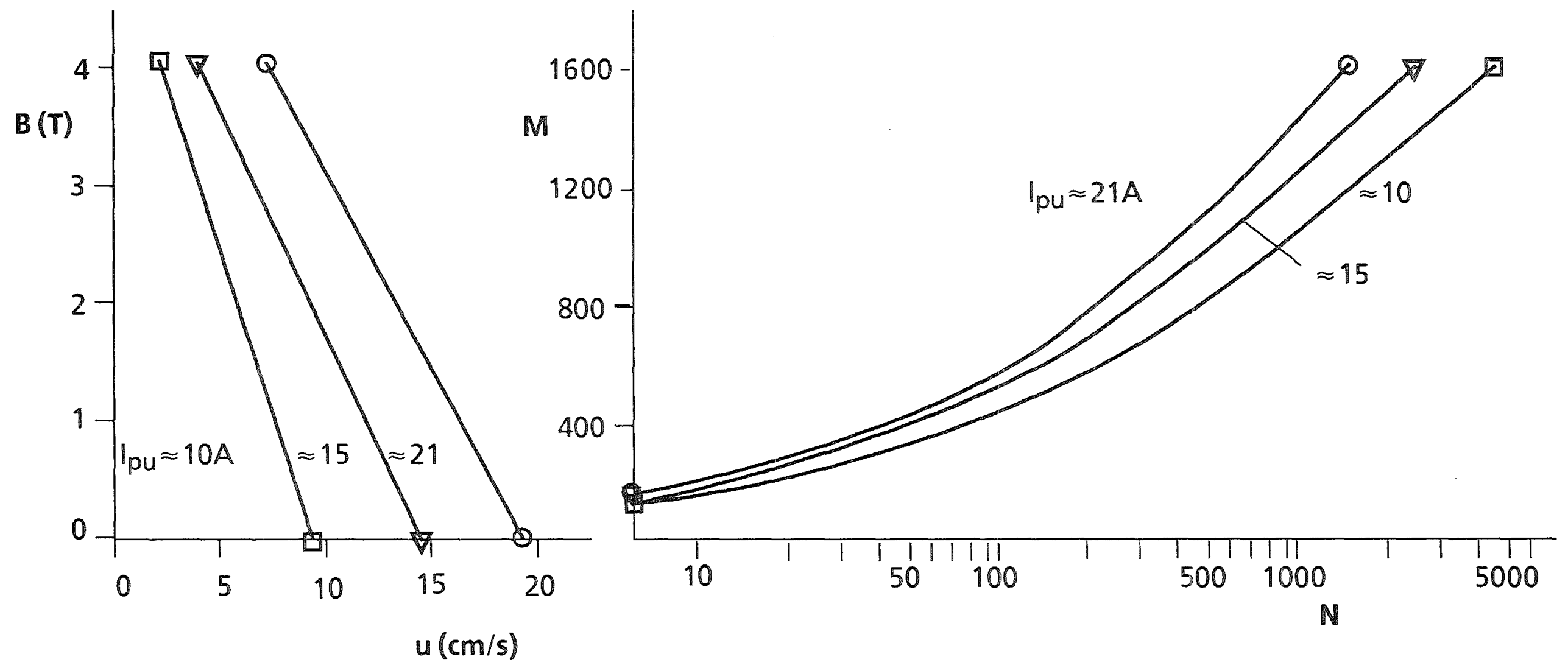

Figure 3.14 Parameter range of present experiments (Channel Geometry I) 


\section{Theoretical Analysis and Essential Results 4.1 Formulation}

Consider the steady flow of a viscous conducting incompressible fluid in a system of n electrically coupled U-Bends (see Fig. 4.1). Each U-bend is composed of two radial ducts perpendicular to the external magnetic field $\mathrm{B}^{\mathrm{e}}=\mathrm{B}_{0} \underline{\mathrm{e}}_{\mathrm{y}}$ and a toroidal duct, parallel to the field. All ducts have rectangular cross-sections. The radial ducts are semi-infinite, so that far away from the junction $\mathrm{x}=0$ the flow is fully developed. The multi-channel $U$-bend is supposed to be symmetric with respect to both $y=1$ and $z=0$ planes. It is also supposed that inertia plays no role, so that the flow in a quarter of the duct $y \leq 1, z \geq 0$ is considered under appropriate symmetry conditions. The bends are numbered in such a way that the duct number 1 is closest to the middle $\mathrm{z}=0$. If $\mathrm{n}$ is an odd number the symmetry plane divides bend 1 in half; if $n$ is even, the plane $z=0$ coincides with one of the side walls of the duct 1 .

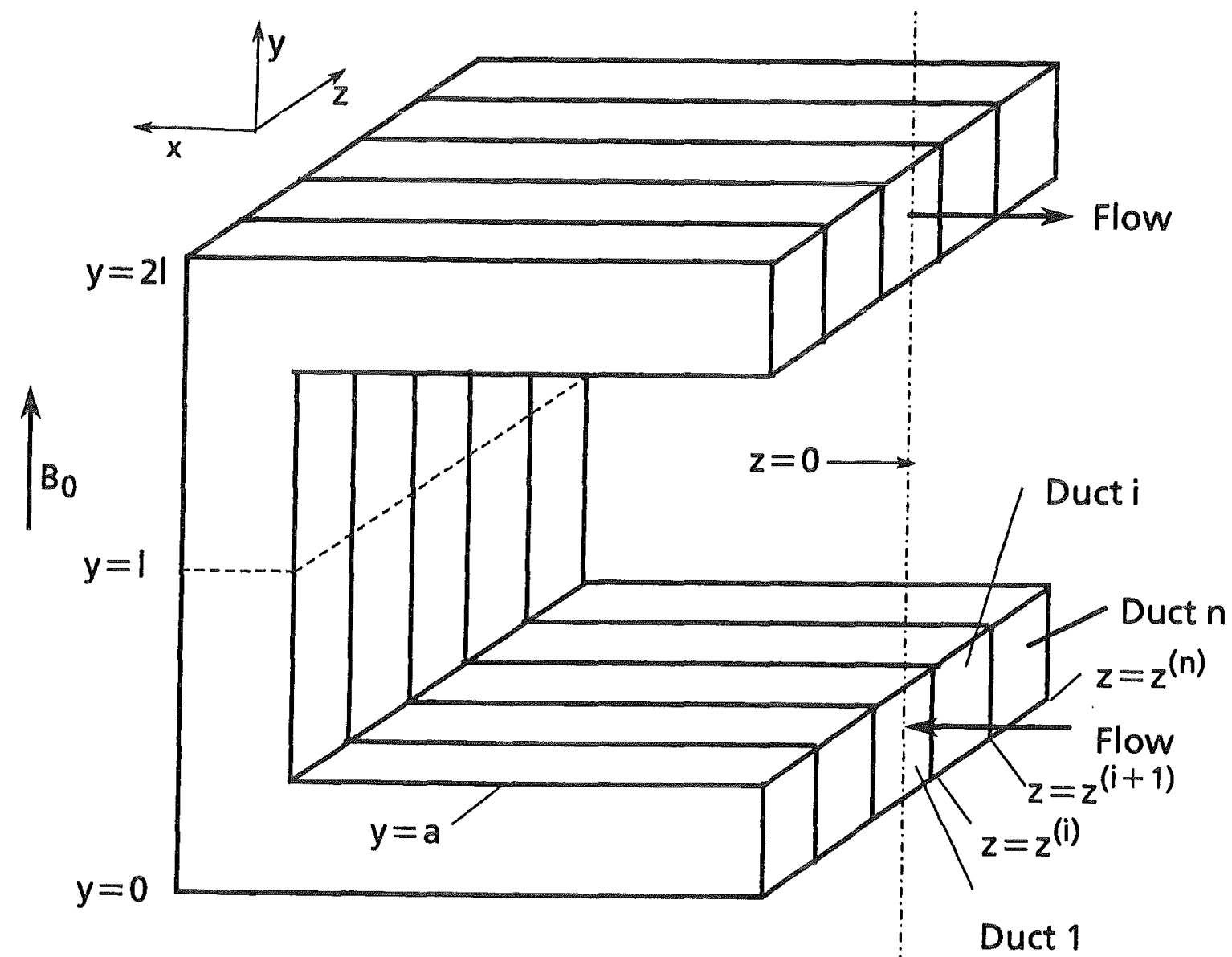

Fig. 4.1 Flow geometry 
Consider the flow in a U-bend $i$. The walls of this part of the bend are numbered from 1 to 7 , as shown in Fig. 4.2a. The walls at $z=z^{(i-1)}$ belong to the bend $\mathrm{i}-1$. The dimensionless inertialess inductionless equations governing the flow in a bend $\mathrm{i}$ are

$$
\begin{gathered}
M^{-2} \nabla^{2} v^{(i)}+j^{(i)} \times e_{y}=\nabla p^{(i)}, \\
j^{(i)}=-\nabla \phi^{(i)}+v^{(i)} \times e_{y}, \\
\nabla \cdot v^{(i)}=0 \\
\nabla \cdot j^{(i)}=0 .
\end{gathered}
$$

The fluid velocity $\underline{v}^{(i)}=u^{(i)} \underline{e}_{x}+v^{(i)} \underline{e}_{y}+w^{(i)} \underline{e}_{z}$, the electric current density $j^{(i)}$, the electric potential $\phi^{(i)}$ and the pressure $p^{(i)}$ are normalized by $v_{0}, v_{0} B_{0} \sigma, v_{0} B_{0} L$ and $\sigma v_{0} B_{0} 2 L$, respectively. The characteristic length $\mathrm{L}$ is equal to half the distance between the side walls of the duct 1 . The characteristic velocity $v_{0}$ is defined as average velocity in the whole part of the multi-channel U-bend being considered, i.e.

$$
\sum_{i=1}^{n} \delta_{i} Q^{(i)}=a z^{(n+1)}
$$

where

$$
\delta_{i}= \begin{cases}1 & \text { for } i \neq 1, \text { or } i=1 \text { and even } n \\ 0.5 \text { for } i=1 \text { and } \text { odd } n\end{cases}
$$

The flow rates $\mathrm{Q}^{(i)}$ are calculated from the equation

$$
\delta_{i} Q^{(i)}=\int_{0}^{a} d y \int_{Z^{(i)}}^{2^{(i+1)}} v^{(i)} d z
$$

The boundary conditions at each wall are the non-slip condition

$$
v^{(i)}=0
$$

and the conditions for the electrical variables which read (see Hua and Picologlou [6], for example)

$$
\begin{gathered}
\left(f^{(i)}-j^{(i+1)}\right) \cdot n_{k}=c_{k} \nabla_{k}^{2} \phi_{k}^{(i)}, \\
\phi_{k}^{(i)}=\Phi_{k}^{(i+1)},
\end{gathered}
$$




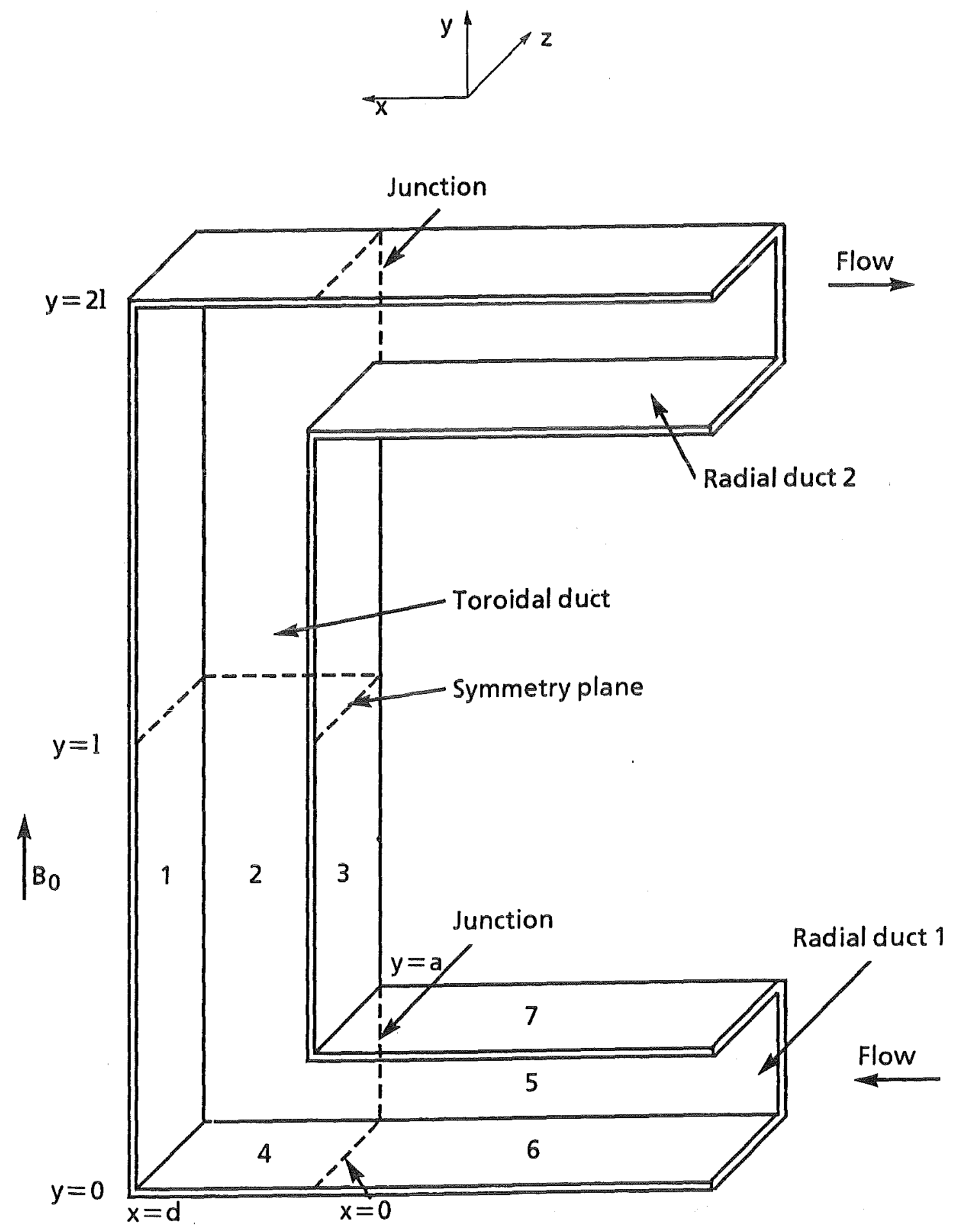

Fig. 4.2 Flow in bend i: a) geometry 
where $\underline{n}_{k}$ is the normal unit vector to the wall $k$, into the fluid; $c_{k}=\sigma_{k} t_{k} / \sigma L$ is the wall conductance ratio; $\sigma_{k}$ and $t_{k}$ are the electrical conductivity and thickness of the wall $k$, respectively; $\nabla_{k} 2$ is the Laplacian in the plane of the wall $k, \delta_{k}(i)$ is the wall potential equal to the fluid potential on the wall $\mathbf{k}$.

\subsection{Flow Analysis at Large Hartmann Numbers}

The problem (4.1) is treated by means of matched asymptotics as $M \rightarrow \infty$. The flow region exhibits the following subregions (Figs. $4.2 \mathrm{~b}$ and $4.2 \mathrm{c}$ ):

- the inviscid cores of the radial and toroidal ducts (CR) and (CT),

- the Hartmann boundary layers $(\mathrm{H})$ near the walls perpendicular to the magnetic field with a thickness $\mathrm{O}(\mathrm{M}-1)$,

- the parabolic layers of $O\left(\mathrm{M}^{-1 / 2}\right)$ thickness. These are at the side walls of both ducts (SR) and (ST), the first wall (F), the second wall (S), and inside the fluid (internal layer) at $\mathrm{x}=0$ (I). Layers I and S merge at $\mathrm{y}=\mathrm{a}$.

The flow in a single U-bend $(n=1)$ has been considered by Molokov and Bühler [7]. Following their analysis, the problem (4.1) is reduced to the system of equations governing the wall potentials and the pressure in the core of the radial duct. It reads

$$
\begin{gathered}
c_{5} \Delta_{5} \phi_{5}^{(i)}=-\frac{\partial p_{c r}^{(i)}}{\partial x}\left(x, z=z^{(i+1)}\right)+\frac{\partial p_{c r}^{(i)}}{\partial x}\left(x, z=z^{(i+1)}\right), \\
c_{7} \Delta_{7} \phi_{7}^{(i)}=a^{-1}\left(\phi_{7}^{(i)}-\phi_{6}^{(i)}\right), \\
c_{6} \Delta_{6} \phi_{6}^{(i)}=-a^{-1}\left(\phi_{7}^{(i)}-\phi_{6}^{(i)}\right), \\
\frac{\partial^{2} p_{c r}^{(i)}}{\partial x^{2}}+\frac{\partial^{2} p_{c r}^{(i)}}{\partial z^{2}}=0, \\
\Delta_{1} \phi_{1}^{(i)}=\Delta_{2} \phi_{2}^{(i)}=\Delta_{3} \phi_{3}^{(i)}=0 \\
l c_{4} \Delta_{4} \Phi_{4}^{(i)}=\phi_{4}^{(i)}, \\
\int_{0}^{a} \Phi_{5}^{(i)}(x, y) d y+a \int_{z}^{z^{(i)}} \frac{\partial p_{c r}^{(i)}}{\partial x}(x, z) d z=\delta_{1} Q^{(i)}
\end{gathered}
$$


On the interface between walls the electrical potential is continuous. In addition, Kirchhof's law applies for components of the wall electric currents normal to the interface. If $\Gamma_{\mathrm{kmj}}$ is the common boundary of three walls $\mathrm{k}, \mathrm{m}$ and $\mathrm{j}$ (the last belongs to the bend $i+1$ ), the conditions read

$$
\begin{gathered}
\phi_{k}^{(i)}=\phi_{m}^{(i)}=\phi_{j}^{(i+1)}, \\
c_{k} \frac{\partial \phi_{k}^{(i)}}{\partial n_{k}}+c_{m} \cdot \frac{\partial \phi_{m}^{(i)}}{\partial n_{m}}+c_{j} \frac{\partial \phi_{j}^{(i+1)}}{\partial n_{j}}=0,
\end{gathered}
$$

where $\underline{n}_{k}, \underline{n}_{m}$, and $\underline{n}_{j}$ are outward normal vectors to $\Gamma_{k m j}$ in the planes of the walls $k, m$, and $j$, respectively.

If only two walls $\mathrm{k}$ and $\mathrm{m}$ intersect, the conditions reduce to

$$
\phi_{k}^{(i)}=\phi_{m}^{(i)}, \quad c_{k} \frac{\partial \phi_{k}^{(i)}}{\partial n_{k}}=-c_{m} \frac{\partial \Phi_{m}^{(i)}}{\partial n_{m}}
$$

As $\mathrm{x}$ goes to $-\infty$, the flow becomes fully developed. This gives

$$
\frac{\partial \Phi_{5}^{(i)}}{\partial x}=\frac{\partial \phi_{6}^{(i)}}{\partial x}=\frac{\partial \phi_{7}^{(i)}}{\partial x}=\frac{\partial p_{c r}^{(i)}}{\partial z}=0 .
$$

The symmetry conditions give

$$
\begin{gathered}
\frac{\partial p_{c r}^{(1)}}{\partial z}=\phi_{1}^{(1)}=\phi_{2}^{(1)}=\phi_{4}^{(1)}=\phi_{6}^{(1)}=\phi_{7}^{(1)}=0 \text { al } z=0, \\
\phi_{1}^{(i)}=\phi_{2}^{(i)}=\phi_{3}^{(i)}=0 \quad \text { at } y=l .
\end{gathered}
$$

\subsection{Numerical Algorithm}

The system of equations (4.2) subject to the boundary conditions (4.3) is solved numerically. The numerical algorithm to solve the equations for a single U-bend $(n=1)$ is described by Molokov and Bühler [7] (method 1). In order to solve the equation governing the flow in a multi-channel U-bend, iterations between solutions for single bends are organized. The currents $-c_{j} \partial \phi_{j}(i+1) / \partial \underline{n}_{j}$ and $\partial p_{c r}(i+1) / \partial x$ 
$(\mathrm{z}, \mathrm{z}=\mathrm{z}(\mathrm{i}+1))$ that enter the walls of bend $\mathrm{i}$ from bend $\mathrm{i}+1$ (see Eqs. $4.2 \mathrm{a}$ and $4.3 \mathrm{~b}$ ) are taken from the solution for bend $i+1$ of the previous iteration step. To solve the equations for bend $i+1$, the potentials $\phi_{m}{ }^{(i)}$ at the plane $z=z^{(i+1)}$ (see Eq. 4.3a) are taken from the solution for bend $i$. The iterations stop when the differences between nodal pressures and potentials two iteration steps were less than 1 per cent.

\subsection{Essential Results}

Far from the junction the flow is fully developed. The flow structure in this region has been considered by Molokov [5]. If the flow rates in all channels are equal, the MCE results in different pressure gradients in the channels. It has been shown that if the conductance ratios of the top and bottom of all radial ducts are equal, the highest pressure drop is created in the middle channel. The side-wall jets in this channel vanish if the number of channels is $n \geq 7$ in the range of parameters relevant to a self-cooled liquid-metal blanket. A typical velocity profile in a threechannel duct in the region of fully developed flow in shown in Fig. 2.2.

The pressure gradients may be evened, if the relation

$$
6 c_{5}^{(n+1)}\left(\frac{1}{c_{6}^{(n)}}-\frac{1}{c_{6}^{(n-1)}}\right)+1 \geq 0
$$

is satisfied, provided the other wall conductance ratios are equal to $\mathrm{c}_{6}(\mathrm{n}-1)$.

When the fluid approaches the junction, three-dimensional currents are induced (for the discussion see Molokov and Bühler [7]). The scheme of 3-D electrical current paths for equal $c_{k}$ is shown in Fig. 4.3. In the duct 1 the induced 3-D currents are stronger than in the outer ducts, so that the 3-D pressure drop is expected to be higher.

Results of calculations are presented for square cross-section of all ducts ( $a=2$, $\left.z^{(i+1)}-z^{(i)}=2 \delta_{i}\right)$, the same wall conductance ratio $c=0.0686$ of all walls and $l=16$. These values are characteristic of the screening multi-channel experiment (see Section 3.1).

Results on the flow in a U-bend with 1, 3 and 5 channels are shown in Figs. 4.4a-c and in Table 4.1. From this table it follows that if the channel number increases, 


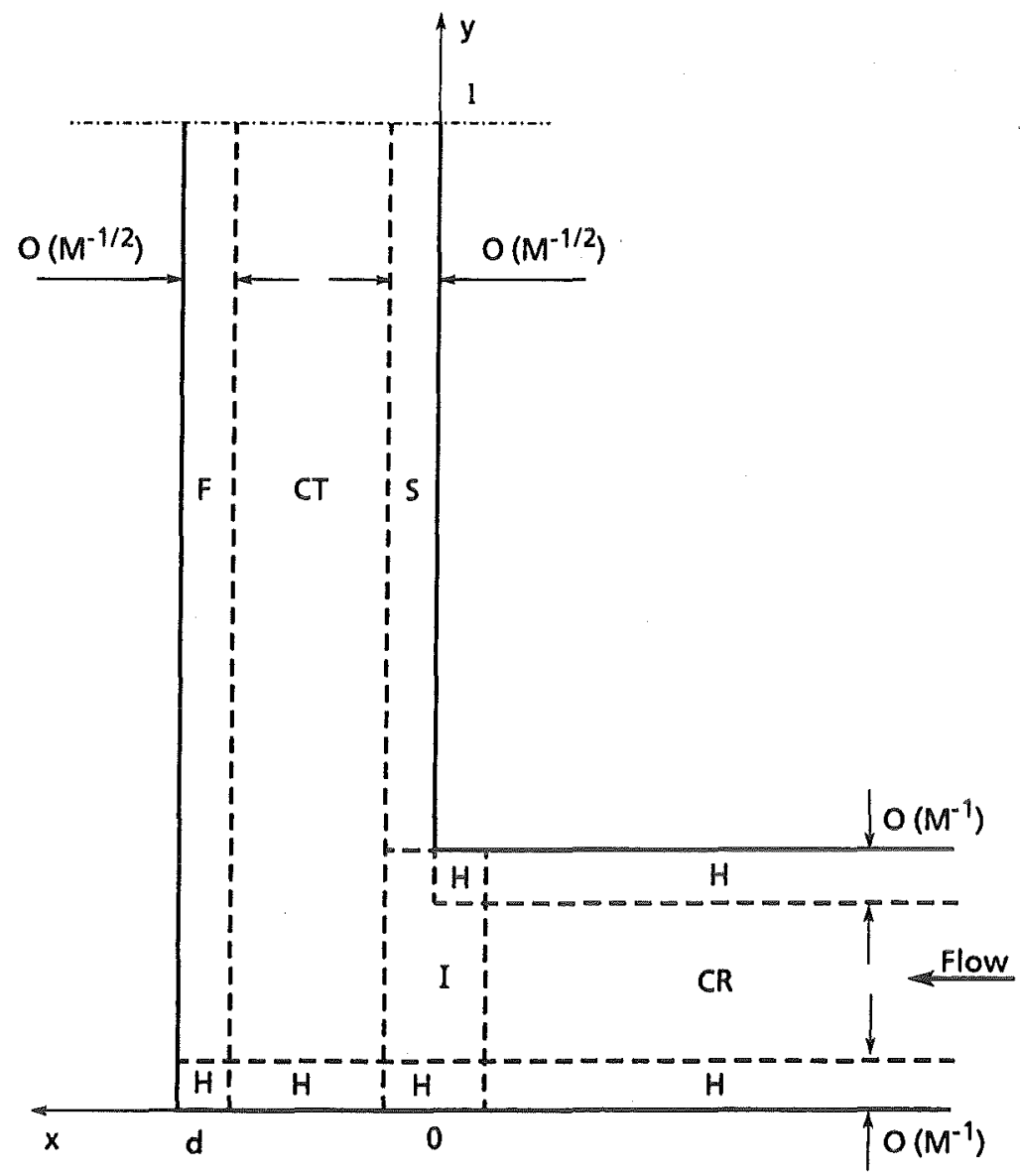

b)

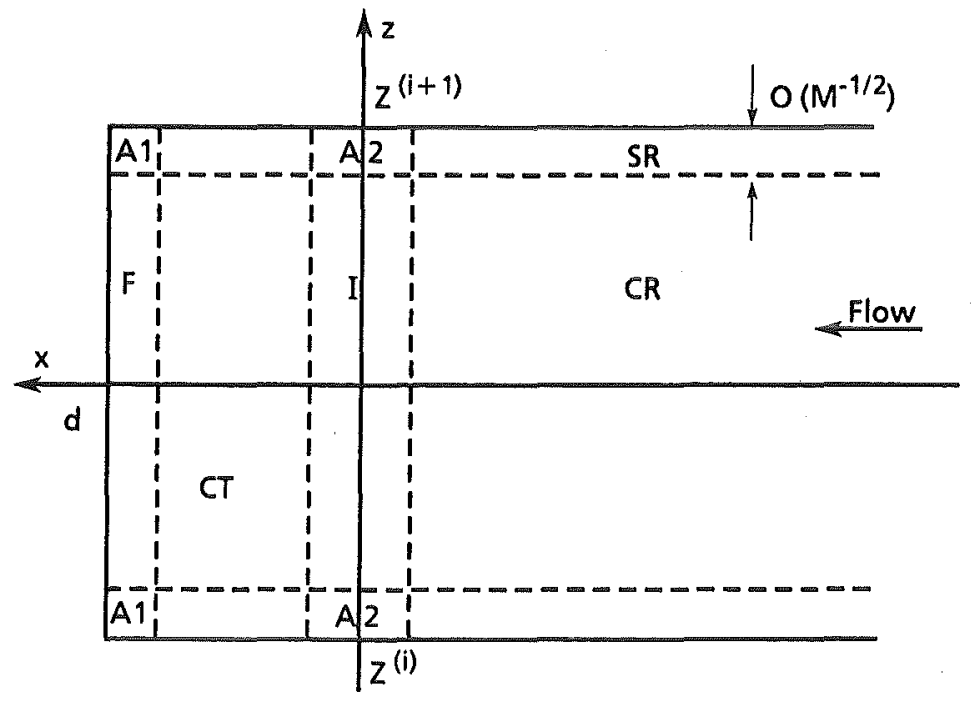

c)

Fig. 4.2 Flow in bend i: b,c) subregions at large values of M 


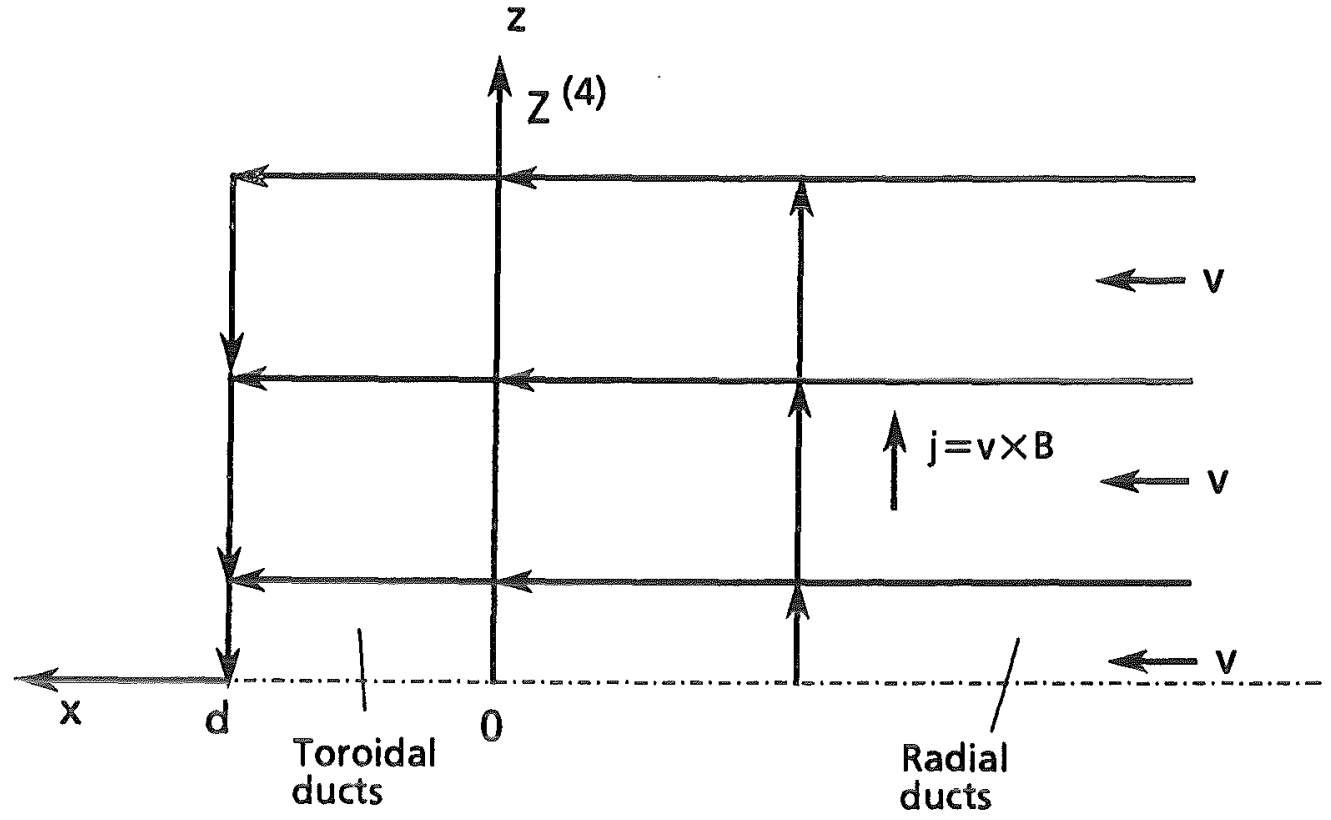

Fig. 4.3 Projection of flow geometry on $\mathrm{xOz}_{\mathrm{z}}$-plane and scheme of 3-D currents

3-D pressure drops in all channels increase. Their contribution to the total pressure drops estimated over a dimensionless length of 6 in the radial ducts increase as well. However, this increase is accompanied by the increase of the volume flux carried by jets at the first wall. This volume flux $\mathrm{Q}_{\mathrm{F}}(\mathrm{i})$ is equal to

$$
\delta_{i} Q_{F}^{(i)}=\int_{0}^{y}\left\{\phi_{1}^{(i)}\left(y, z=z^{(i+1)}\right)-\phi_{1}^{(i)}\left(y, z=z^{(i+1)}\right)\right\} d y=-\frac{1}{c_{1}^{(i)}} I_{1, z}^{(i)}
$$

(see Molokov and Bühler [7]), where $I_{1, z}$ (i) is the z-component of the total current which crosses the first wall of channel $i$, integrated from the bottom of the toroidal duct to the position y and averaged with respect to z. Only 3-D currents contribute to the value of flow rates in the expression (4.5). Thus, the increase of strength of 3-D currents due to MCE leads to higher volume fluxes at the first wall.

For the flow in a single bend the flow direction at the second wall under certain circumstances may become reversed (Molokov and Bühler [7]). This reversed flow is associated with a vortex close to the symmetry plane $y=l$. The rest of the fluid flows around the vortex. The amount of fluid that takes part in vortex motion is determined by the potential of the bottom of the toroidal duct. The fluid in the core of the toroidal duct flows perpendicular to the magnetic field along lines of con- 


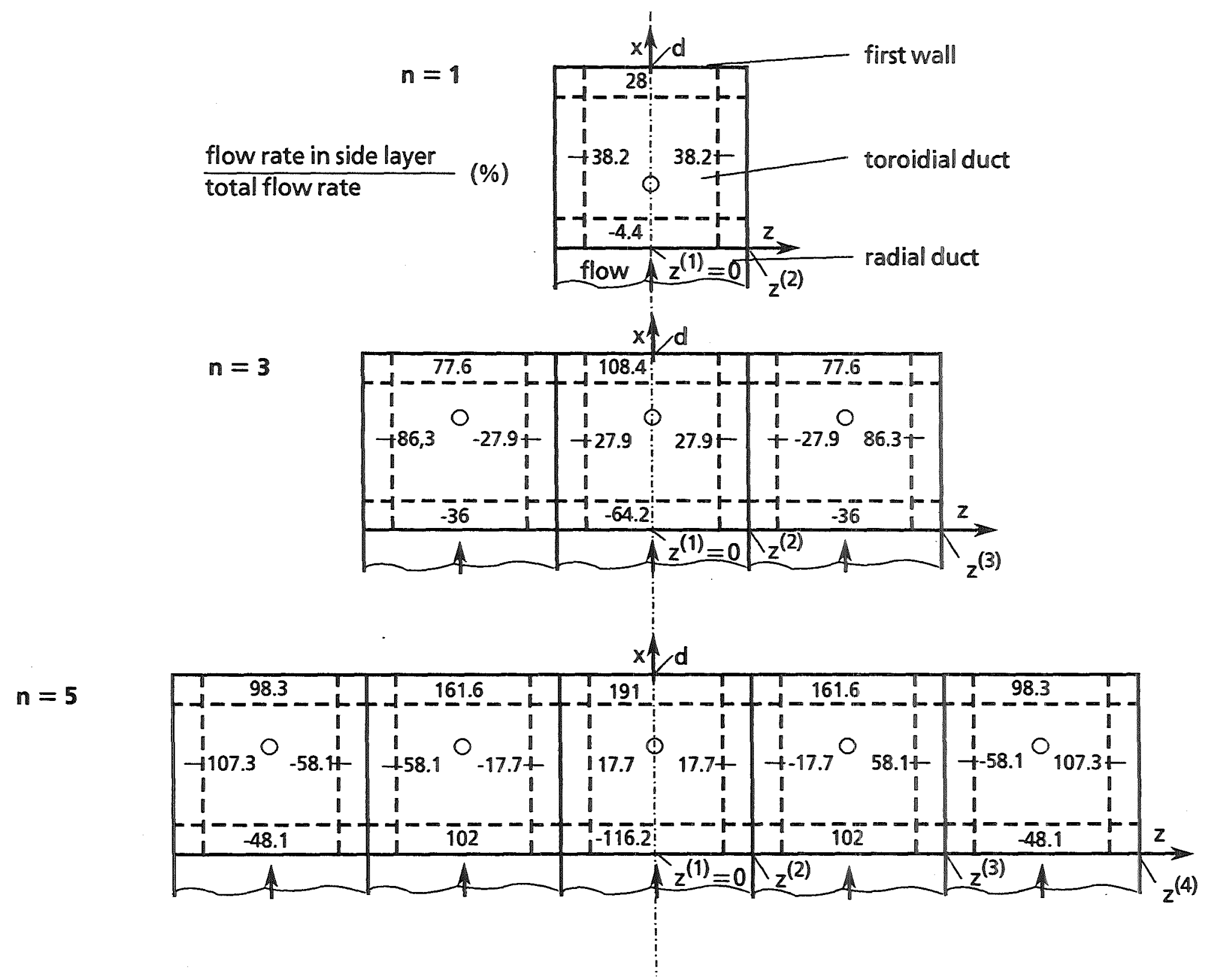

Fig. 4.4 Flow distribution in toroidal ducts at $\mathrm{y}=1$ for $\mathrm{n}=1 ; 3$ and 5 


\begin{tabular}{|cc|c|c|c|}
\hline & $\begin{array}{c}\Delta \mathrm{p}_{\text {tot }} \\
(1)\end{array}$ & $\begin{array}{c}\Delta \mathrm{p}_{3 \mathrm{D}} \\
(1)\end{array}$ & $\begin{array}{c}\mathrm{QFW}_{(\%)} \\
(\%)\end{array}$ \\
\hline $\mathrm{n}=1$ & 0.35 & 0.05 & 28 \\
\hline $\mathrm{n}=3 ;$ & $\mathrm{Z}=2$ & 0.431 & 0.093 & 77 \\
\hline $\mathrm{n}=5 ;$ & $\mathrm{Z}=1$ & 0.50 & 0.126 & 108 \\
\hline & $\mathrm{Z}=3$ & 0.445 & 0.107 & 98 \\
\hline & $\mathrm{Z}=2$ & 0.544 & 0.165 & 161 \\
\hline $\mathrm{Z}=1$ & 0.566 & 0.182 & 181 \\
\hline
\end{tabular}

Tabelle 4.1

stant potential of the bottom and is distributed between the layers at the first and the side walls. The fluid is taken from the layer at the second wall, and if the pumping in the core is strong enough, the flow at the second wall changes the direction. The same type of flow structure occurs in a multichannel U-bend. However, it is even more complicated because the reversed flow is present at some side walls of the toroidal ducts.

From Fig. 4.4 it follows that in all toroidal ducts of a multi-channel U-bend mixing of the fluid is even more intense than in a single U-bend. This should lead to desirable heat-transfer conditions. 


\section{Experimental Results \\ 5.1 General Tendencies}

In the Sections 5.1-5.3 results are presented for the case that the magnetic field was aligned with the axis of the toroidal channels. The influence of the inclination of the magnetic field will be discussed in Section 5.4.

Compared with Section 4 the channels are numbered in a different way: for a total number of 5 channels $(k=5)$ the middle channel is numbered with $i=3$ and the outer channels with $\mathrm{i}=1$ and $\mathrm{i}=5$. For $\mathrm{k}=3$, the middle channel is numbered with $\mathrm{i}=2$.

As mentioned, two modes of experimental conditions were anticipated, either "Q $\mathrm{Q}_{\mathrm{i}}=$ const" or $\Delta \mathrm{p}_{\mathrm{i}}=$ const". The first mode was realized by appropriately adjusting the throttles, the other mode by using completely opened throttles and assuming that the additional pressure drops at the test section inlet and outlet and in the manifolds are approximately equal for each channel. This is obviously not true as shown in Fig. 5.1a) for Geometry II, where the individual flow rates $Q_{i}$, normalized by the sum $Q_{1}-Q_{5}$, and the measured pressure differences are shown. The higher volume flow rate in a channel with a lower pressure drop due the MCE causes higher additional pressure drops in other parts which results in an unequal pressure distribution with the maximum measured value in that channel where the volume flow rate is lowest.

Although the individual pressure differences are different, no resultant leakage flow from one channel to the other is expected, as shown in Fig. 5.2. For open throttles the pressure difference distribution should be symmetric to the middle of the test section if the additional pressure drops upstream and downstream of the $U$ bend are equal. Then the signs of the pressure difference between two channels is different in the two halfs of the test section and if there are local leakage flows, they would compensate.

The pressure differences between the channels might become of importance for the mode $Q_{i}=$ const. as also shown in Fig. 5.2. Here, the mean pressure difference between two channels is about half of the measured value of the upstream positions. The maximum mean value was about 0.05 bar. Then, a leakage flow rate of 0.005 $1 / \mathrm{s}$ is expected, assuming a linear dependency between leakage flow rate and pressure difference, which is less than $5 \%$ of a typical flow rate through the channel. 

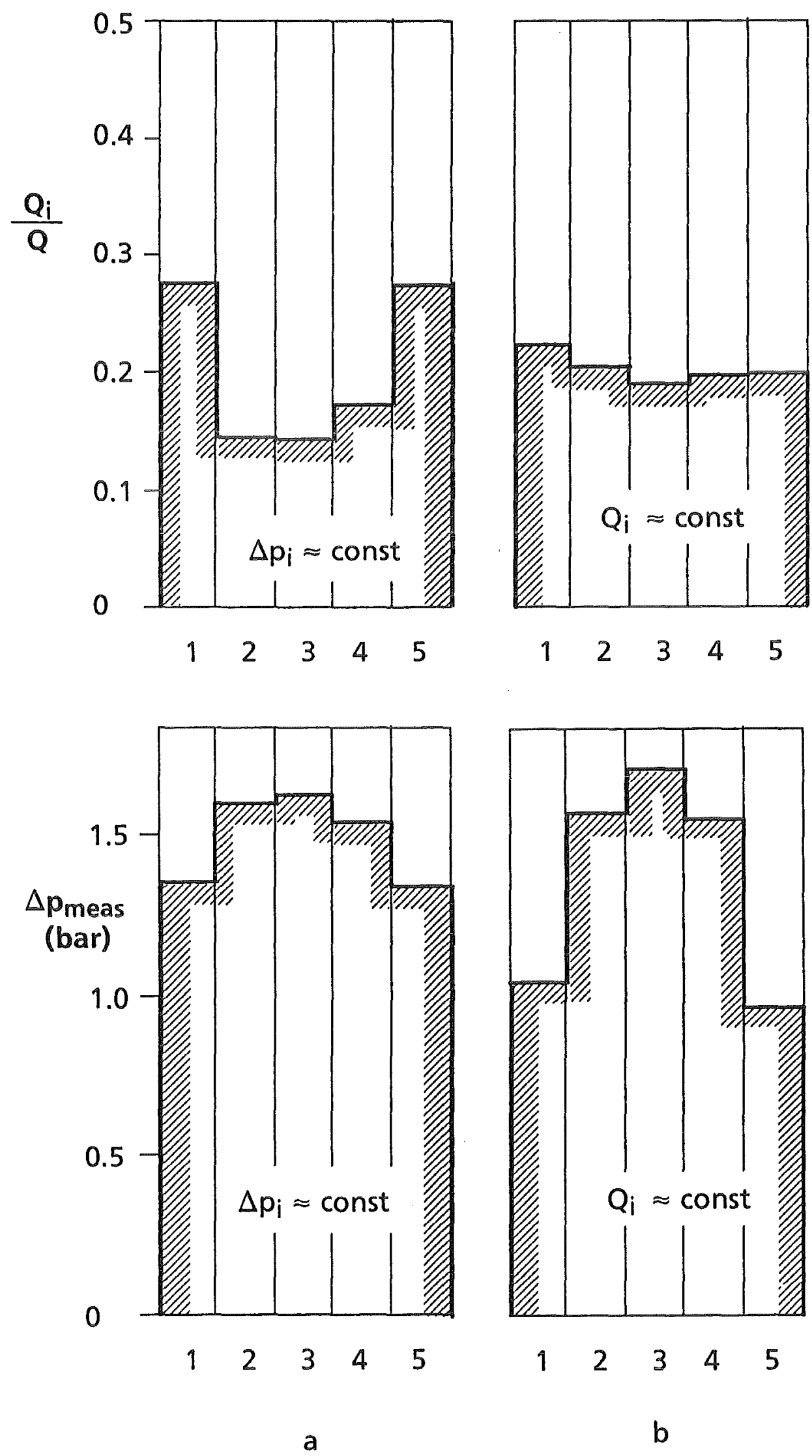

Figure 5.1 Characteristic results for experiments with $\Delta \mathrm{p}_{\mathrm{i}} \approx$ const and $\mathrm{Q}_{\mathrm{i}} \approx$ const (Channel Geometry II, $\mathrm{M} \approx 1600, \mathrm{~N} \approx 1760$ ) 

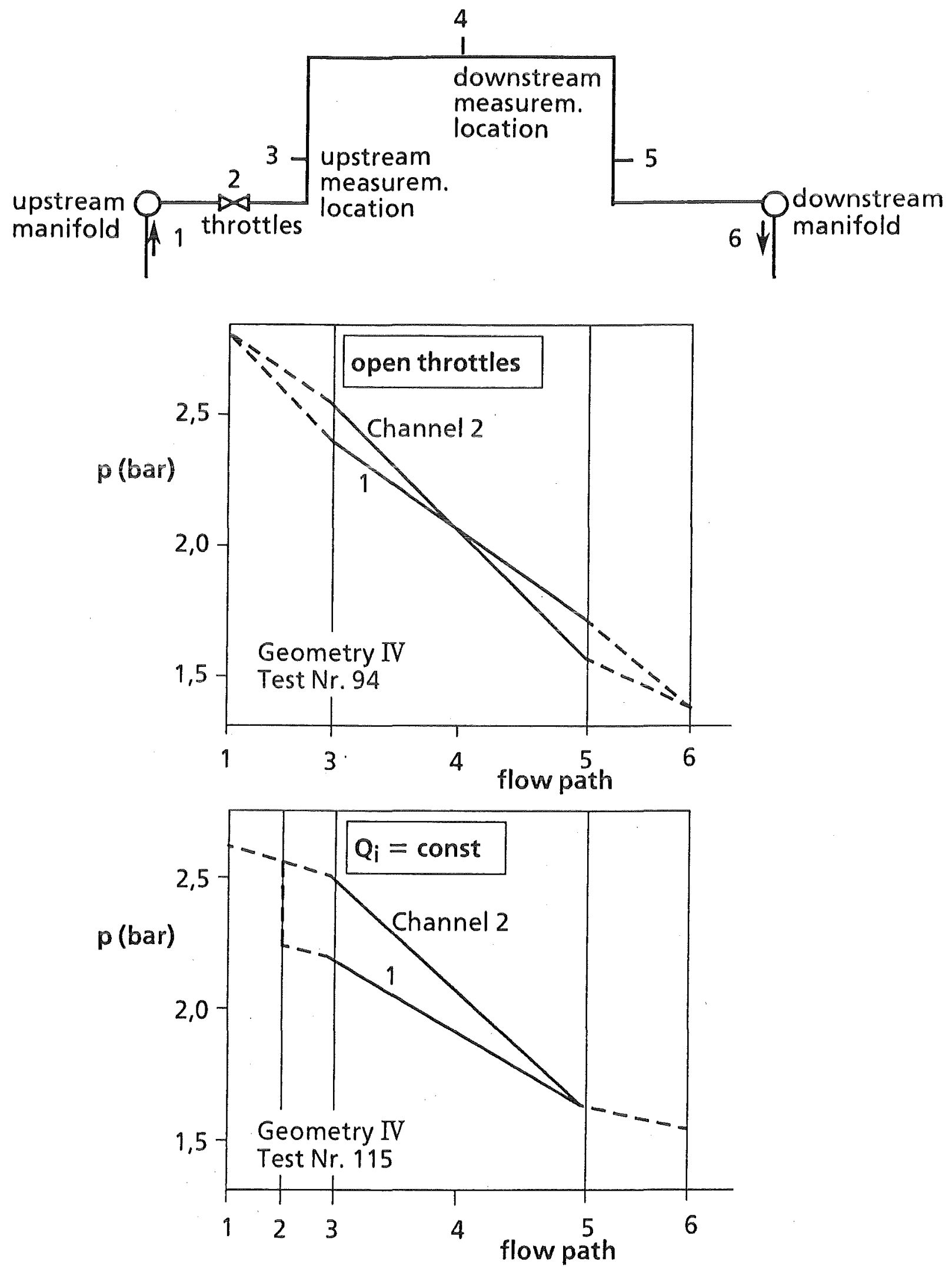

Figure 5.2 Schematic pressure distribution in different channels 
Figure 5.1a shows another effect which is characteristic for all investigated channel geometries as shown in detail in Figs. 5.4-5.11: the flow rate distribution is not axisymmetric to the middle channel, as expected for high Hartmann Numbers and Interaction Parameters. It is believed that the reason for this is the improper consideration of the influence of the magnetic field on the flow rate measurements.

Figure 5.1b shows characteristic results for the anticipated mode " $Q_{i}=$ const." Again, this condition was not perfectly adjusted

i) due to the limited experimental time

ii) due to the fact that some flow rate corrections were applied later.

Although the conditions " $\Delta \mathrm{p}_{\mathrm{i}} \approx$ const" and " $\mathrm{Q}_{\mathrm{i}} \approx$ const" are not realized very accurately, these terms are used in the following. The deviations from constant values do not play any role if the data are used for comparisons with model predictions because, then, the measured data are used as input values.

\subsection{Volume Flow Rate Distribution for $\Delta \mathrm{p}_{\mathrm{i}} \approx \mathrm{const}$}

\subsubsection{Dependence on Hartmann Number and Interaction Parameter}

Figure 5.3a shows the flow rate distribution for increasing magnetic field for a constant power of the EMF-pump (corresponding to $\mathrm{I}_{\mathrm{pu}} \approx 21 \mathrm{~A}$ ). For $\mathrm{B}=0 \mathrm{~T}$, the distribution is not equal and differs the most for flow direction "e". These initial distributions are fairly equal for all channel geometries and are propably dominated by the pressure drops in the manifolds which are different for the two flow directions.

With increasing $B$, the flow rates $Q_{i}$ decrease due to the increasing MHD pressure drops. Connected with this is the development of the MCE (which means for $\Delta \mathrm{p}_{\mathrm{i}} \approx$ const the increase of the flow rates in the outer channels and the decrease in the others).

The Figs. 5.4-5.11 show the normalized flow rate distribution $\mathrm{Q}_{\mathrm{i}} / \mathrm{Q}$ as a function of the magnetic field strength B, and Hartmann Number M, respectively. For high values of $\mathrm{M}$ and $\mathrm{N}$ the flow distribution is dominated by MHD pressure losses and the distributions should become independent from $\mathrm{M}$ and $\mathrm{N}$ (and should be also independent from the initial distribution at $\mathrm{B}=0$ ). 
The figures show that this independence is reached at about $M \approx 800$ and corresponding values (compare Fig. 3.14) of $N \approx 200$ for conducting outside walls (Geometries II and III). For nonconducting outside walls (Geometries I and IV) those values are higher $(M \approx 1000 ; N \approx 350$ for Geometry $I$ and $M \approx 1600 ; N \approx 1400$ for Geometry IV).

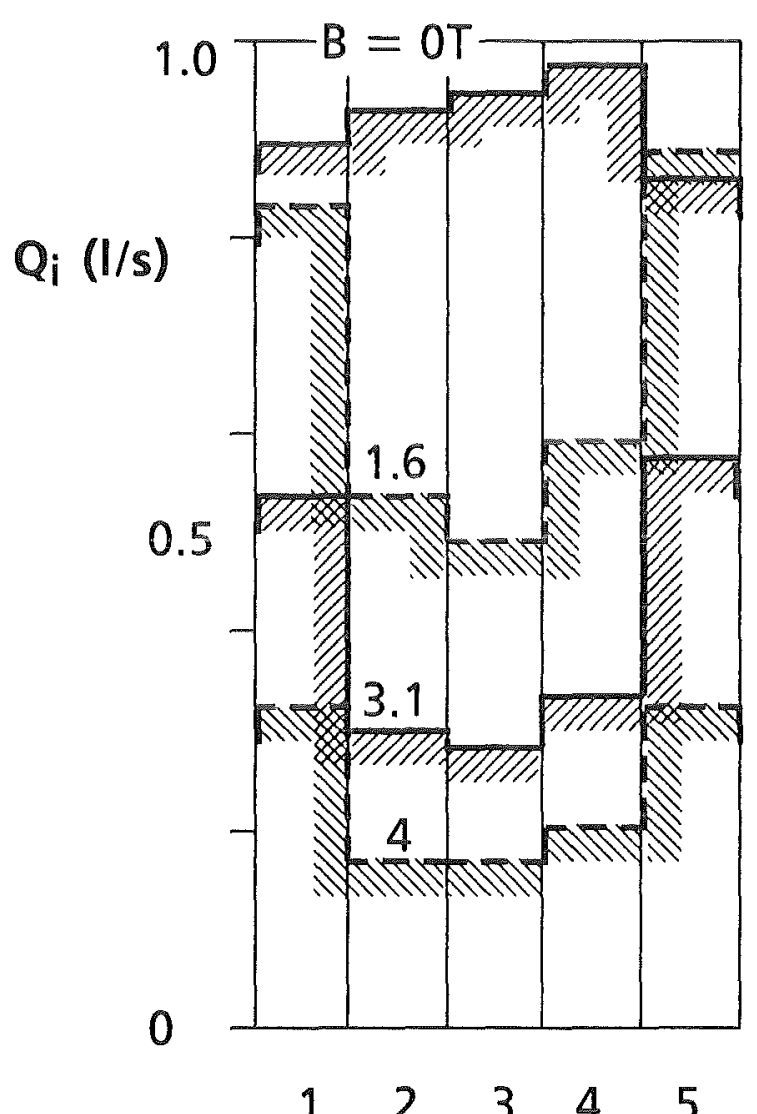

a) Flow direction " $w$ "

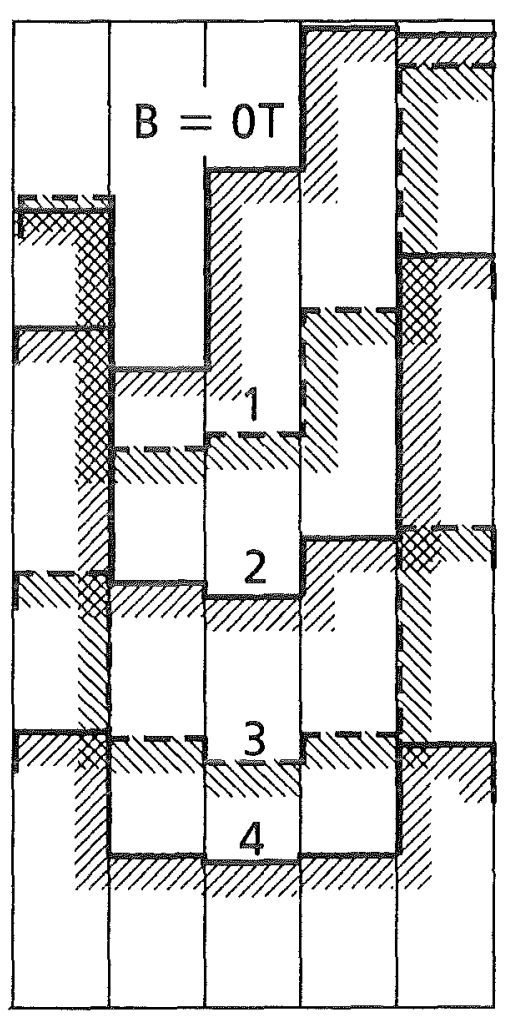

$\begin{array}{lllll}1 & 2 & 3 & 4 & 5\end{array}$

b) Flow direction " $\mathrm{e}$ "

Figure 5.3 Flow rate distribution for different values of the magnetic field strength B (Channel Geometry II, $\mathrm{k}=5 ; \mathrm{I}_{\mathrm{pu}} \approx 21 \mathrm{~A}$ )

The reason for the difference between conducting and nonconducting outside wall are the higher electric currents in the liquid metal in the first case which cause a shorter developing length to reach fully developed MHD flow.

For $\mathrm{M}=$ const., in general, the MCE is expected to depend on N. However, a clear tendency is not observed because 


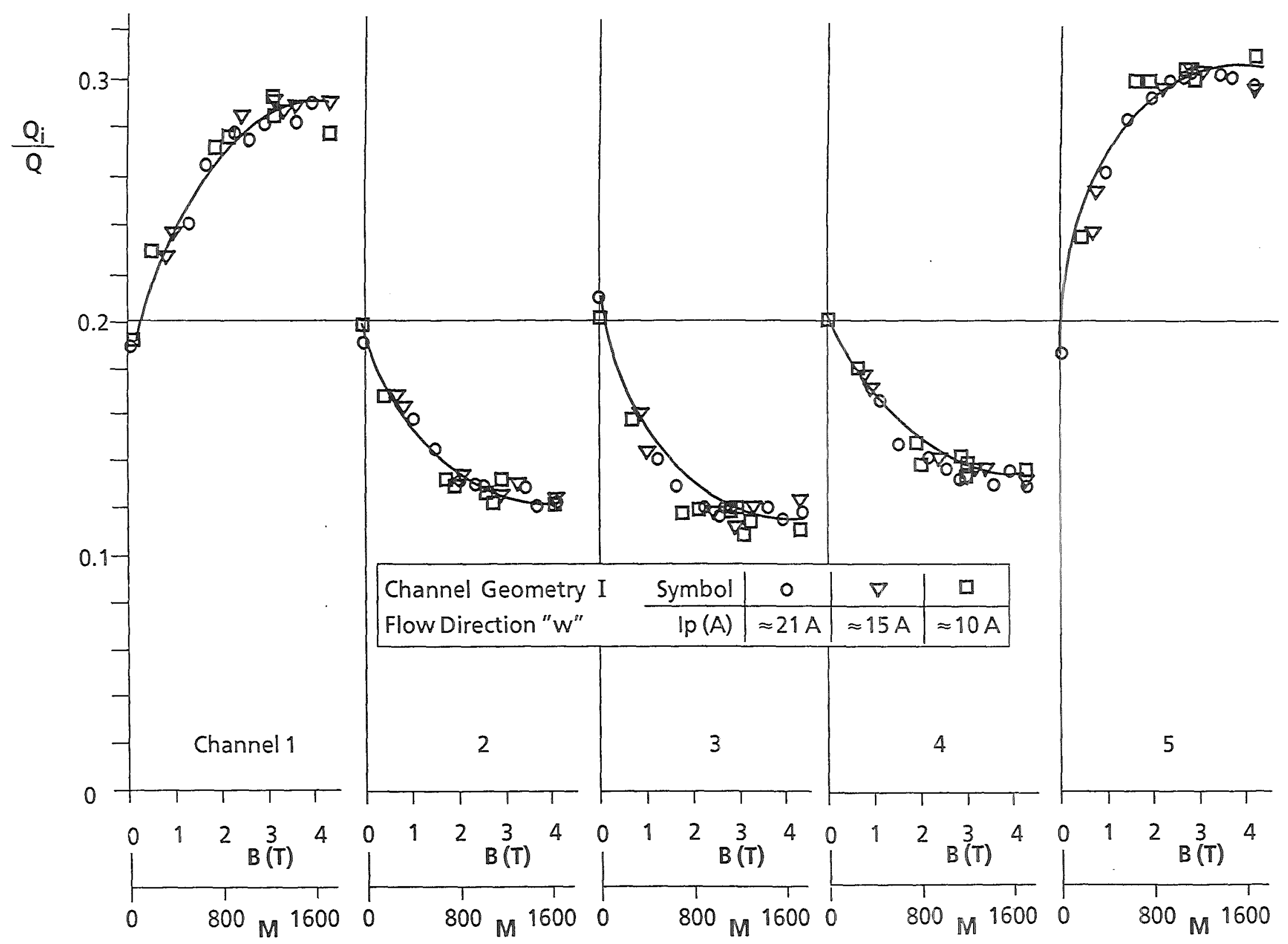

Figure 5.4 Flow rate distribution as a function of Hartmann Number for Flow Geometry I and flow direction "w" 


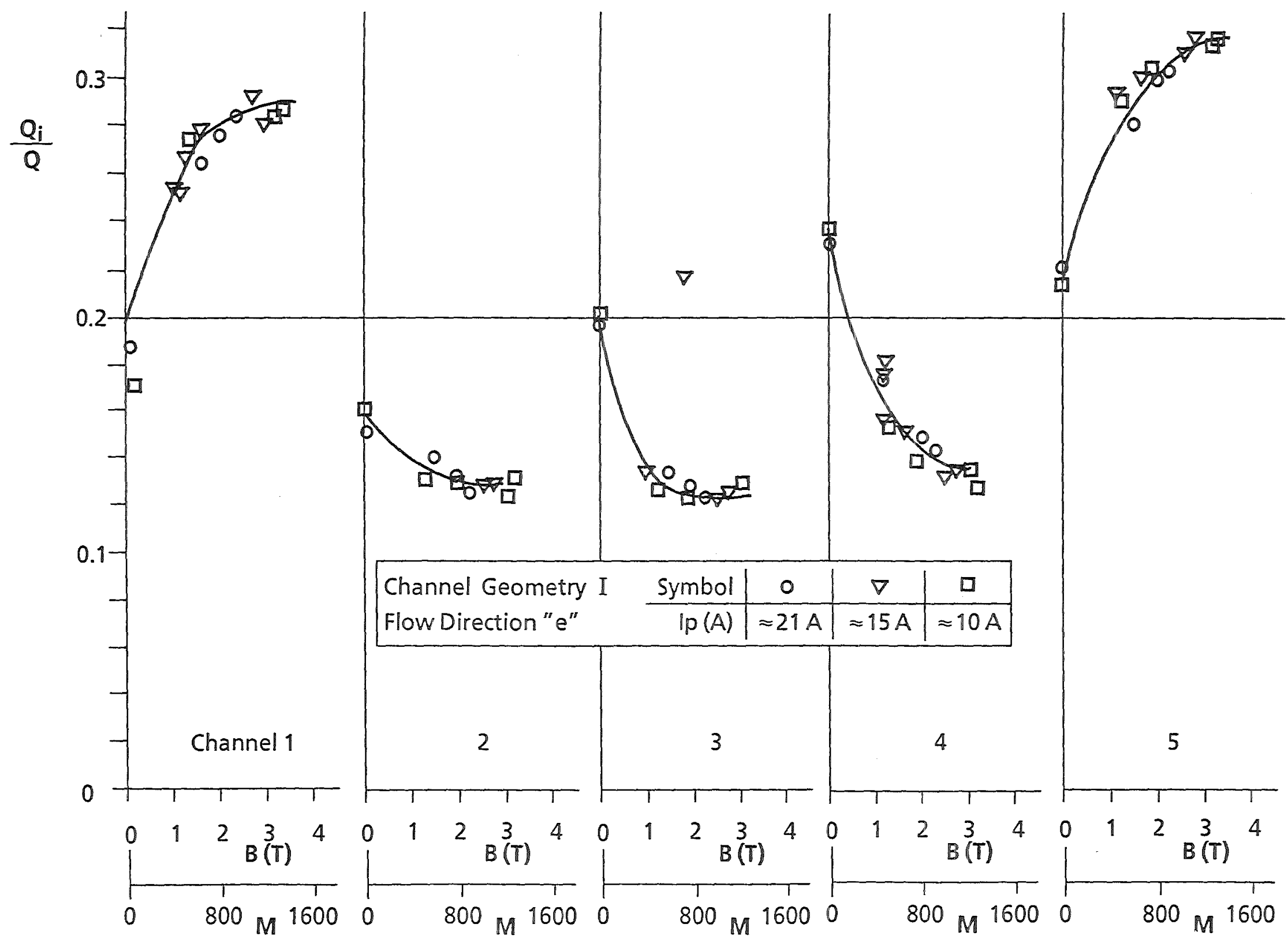

Figure 5.5 Flow rate distribution as a function of Hartmann Number for Flow Geometry I and flow direction "e" 


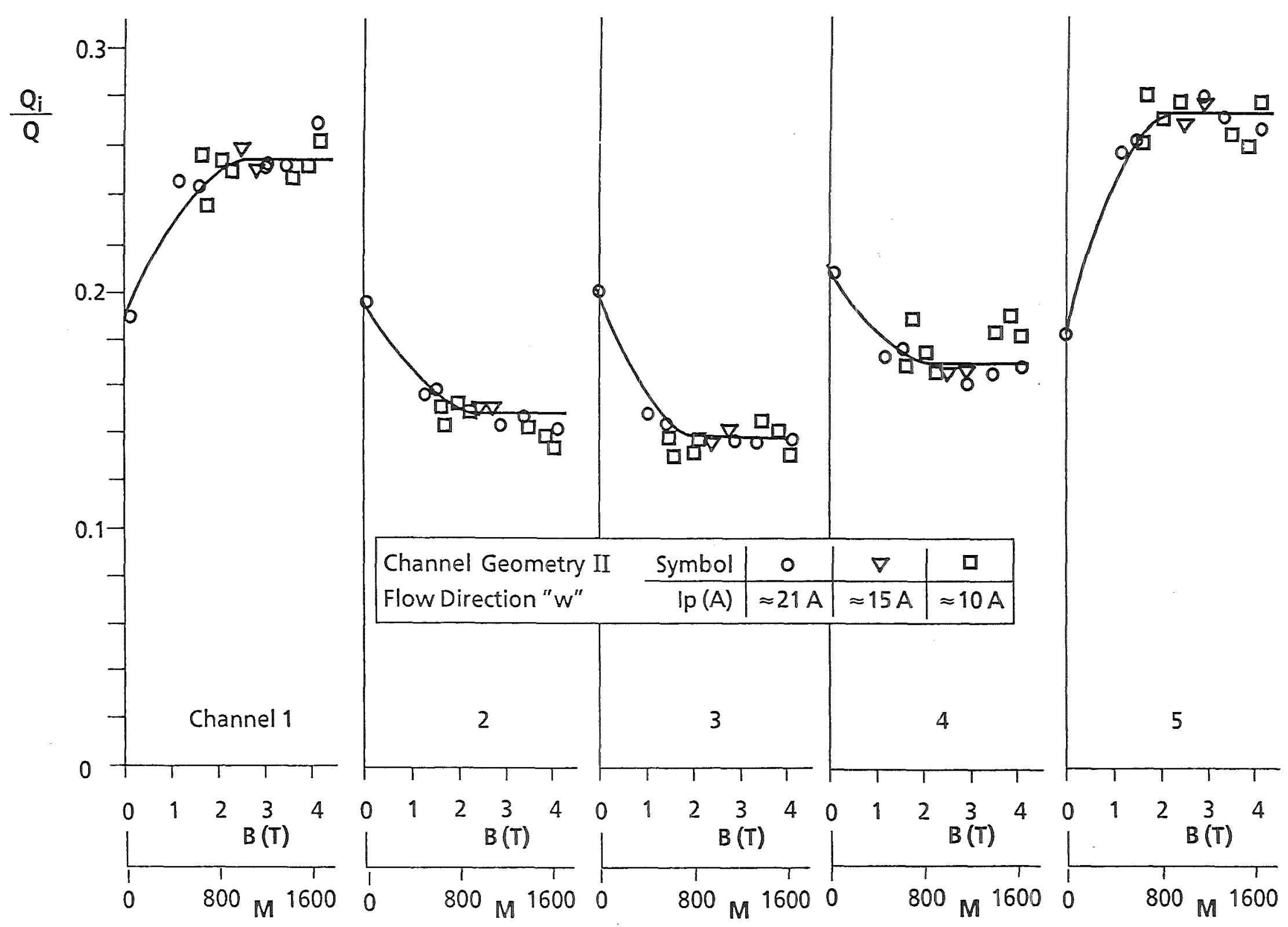

Figure 5.6 Flow rate distribution as a function of Hartmann Number for Flow Geometry II and flow direction "w" 


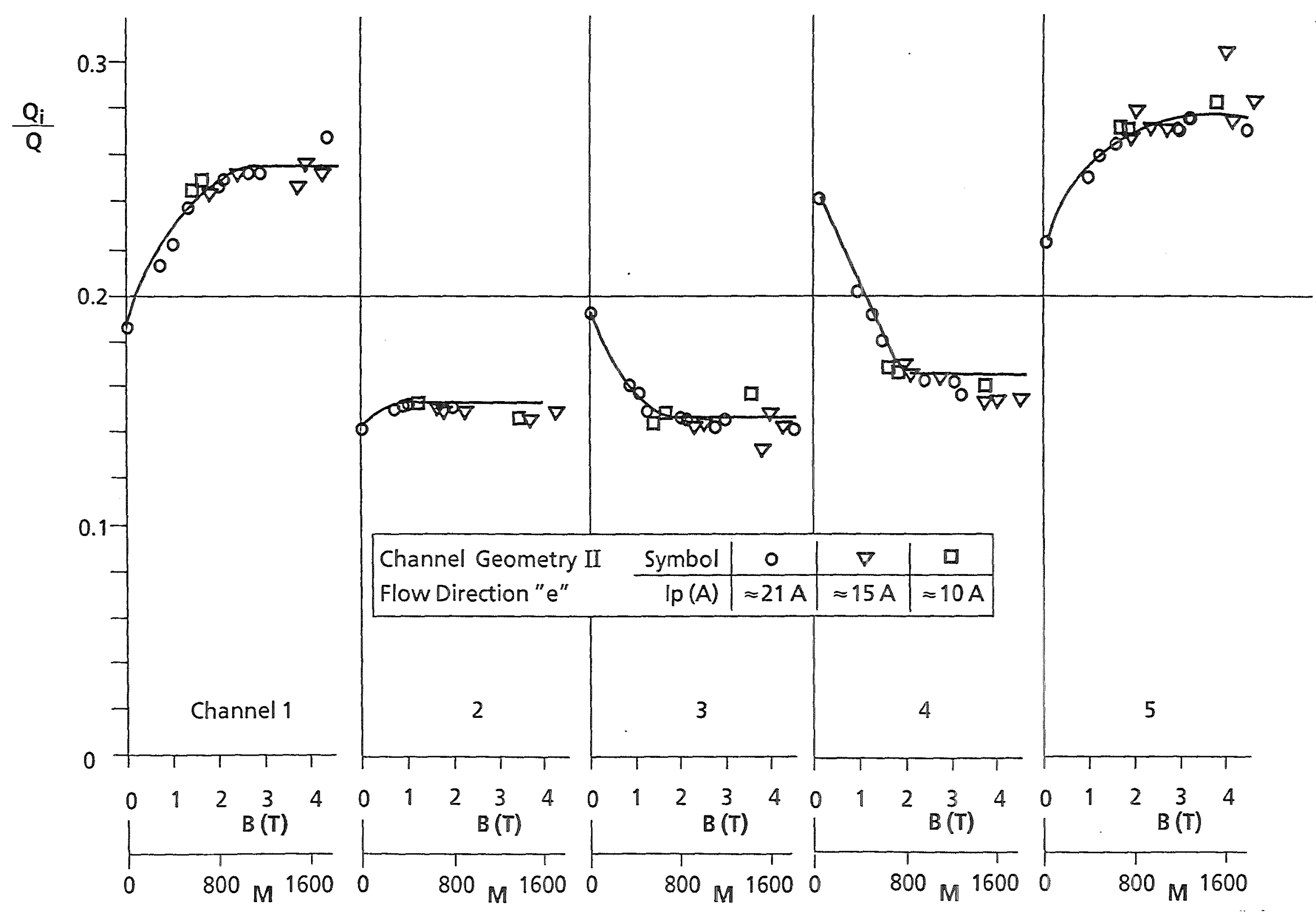

Figure 5.7 Flow rate distribution as a function of Hartmann Number for Flow Geometry II and flow direction "e" 


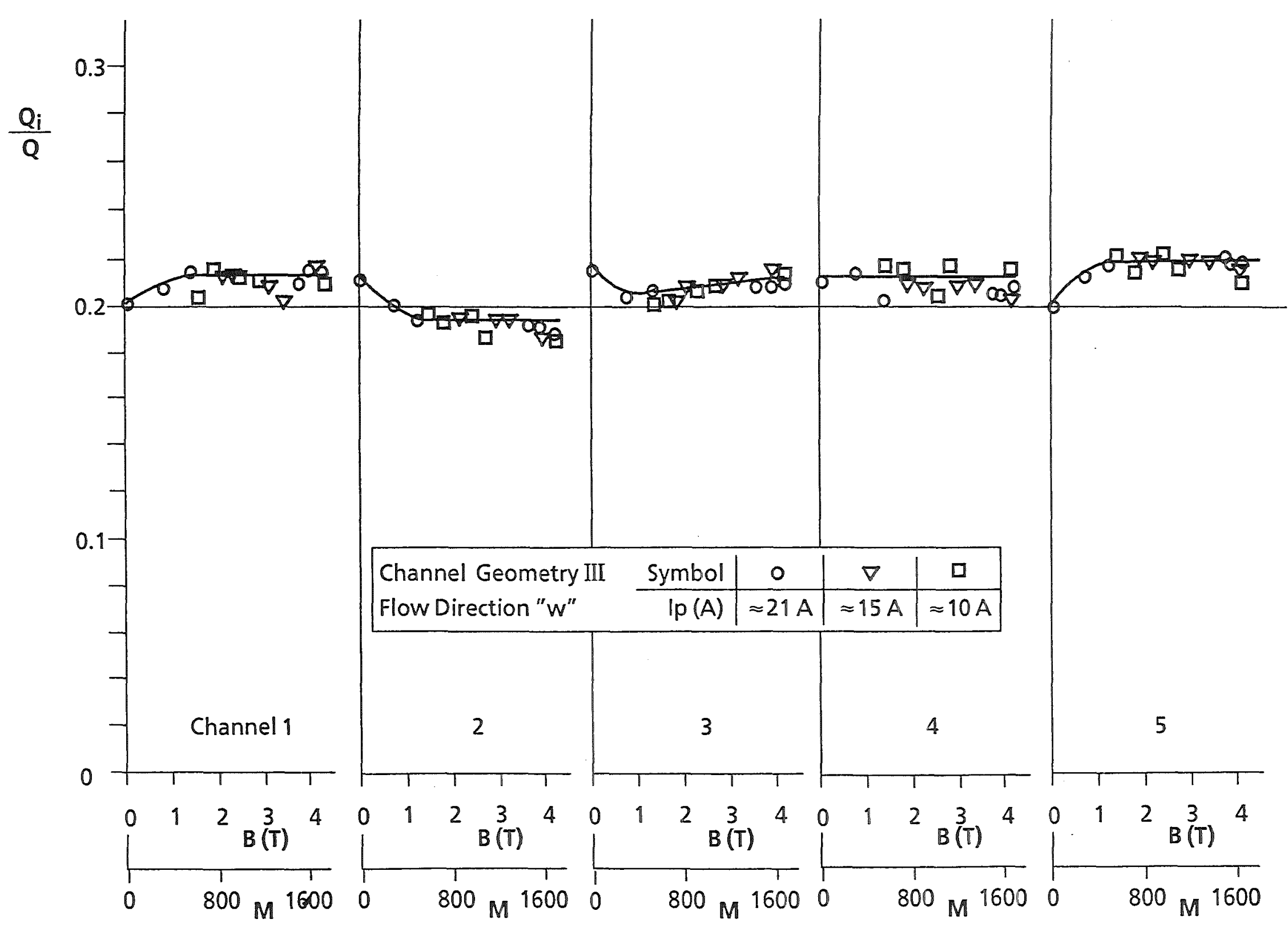

Figure 5.8 Flow rate distribution as a function of Hartmann Number for Flow Geometry III and flow direction "w" 


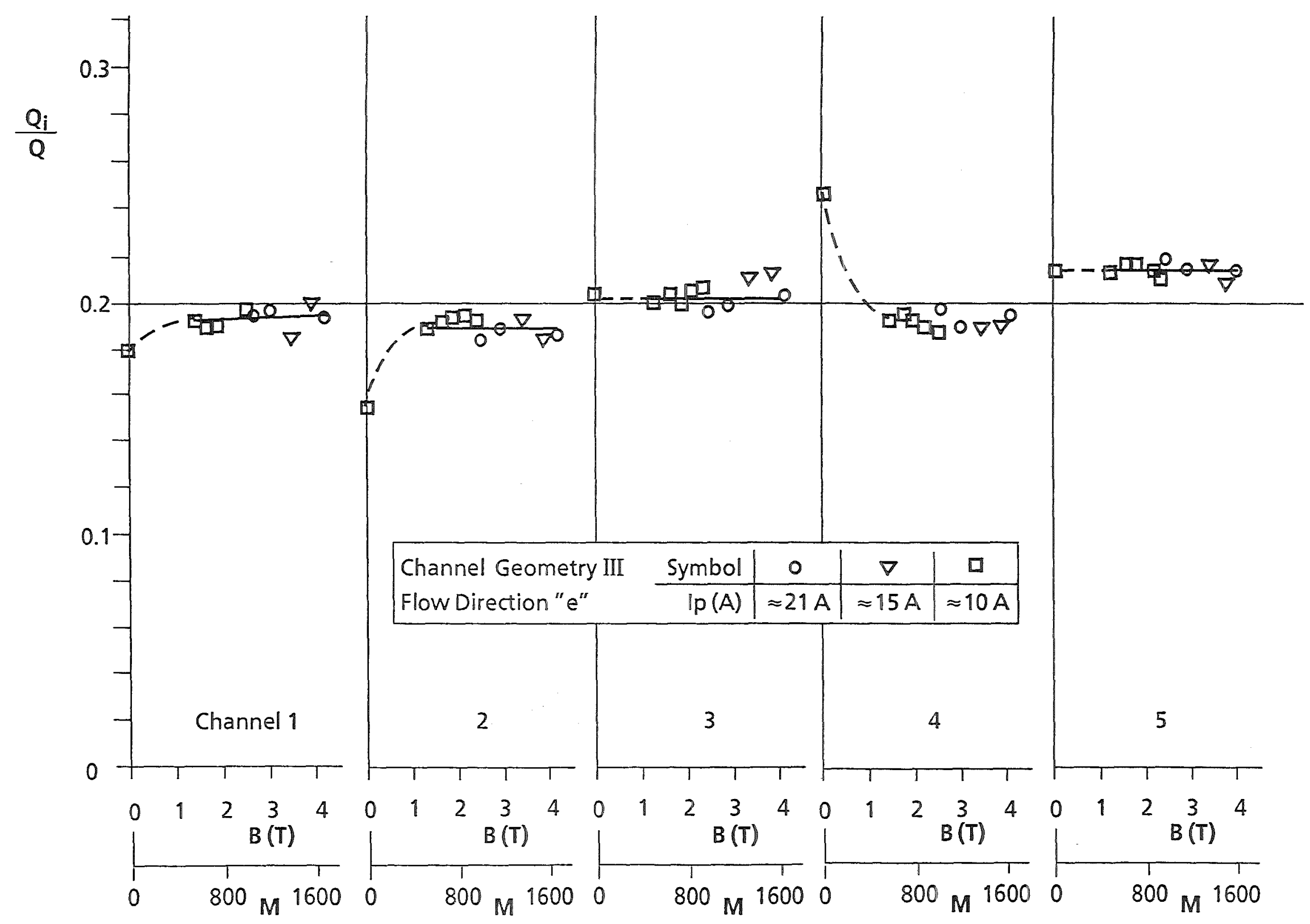

Figure 5.9 Flow rate distribution as a function of Hartmann Number for Flow Geometry III and flow direction "e" 


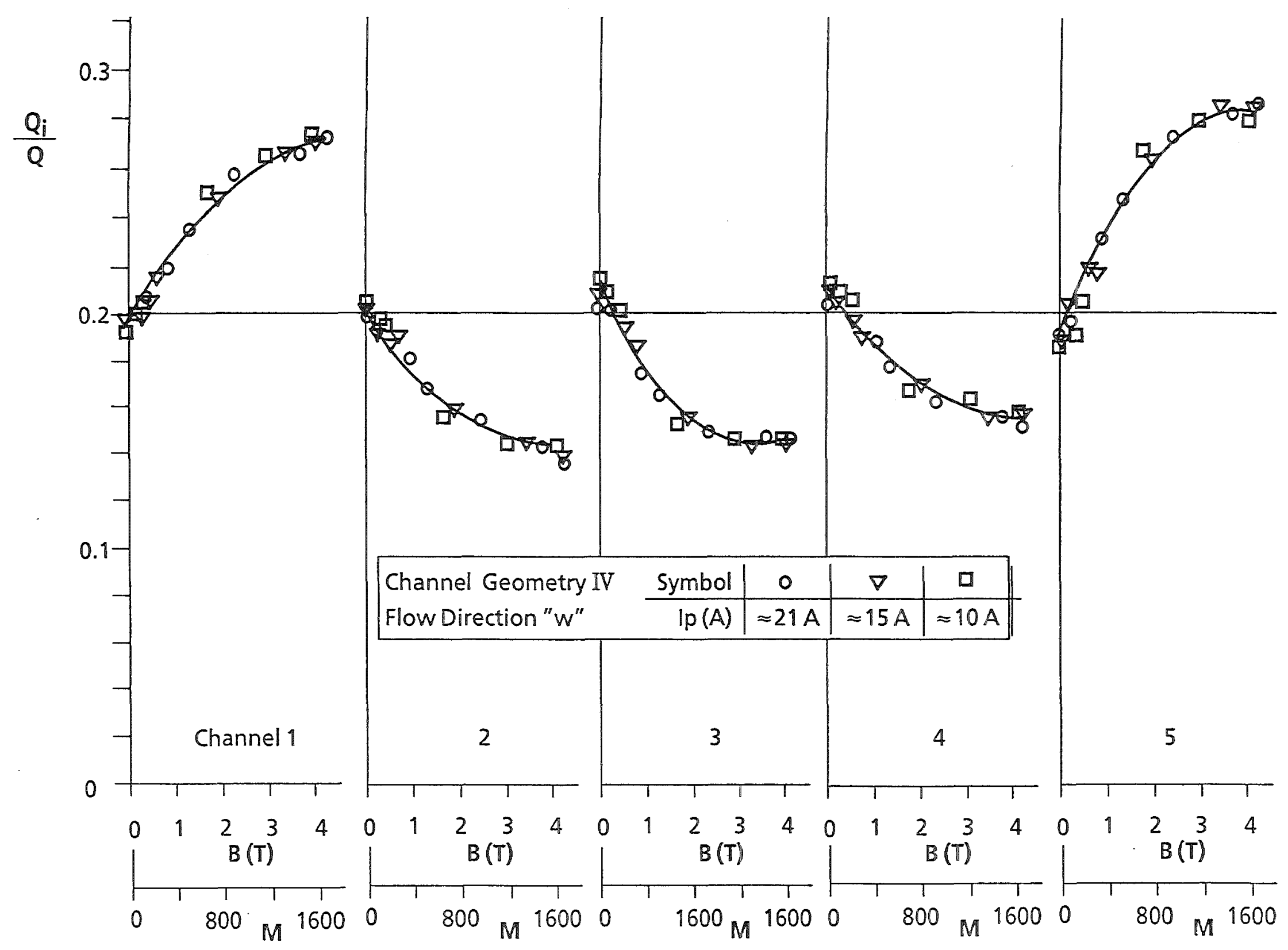

Figure 5.10 Flow rate distribution as a function of Hartmann Number for Flow Geometry IV and flow direction "w" 


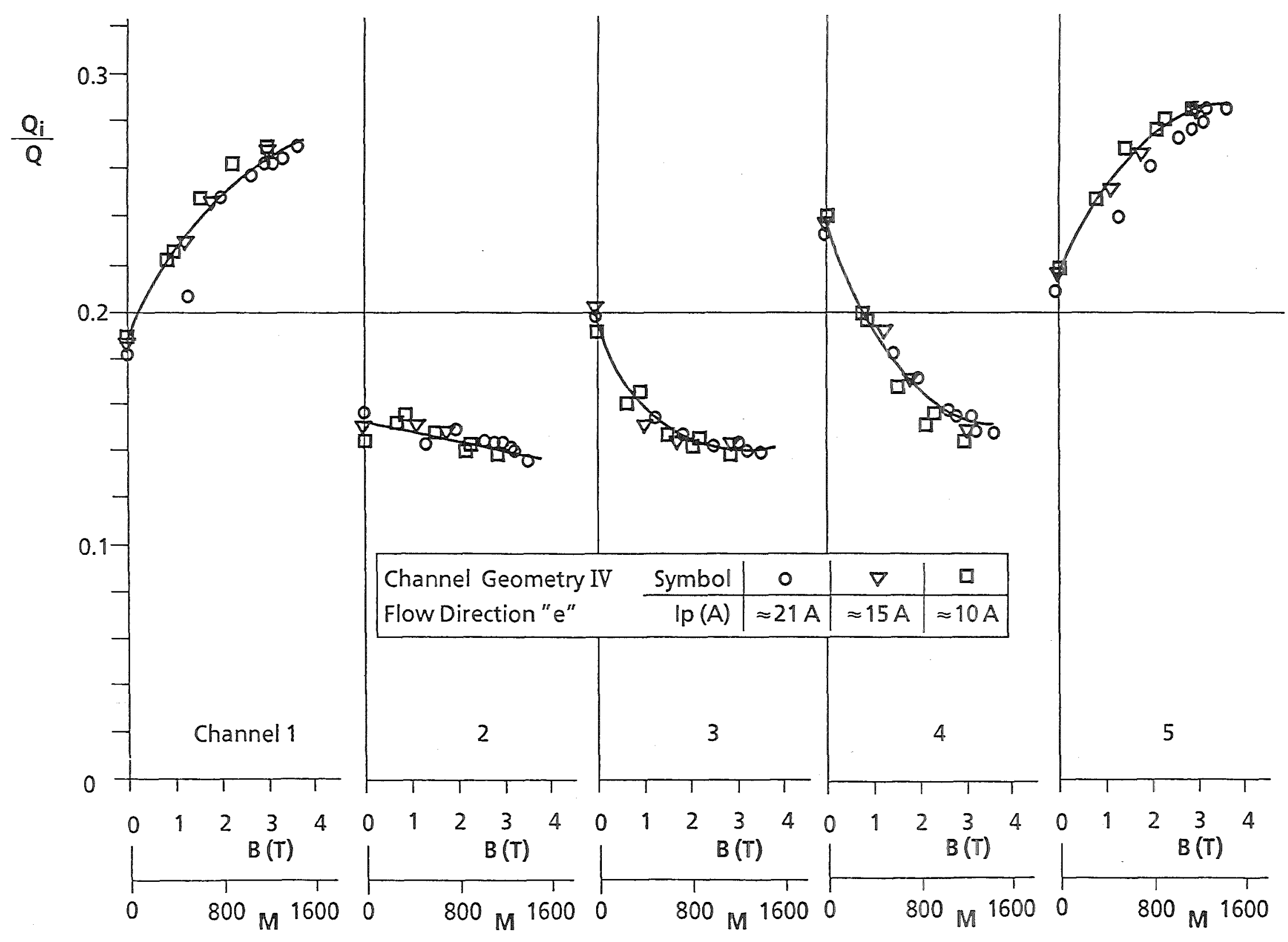

Figure 5.11 Flow rate distribution as a function of Hartmann Number for Flow Geometry IV and flow direction "e" 
i) the experimental variation of $\mathrm{N}$ for $\mathrm{M}=$ const was small, compare Fig. 3.14, and

ii) pronounced flow rate oscillations occured at high $\mathrm{M}$ and low volume flow rates (high $\mathrm{N}$ ). The reason for these oscillations was not clear.

Comparing the two flow directions, no significant difference is found for high values of $M($ and N). Therefore, (resultant) leakage flows were negligible.

\subsubsection{Dependence on Channel Geometry and Channel Number $k$}

Figure 5.12 shows a summary of the results for all channel geometries and Hartmann Numbers $M \approx 1600$ and Interaction Parameters $N$ between 1700 and 2500 .

The influence of the number of channels, $k$, used in the different test configurations is demonstrated with Fig. 5.12a: For $k=2$, the flow rate in the two channels should be equal. This is confirmed pretty well by the measurements. For $k=3$, the flow rate in the outside channels is about twice the flow rate in the middle channel. For $k=5$, again the flow rate in the outside channels is considerably larger than the flow rate of the inside channels. It is worth to note that the values for the inside channels are very close together. This effect was also predicted by Madarame for large values of $k$.

The difference between conducting and nonconducting outside walls (Geometry II and I) can be seen by comparing Figs. 5.12a and b: The MCE is less pronounced for conducting outside walls because the electrical circuit through the walls decreases the global electrical circuits through the liquid metal compared to nonconducting walls.

The difference between a multichannel U-bend and a multichannel single bend (Geometry I and IV) is revealed by comparison of Figs. 5.12a and c: The MCE is stronger for the U-bend because large global currents in the toroidal region are favoured due to the reversed flow direction of the electrical currents in the second bend, compare Fig. 2.2d). However, the difference for the two geometries is not large. This result will be discussed in more detail in Section 5.3.3.

Summarizing the results for the Geometries I, II and IV, it can be pointed out that a strong MCE was observed both for conducting and nonconducting outside walls. This effect would be even more pronounced if the condition of $\Delta \mathrm{p}_{\mathrm{i}}=$ const were re- 


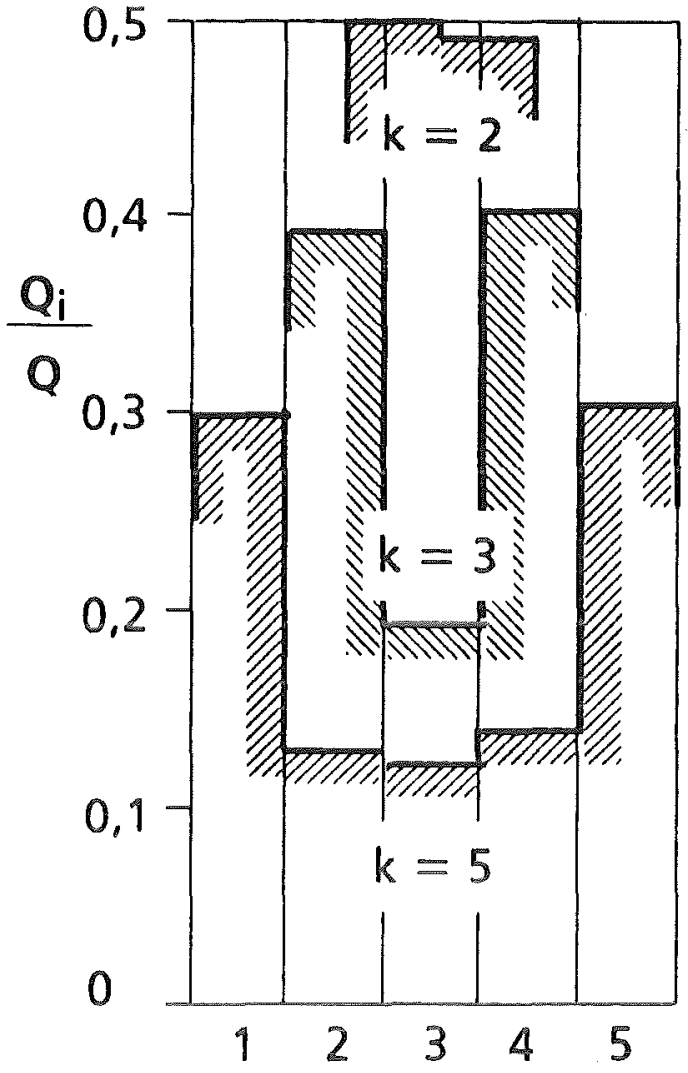

a) Channel Geometry I

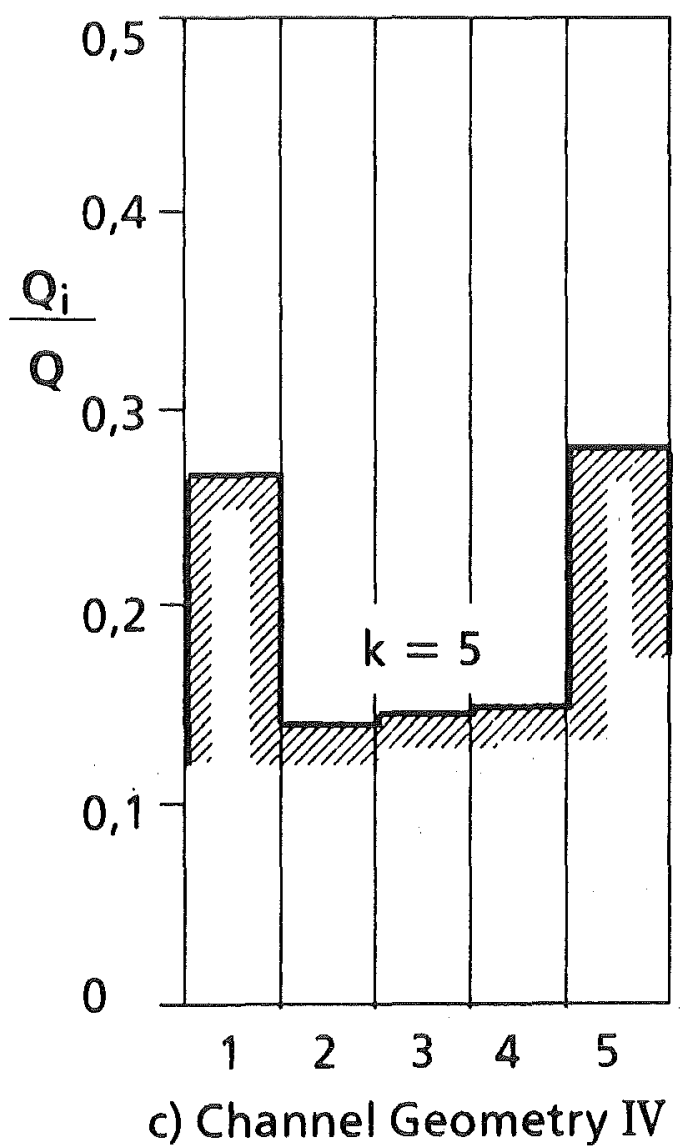

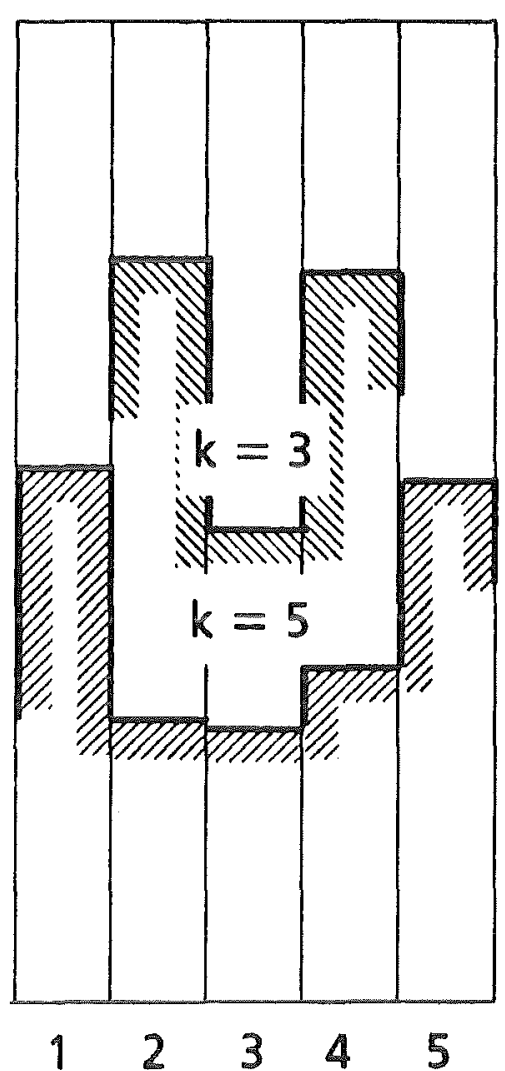

b) Channel Geometry II

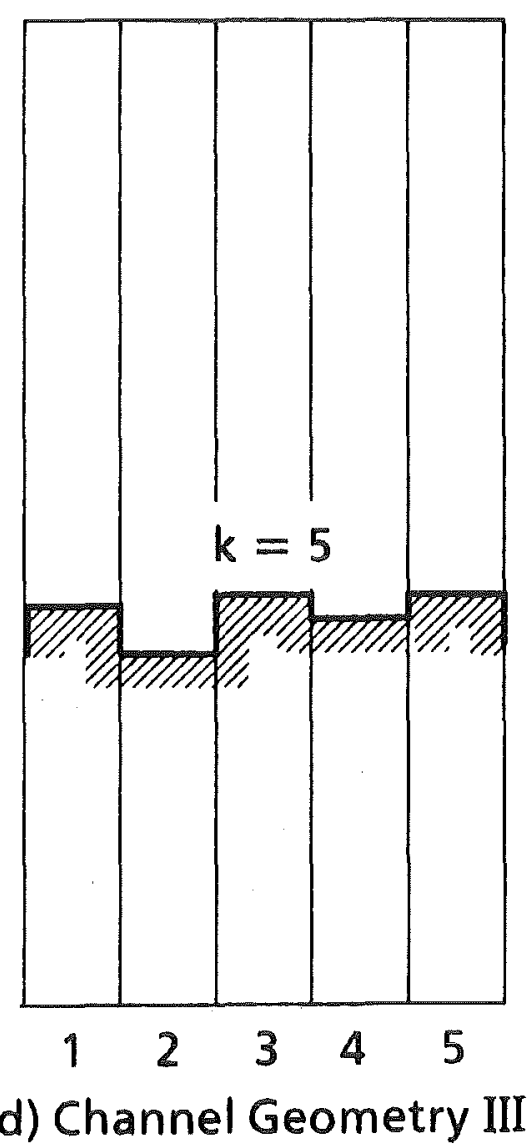

Figure 5.12 Flow rate distribution for $\Delta \mathrm{p}_{\mathrm{i}} \approx$ const and high Hartmann Numbers and Interaction Parameters $(M \approx 1600,1700<\mathrm{N}<2500)$ 
alized in the experiments. Presently, no comparisons with model predictions can be made for nonconducting outside walls; the comparison with Geometry II will be presented in Section 5.3.2.

Figure $5.12 \mathrm{~d}$ contains the corresponding results for that channel geometry where the radial channels are electrically decoupled by using insulated dividing walls. No marked MCE is observed which indicates that the single channel behave similar to separated single channel U-bends.

\subsection{Pressure Drop Distribution}

\subsubsection{Single Channel Pressure Drop}

The measured pressure drop in a single channel, $\Delta \mathrm{p}_{\mathrm{sc}}$, can be interpreted as the sum of the pressure drop in the channel perpendicular to the magnetic field (the radial channel), $\Delta \mathrm{p}_{\mathrm{rc}}$, and the pressure loss in the bend, $\Delta \mathrm{p}_{\mathrm{b}}$, as shown schematically in Fig. 5.13. The pressure drop in toroidal channel where $B$ is parallel to the flow velocity is negligible compared to the other terms.

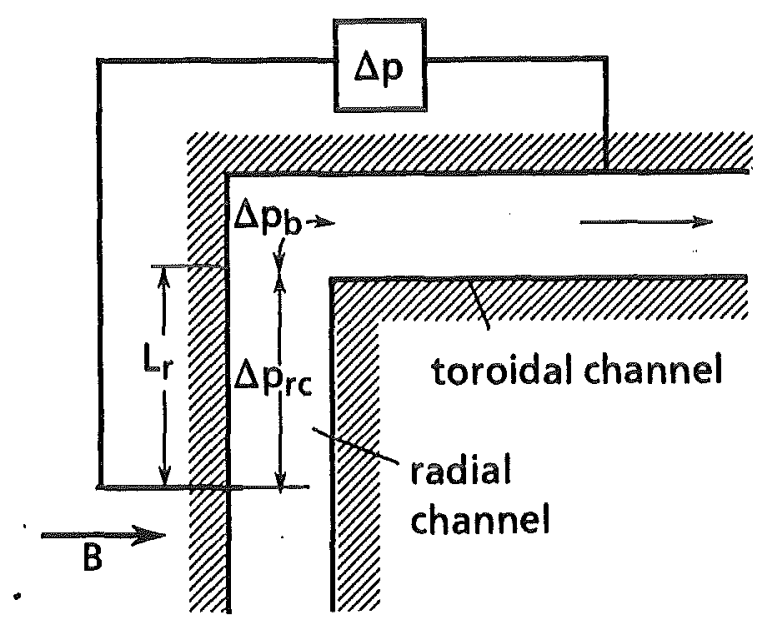

Figure 5.13 Schematic presentation of channel and bend pressure drop

For thin conducting walls, the first term is calculated using the Core Flow Solution, compare e.g. Walker /8/. For a square duct the following expression is obtained:

$$
\begin{gathered}
\Delta p_{s c}=\Delta p_{r c}+\Delta p_{b} \\
\Delta p_{r c}=u B^{2} l_{r} o C /(4 / 3+C) .
\end{gathered}
$$


This expression agreed very well with experiments from Miyazaki et al /9/ where the duct dimensions and conductance ratio $\mathrm{C}$ were similar as in the present experiments.

The second term can be calculated again with the Core Flow Solution and is expressed by

$$
\Delta p_{b}=d_{3 d} \Delta p_{r c} / L_{r}
$$

where the equivalent flow path length $\mathrm{d}_{3 \mathrm{~d}}$ depends on the conductance ratio $\mathrm{C}$ and the length of the toroidal channel. Typically, $\mathrm{d}_{3 \mathrm{~d}}$ is about the characteristic length a. For the present geometry, a value of $\mathrm{d}_{3 \mathrm{~d}}=1.063 \mathrm{a}$ is obtained. For the present length of the radial channel $\mathrm{L}_{\mathrm{r}}=6 \mathrm{a}$, the bend pressure drop is about $18 \%$ of the pressure drop in the radial channel.

Therefore, it follows for the single channel with thin conducting walls

$$
\Delta p_{s c c}=\left(1+1.063 a / L_{r}\right) L_{r} \sigma(C /(4 / 3+C)) u B^{2}
$$

With the present values, one obtains

$$
\Delta p_{s c c}=2.32 \cdot 10^{4} u B^{2}
$$

The term $\Delta \mathrm{p}_{\mathrm{sec}}$ will be mostly used in the following to normalize the measured pressure differences.

For nonconducting walls the pressure drop in the radial channel is given by

$$
\Delta p_{r c}=u B L_{r}(\rho \vee \cdot 0)^{0.5 / a}
$$

which gives for the present values

$$
\Delta p_{r c}(m b a r)=722 u B\left(m s^{-1} T\right)
$$

This expression is proportional to $\mathrm{uB}$. However, for the present experiments this pressure drop $\Delta \mathrm{p}_{\mathrm{rc}}$ is negligible compared to the values obtained with Eqs (5.2) or (5.4).

No correlation was found in literature for the bend pressure drop. However, for a straight duct with insulating walls in a nonuniform magnetic field, the pressure 
drop is proportional to $\mathrm{uB} 3 / 2 / 10 /$. The bend pressure drop must also be proportional to $\mathrm{uB}^{3 / 2}$. Nevertheless, it is convenient to normalize the pressure drop for the nonconducting bend with $\mathrm{uB}^{2}$ in order to compare data for different wall conductance ratios.

For a single channel with conducting outside walls (Flow Geometry $I, k=1$, see Fig. 3.13), Eq. (5.4) is appropriate to normalize the measured pressure drop. This procedure is also used for the data from Geometry III as also shown in Fig. 5.14.

The results are presented as a function of the magnetic field strength, and Hartmann Number $M$. With increasing $M$, the Interaction Parameter $\mathrm{N}$ also increases, see Fig. 3.14. In Fig. 5.14, a strong decrease of the normalized pressure drop is observed with increasing M. However, it is not clear from this figure if this is due to the increase of M or N. Fig. 5,15 shows the same results as a function of N. As ordinate $\Delta \mathrm{p}^{*}=\Delta \mathrm{p}_{\text {meas }} /\left((\rho / 2) \mathrm{u}^{2} \mathrm{~N}\right)$ is used which differs only by a constant factor from $\Delta \mathrm{p}_{\text {scc. }}$. The data scatter much less around a mean value which indicates that the influence of $\mathrm{N}$ is more expressed than of $\mathrm{M}$. This fact agrees with observations from many other experimental results obtained in the LAS (Lielausis [11]).

Concerning the results for the single channel (top figure of left column) one observes a decrease of pressure drop with increasing $\mathrm{N}$. At high $\mathrm{N}$ the experimental results go asymptotically to the value predicted by the theoretical analysis (designated with $\mathrm{N} \rightarrow \infty$ ).

\subsubsection{Multichannel U-bends: Dependence on Interaction Parameter}

First, results are discussed for the channel geometries with electrically coupled channels. Figure 5.16 contains the results for the multichannel U-bend with thin conducting outside walls (Geometry II). Both the results for the experiments with $\Delta \mathrm{p}_{\mathrm{i}} \approx$ const and $\mathrm{Q}_{\mathrm{i}}=$ const are presented. To normalize $\Delta \mathrm{p}_{\text {meas }} \mathrm{i}$ the measured mean channel velocity $u_{i}=Q_{i} / A_{i}$ was used. Mean values were used for symmetric channels ( $\mathrm{i}=1 ; 3$ for $\mathrm{k}=3 ; \mathrm{i}=1 ; 5$ and $\mathrm{i}=2 ; 4$ for $\mathrm{k}=5$ ). The pressure drop distributions exhibit a strong MCE with the highest pressure drop in the middle channel and the lowest in the outer channels. There is a much stronger effect of the Interaction Parameter compared to the single channel U-bend; at $N \approx 10000$ the calculated values valid for $\mathrm{N} \rightarrow \infty$ are by far not reached yet. 


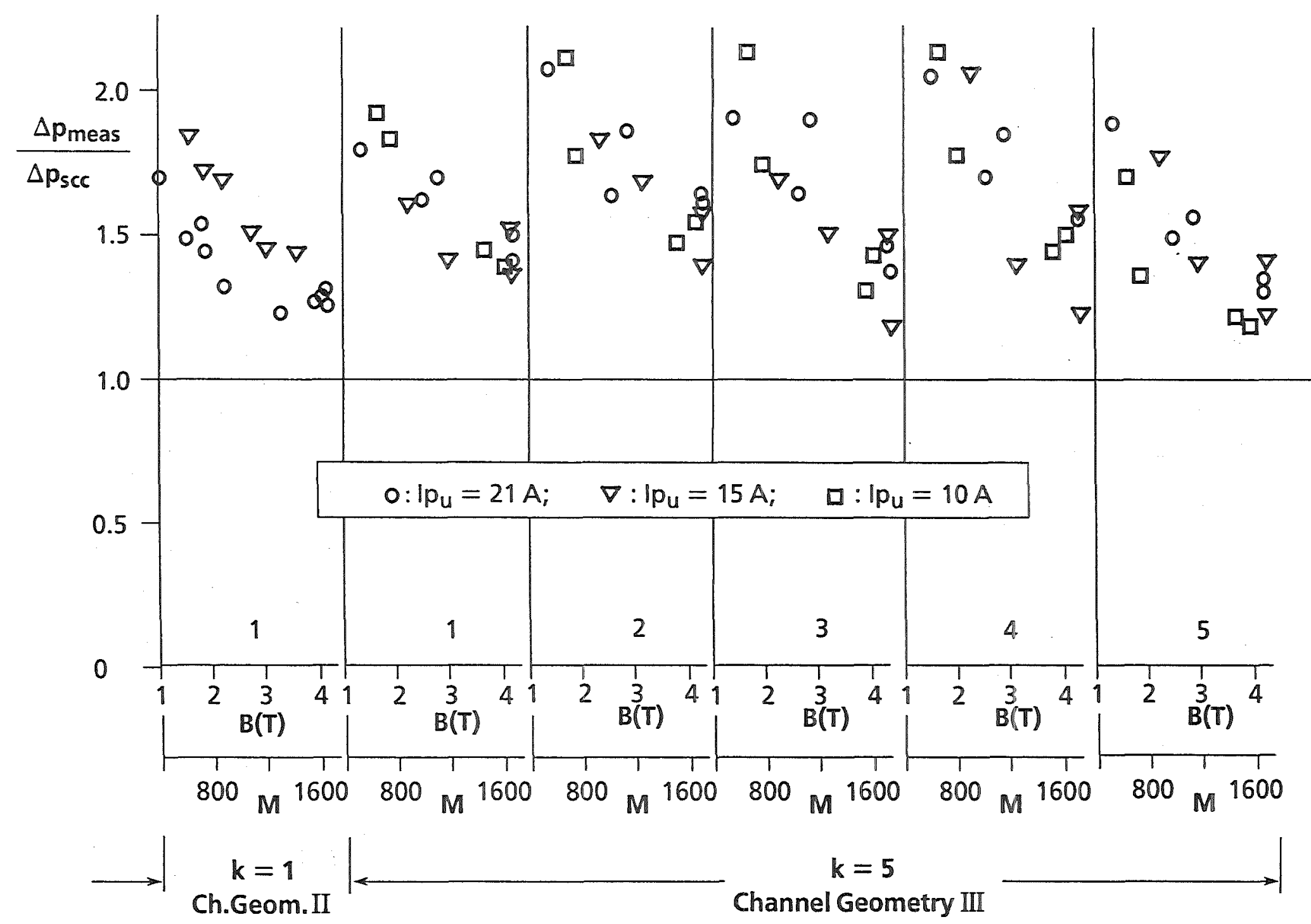

Figure 5.14 Pressure drop ratio as a function of Hartmann Number for a single channel U-bend with conducting outside walls (Geometry $\Pi$, $\mathrm{k}=1$ ) and the multichannel $\mathrm{U}$-bend with electrically decoupled radial channels (Geometry $\mathbb{I I I}$ ) 

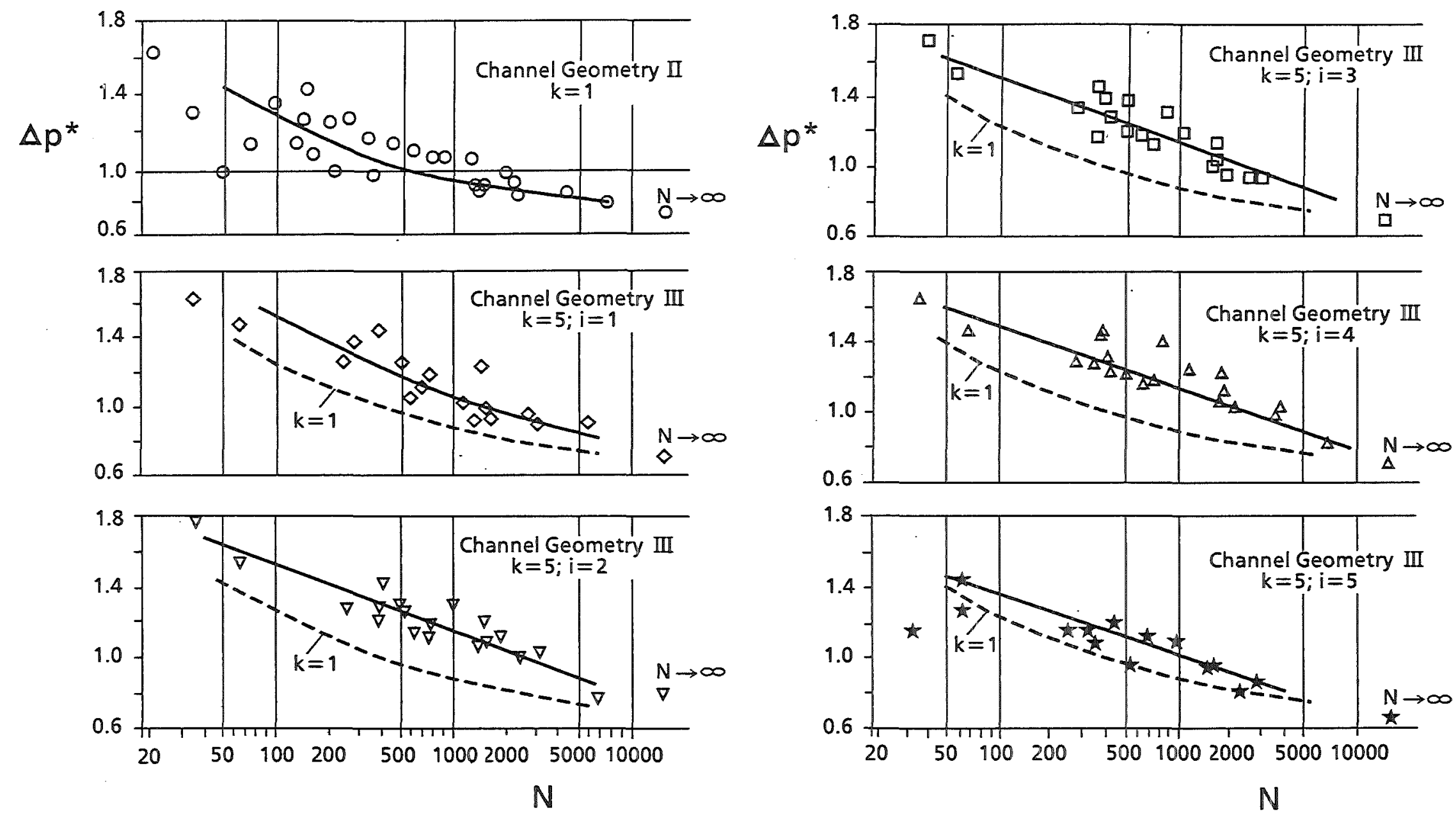

a)

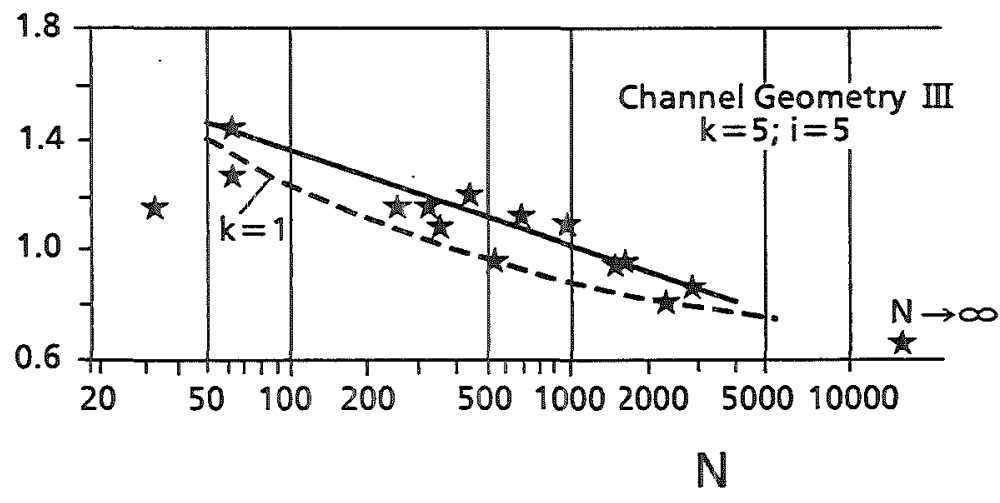

b)

Figure 5.15 Pressure drop ratio as a function of Interaction Parameter for a single channel U-bend with conducting outside walls (Geometry $I I, \mathrm{k}=1$ ) and the multichannel U-bend with electrically decoupled radial channels (Geometry III) 


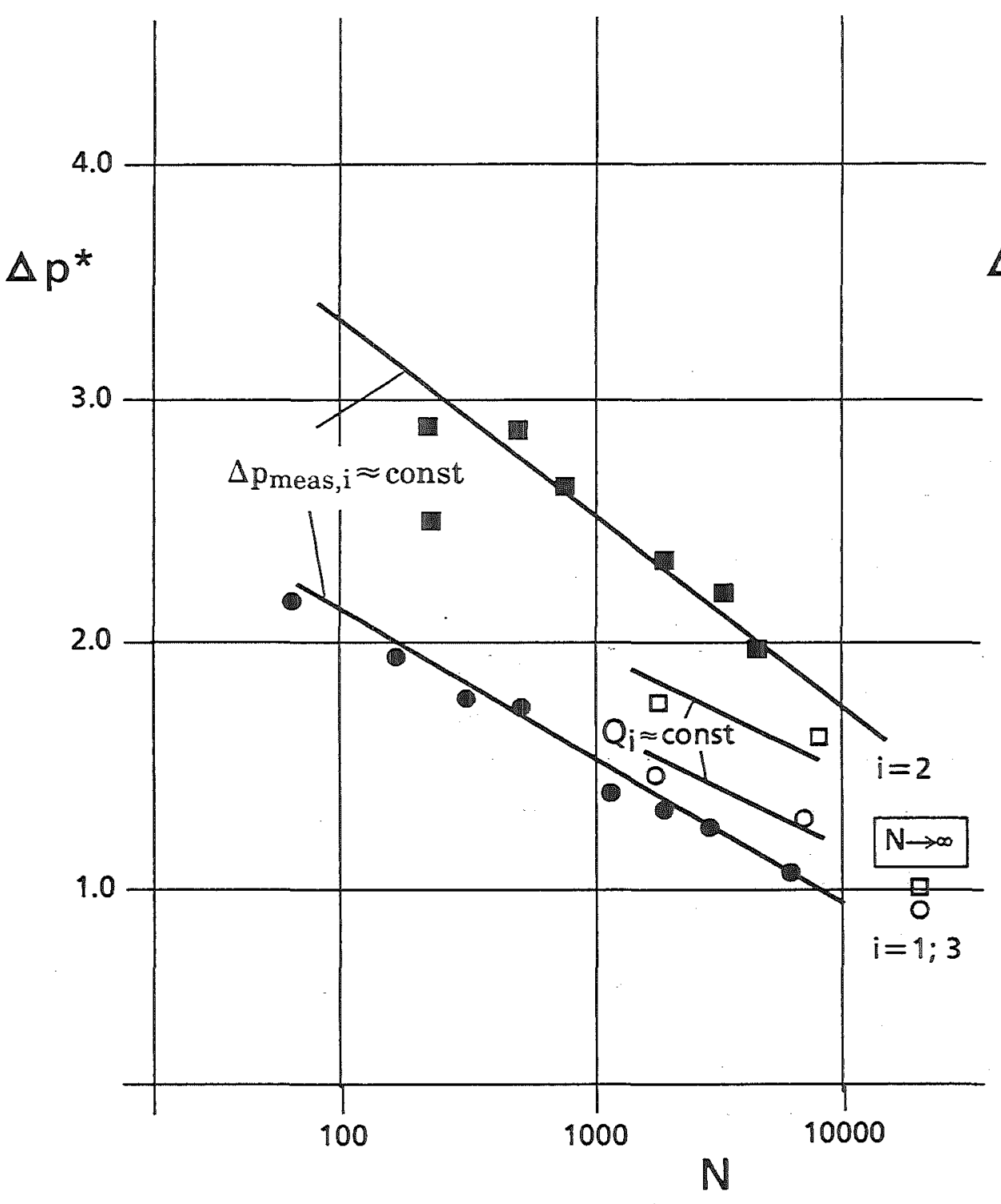

Channel Geometry II, $k=3$

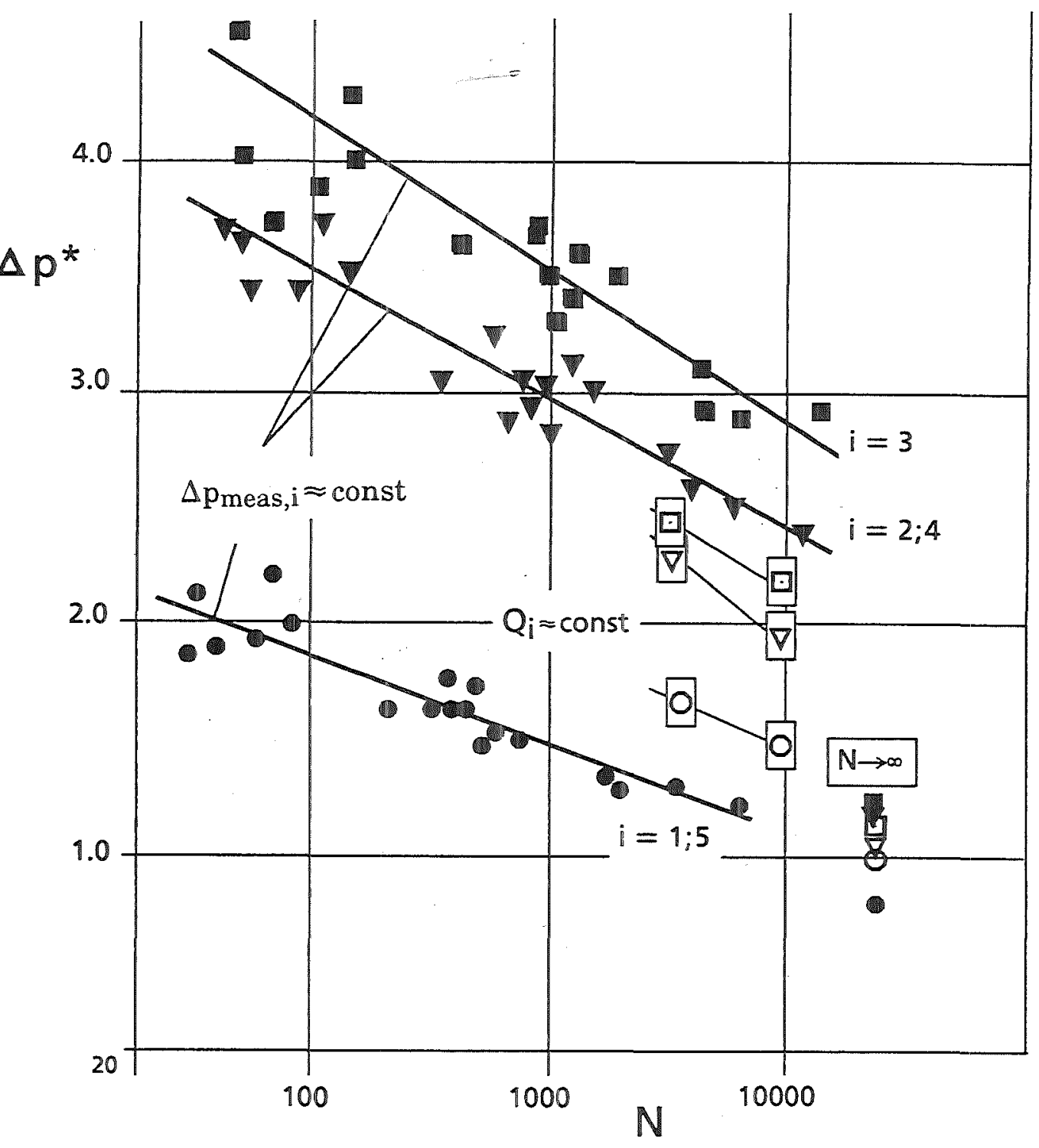

Channel Geometry II , $k=5$

Figure 5.16 Pressure drop ratio as a function of Interaction Parameter for the multichannel U-bend with conducting outside walls (Channel Geometry II) 
This strong dependence may be partly due to the experimental inlet conditions, see Fig. 3.2. A length of only 4 a existed between the small diameter inlet tube and the first pressure measurement tab which might be sufficient for a simple duct flow at high values of $\mathrm{M}$ and $\mathrm{N}$. However, the theoretical analysis (for $\mathrm{N} \rightarrow \infty$ ) proved that with increasing channel number the required lengths of the radial channels increase considerably in order to obtain developed flow at the inlet (for the 5 channel U-bend the developing length is about 16 a!). This means that $3 \mathrm{D}$ effects are of influence over a much longer length and with this the influence of inertia for finite values of $\mathrm{N}$ might be enhanced, too.

Because of the differences between measured and predicted pressure differences one can expect that the existing velocity distributions differ from those obtained by theoretical analyses, too.

An interesting result is that the MCE is more expressed for the experiments with $\Delta \mathrm{p}_{\mathrm{i}} \approx$ const than for those with $\mathrm{Q}_{\mathrm{i}}=$ const. This tendency is also predicted theoretically. Therefore, one might conclude that the theoretical results represent the extrapolation of the experimental results for $\mathrm{N} \rightarrow \infty$.

The Figs. 5.17 and 5.18 contain the results for the multichannel ducts with nonconductive outside walls. Again, a strong influence of $\mathrm{N}$ is found. Due to the fact that the asymptotic values for $\mathrm{N} \rightarrow \infty$ are expected to be lower than for Channel Geometry II, the dependency appears to be even stronger for ducts with nonconductive outside walls.

No significant difference is observed between the multichannel U-bend and multichannel single bend (Geometry I and IV).

Of special interest are the results for the blanket relevant geometry (Channel Geometry III). Figure 5.15 contains also these results. Similar to the volume flow rate distribution, the pressure drop dependence for the single channels does not differ significantly and is quite close to that one for the single channel U-bend. Summarizing these results it can be said that the electrical decoupling of the radial channels by the suggested flow channel inserts is a very effective measure to reduce significantly the MCE in respect to maldistribution of volume flow rates and increase in pressure drop. 


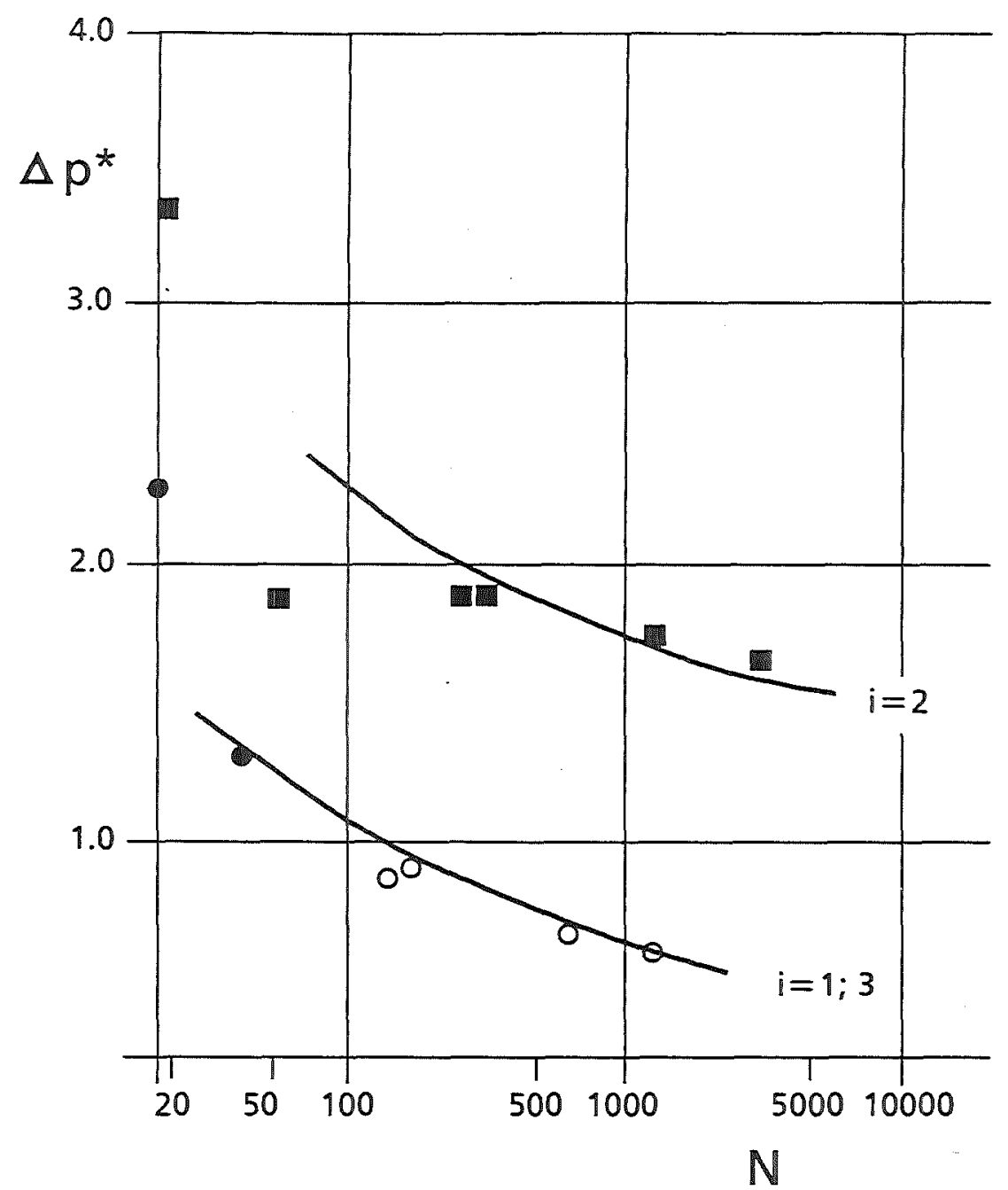

Channel Geometry I, $k=3$

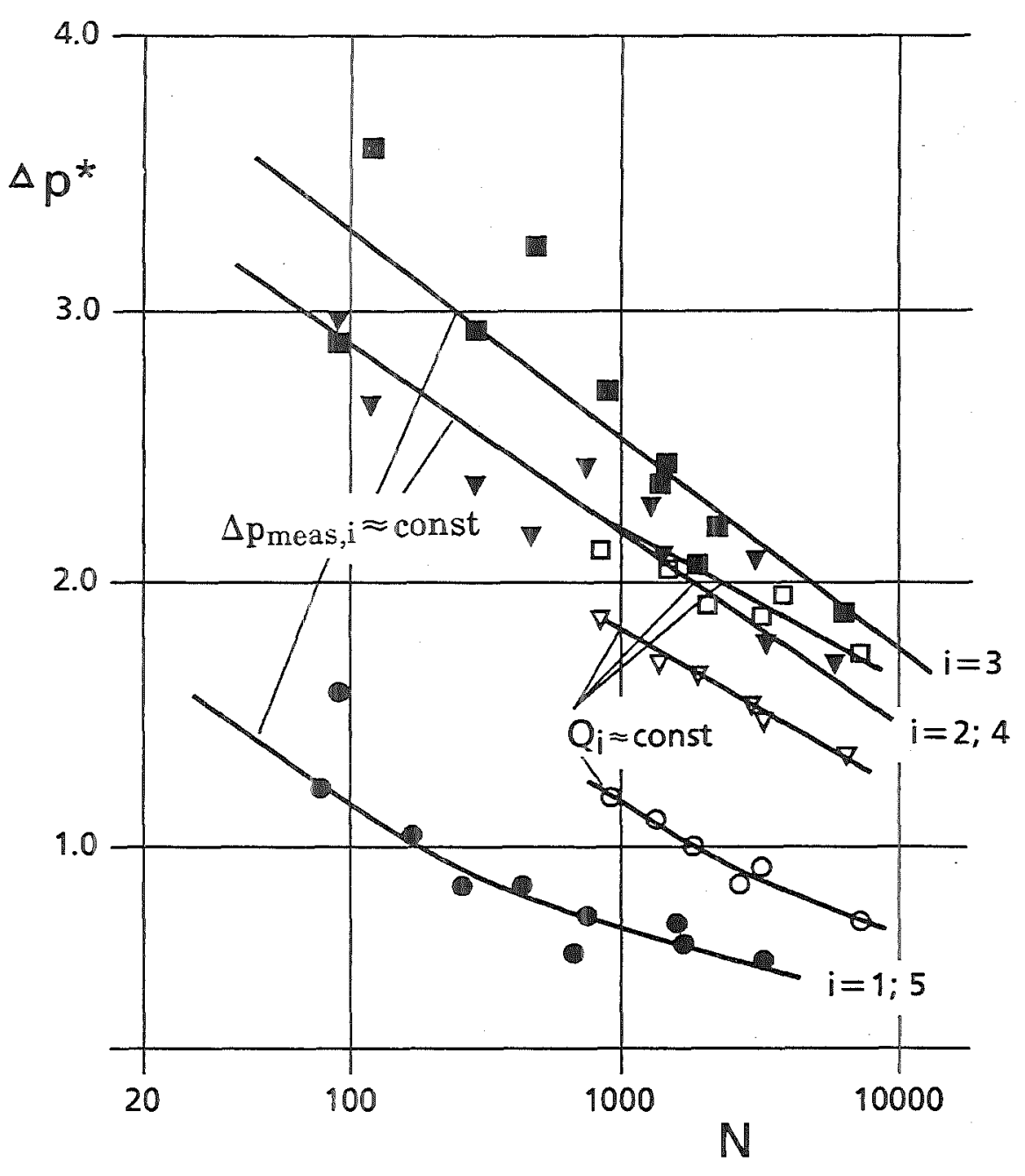

Channel Geometry I, $k=5$

Figure 5.17 Pressure drop as a function of Interaction Parameter for the multichannel U-bend with nonconducting outside walls (Channel Geometry I) 


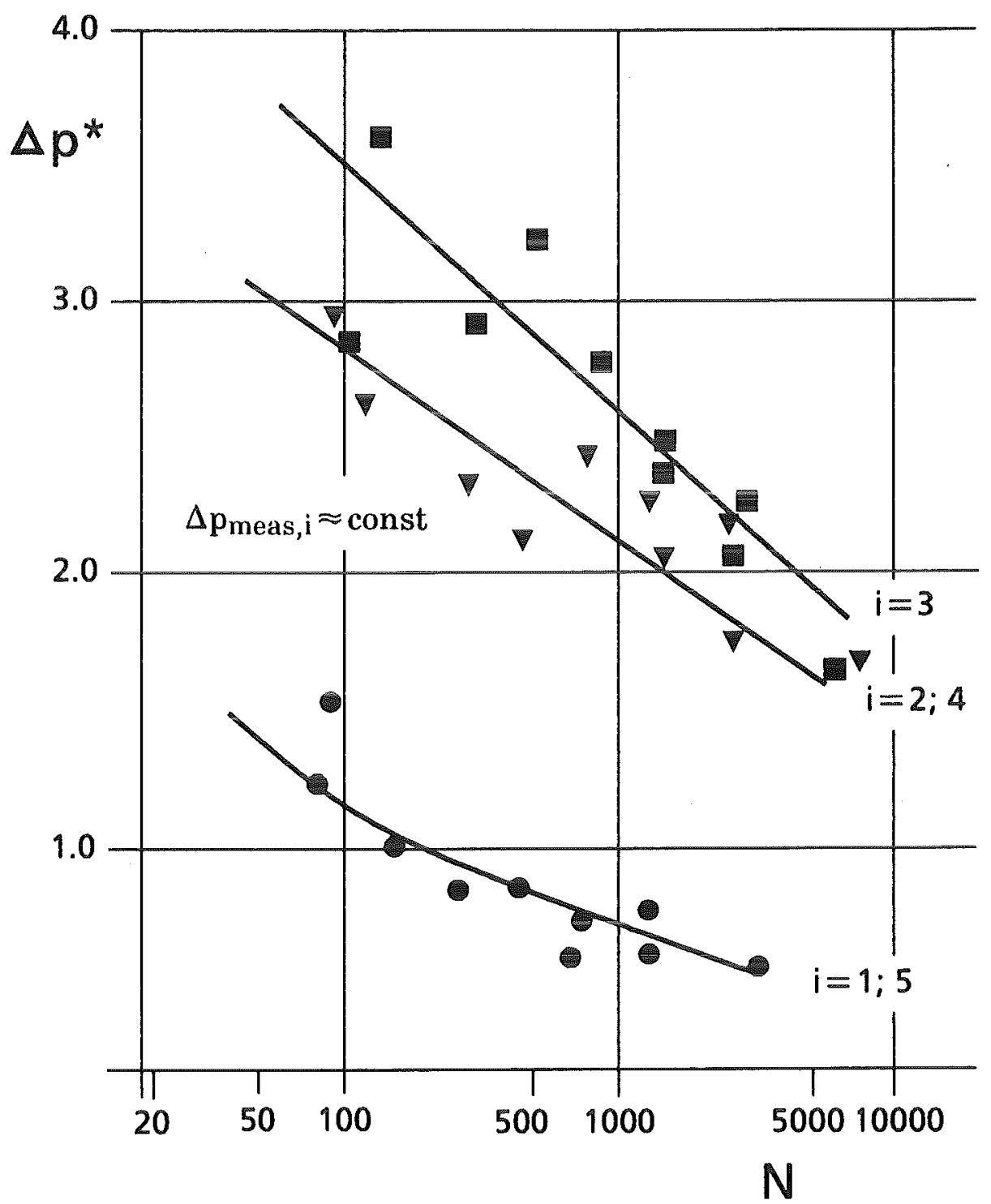

Channel Geometry IV, $k=5$

Figure 5.18 Pressure drop as a function of Interaction Parameter for the multichannel single bend (Channel Geometry IV) 


\subsubsection{Comparison of Different Channel Geometries at high $\mathrm{N}$ and $\mathbf{Q}_{\mathbf{i}} \approx$ const}

Figure 5.19 shows characteristic results for high Hartmann numbers and high Interaction Parameters for $\mathrm{Q}_{\mathrm{i}} \approx$ const.

The pressure drop for Geometry I is significantly smaller than for Geometry II due to the smaller portion of the pressure drop in the radial channel. The MCE, which is characterized by both the pressure increase compared with a single $U$-bend and the uneven distribution between the individual channels of the multichannel duct, however, is more expressed for this geometry than for the duct with conducting outside walls.

For multiple channels it is of interest to extract the "pure" MCE, that means the pressure drop distribution without the pressure drop term for the single radial channel. For conducting outside walls $\Delta \mathrm{p}_{\mathrm{MCE}}$ is obtained by subtracting, $\Delta \mathrm{p}_{\mathrm{c}}$ according to Eq. (5.2) from $\Delta p_{\text {meas }}$; for nonconducting walls, $\Delta p_{\text {meas }}$ represents already fairly well $\Delta$ pMCE.

Figure 5.20 contains the normalized term $\triangle \mathrm{pMCE}$ for Channel Geometry II. The comparison with Fig. 5.19a reveals that the values are quite close to those for Geometry I. 


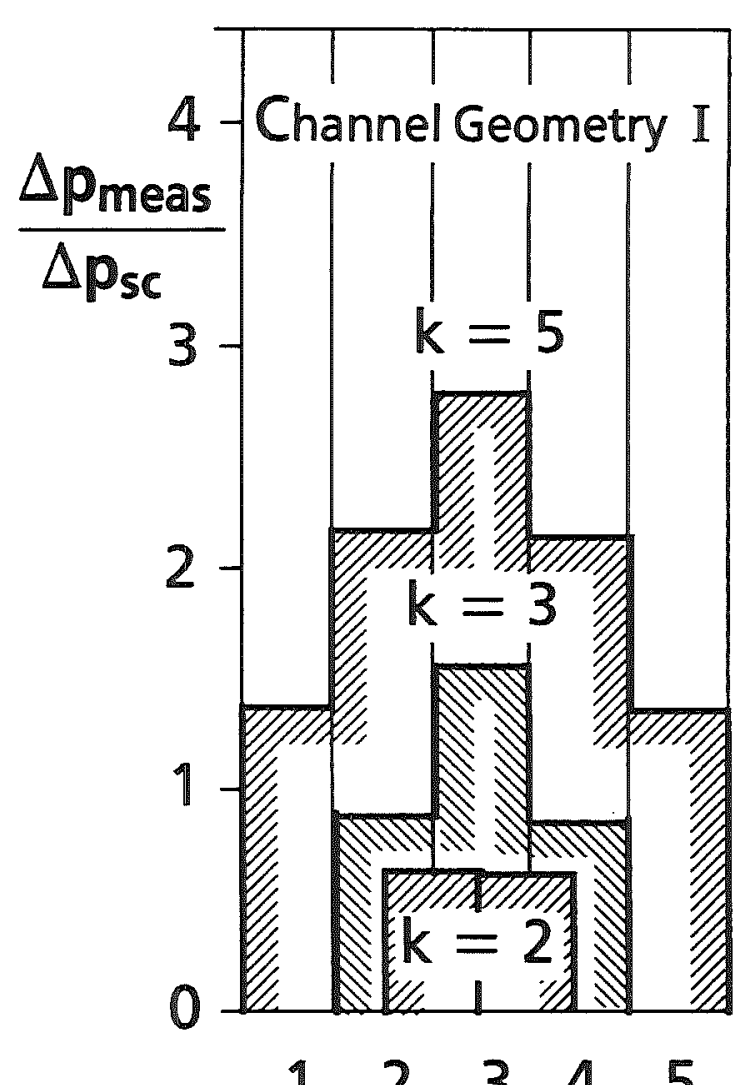

a) Channel Geometry I (noncond. outside walls cond. dividing walls)
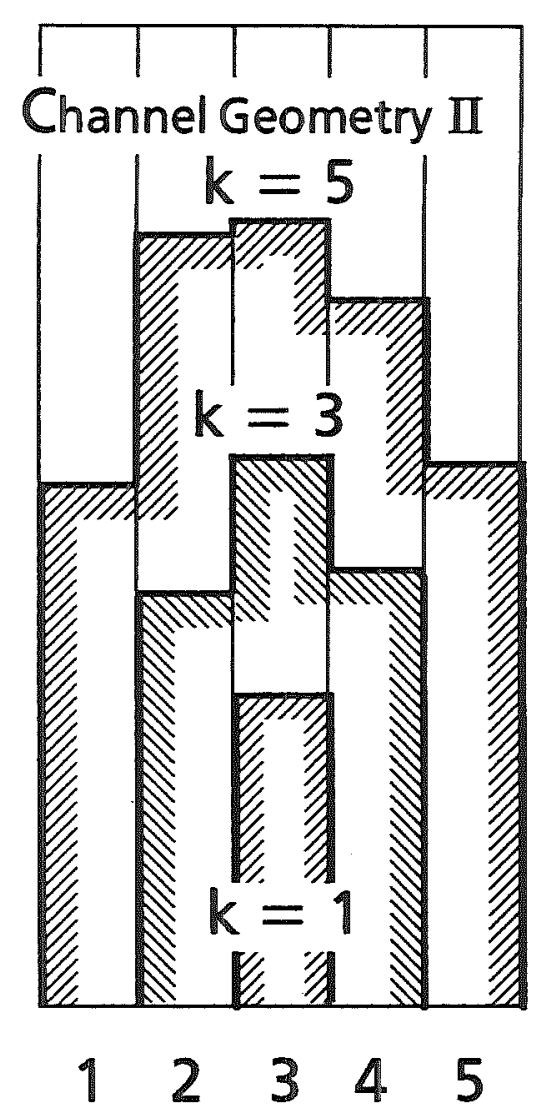
b) Channel Geometry II (cond. outside walls cond. dividing walls)

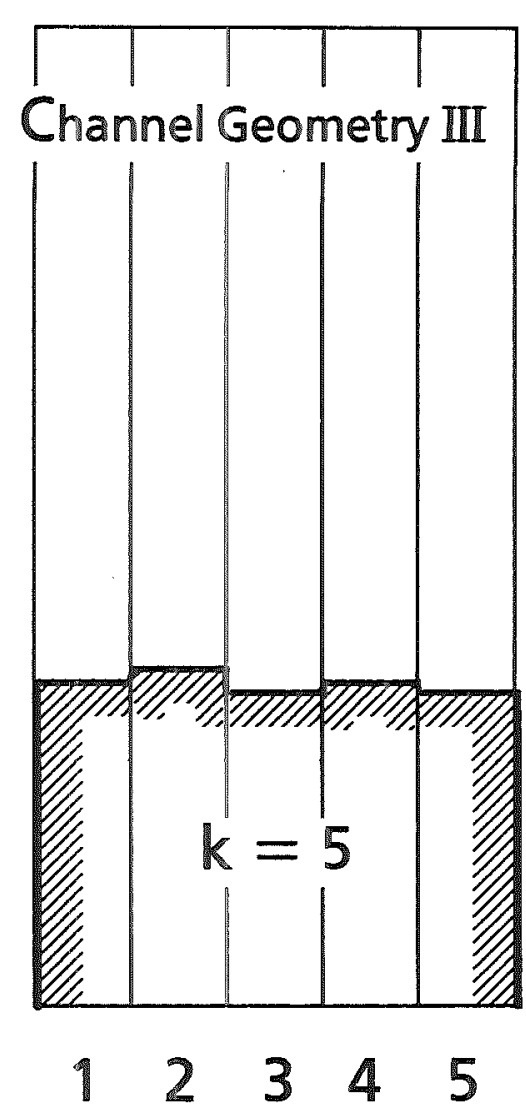

c) Channel Geometry III (cond. outside walls cond./ noncond. div. walls)

Figure 5.19

Pressure drop distributions for $\mathrm{Q}_{\mathrm{i}}=$ const and high Hartmann

Numbers and Interaction Parameters $(M \approx 1600,1760<\mathrm{N}<2800)$;

$\mathrm{Q}_{\mathrm{i}} \approx$ const 


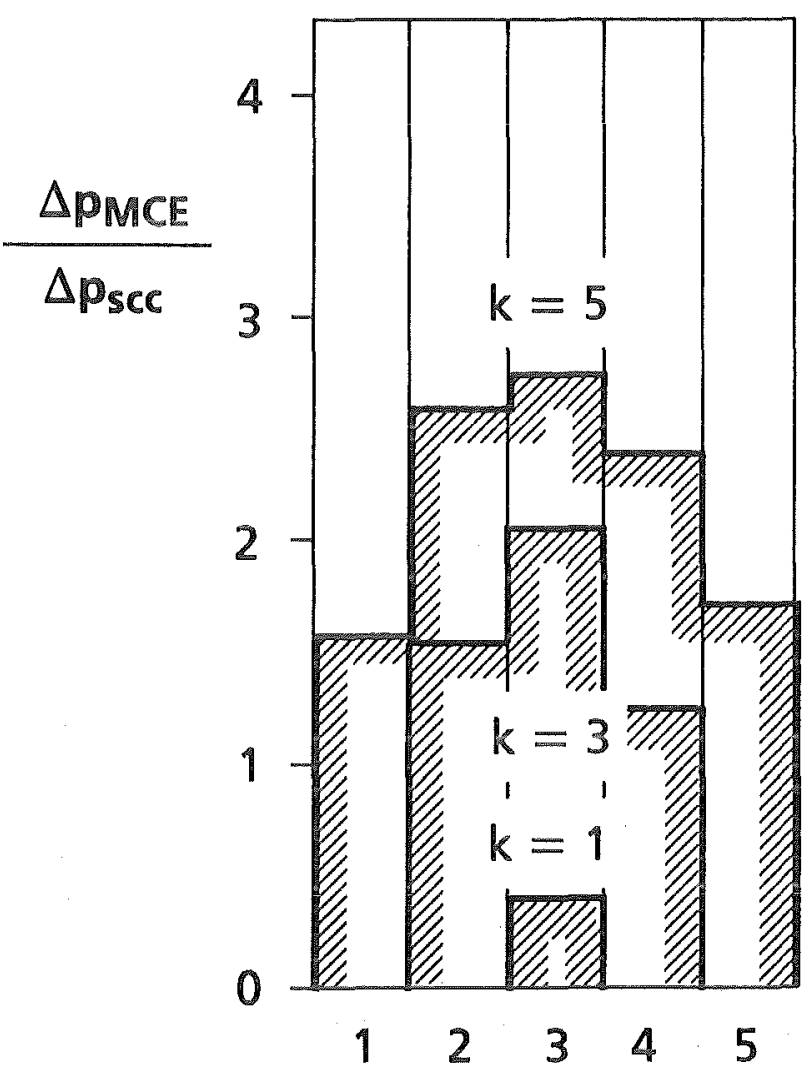

Figure 5.20 : Multichannel pressure drop for Channel Geometry $\amalg$ and $Q_{i}=$ const

\subsection{Effect of Inclination}

\subsubsection{Single channel U-bend}

The experiments discussed in the previous sections were performed with the magnetic field parallel to the axis of the toroidal channels. In a fusion reactor a small inclination of the B field will exist which results in a magnetic field strength component perpendicular to the flow in the toroidal ducts of about $10 \%$ of the total magnetic field strength. This inclination corresponds to a rotation of the test section in the magnet as shown in Fig. 3.1.

To investigate the effect of inclination some experiments were performed with an inclination angle $\beta=12^{\circ}$ which results in a magnetic field component perpendicular to the toroidal channels of about $21 \%$. The length of the toroidal channels within the pressure tabs is about 2.2 times larger than the corresponding length of the radial channels. For channels with conducting outside walls, the pressure drop is proportional to $\mathrm{B}^{2}$. Then a pressure drop in the toroidal channels of about $10 \%$ of that of the radial channel for $\beta=0^{\circ}$ is expected. This additional pressure drop is not very large especially for multiple channel ducts where $\triangle \mathrm{pMCE}$ is very signifi- 
cant. For nonconducting outside walls, the effect of inclination on pressure drop in the toroidal channels is expected to be negligible.

In the radial channels the magnetic field is no longer aligned with the side walls for $\beta \neq 0$. This changes the velocity distribution in the channel cross-section, as predicted with the Core Flow Solution for a single channel with conducting outside walls in Fig. 5.21 (Bühler/12/). The influence of the inclination angle on pressure drop for this geometry is shown in Fig. 5.22 (from Bühler $/ 13 /$ ). For $\beta=12^{\circ}$, an increase of the pressure drop of about $6 \%$ is predicted. Therefore, the total pressure drop for a single channel with Geometry II should be about $16 \%$ higher for $\beta=12^{\circ}$ compared to $\beta=0$ assuming that the bend pressure drop $\Delta \mathrm{p}_{\mathrm{b}}$ is not significantly influenced by the inclination.

There is only one experiment for $\beta=12^{\circ}$ with Channel Geometry II and $k=1$. About the same pressure drop was measured for $\beta=12^{\circ}$ and $\beta=0^{\circ}$ as shown in Fig. 5.24. More results exist for Channel Geometry III, where the 5 channels can be considered as electrically separated channels, as discussed previously. Figure 5.23 a contains results where the test section inclination was $\beta=0,+12$ and $-12^{\circ}$. The flow rate is in a first approximation not affected by the inclination. (The deviations from $\beta=0^{\circ}$ are believed to be caused by flow fluctuation, which preferentielly occured at high values of the Interaction Parameter and Hartmann Number.) The pressure measurements show a characteristic increase for $\beta=+12^{\circ}$ and $\beta=-12^{\circ}$ which agrees fairly well with the predicted values.

Figure 5.23b shows results for a lower value of the Interaction Parameter. Again the volume flow rate distribution is not changed by the inclination whereas the pressure drop increases slightly.

\subsubsection{Multichannel U-bend}

The assessment of the influence of inclination for the other flow geometries is much more difficult. For radial channels with nonconducting outside walls an increase of the pressure drop by $10 \%$ was predicted by Molokov $/ 14 /$ for $\beta=12^{\circ}$ compared to $\beta=0^{\circ}$. This value is so small that this effect may not observed in the measurements because the multichannel bend pressure drop is the dominating term. 'The same holds for the pressure drop in the toroidal channels. 

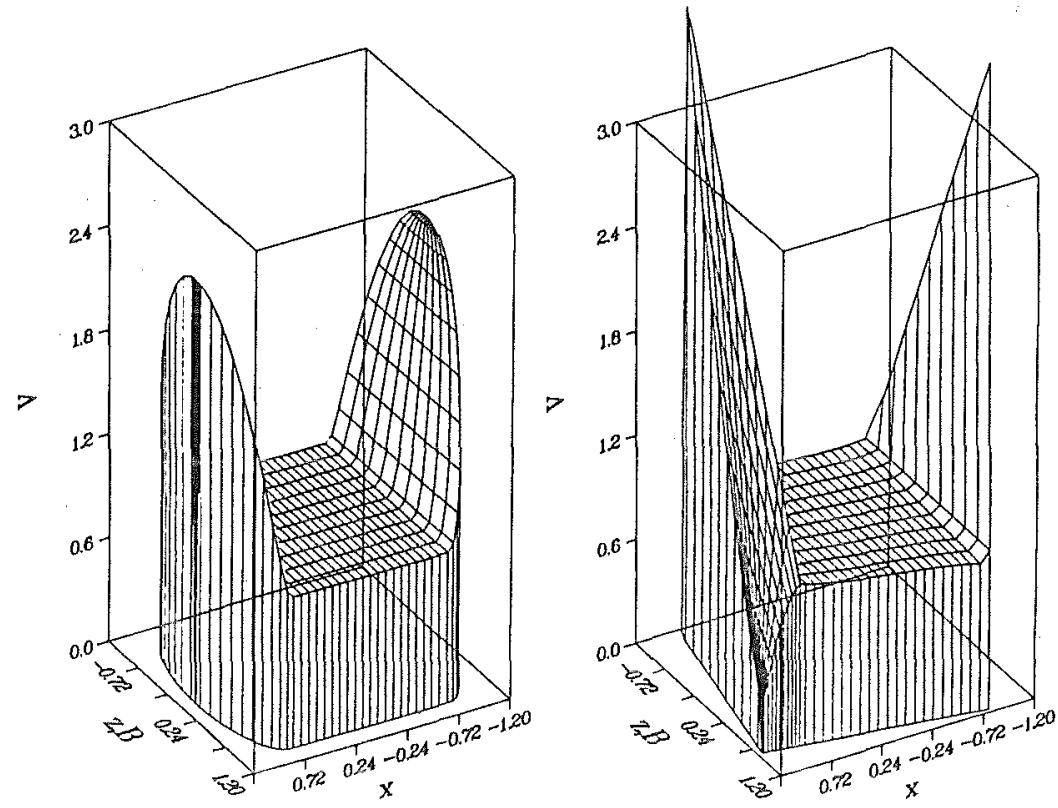

Fig. 5.21 Prediction of the effect of inclination of magnetic field on velocity distribution in a radial single channel (from Bühler /12/)

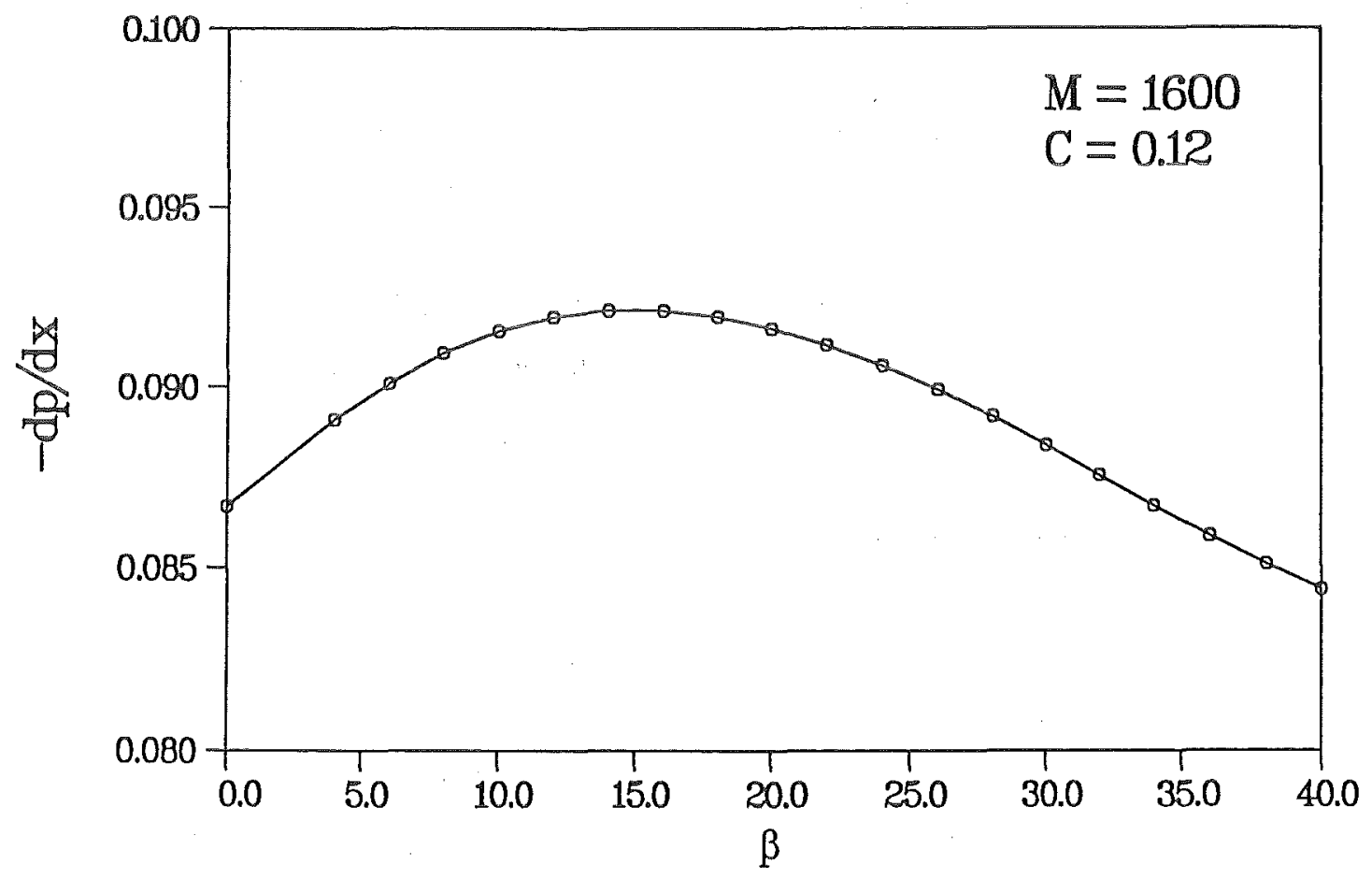

Fig. 5.22 Prediction of the effect of inclination of magnetic field on dimensionless pressure drop in a radial single channel (from Bühler /13/) 

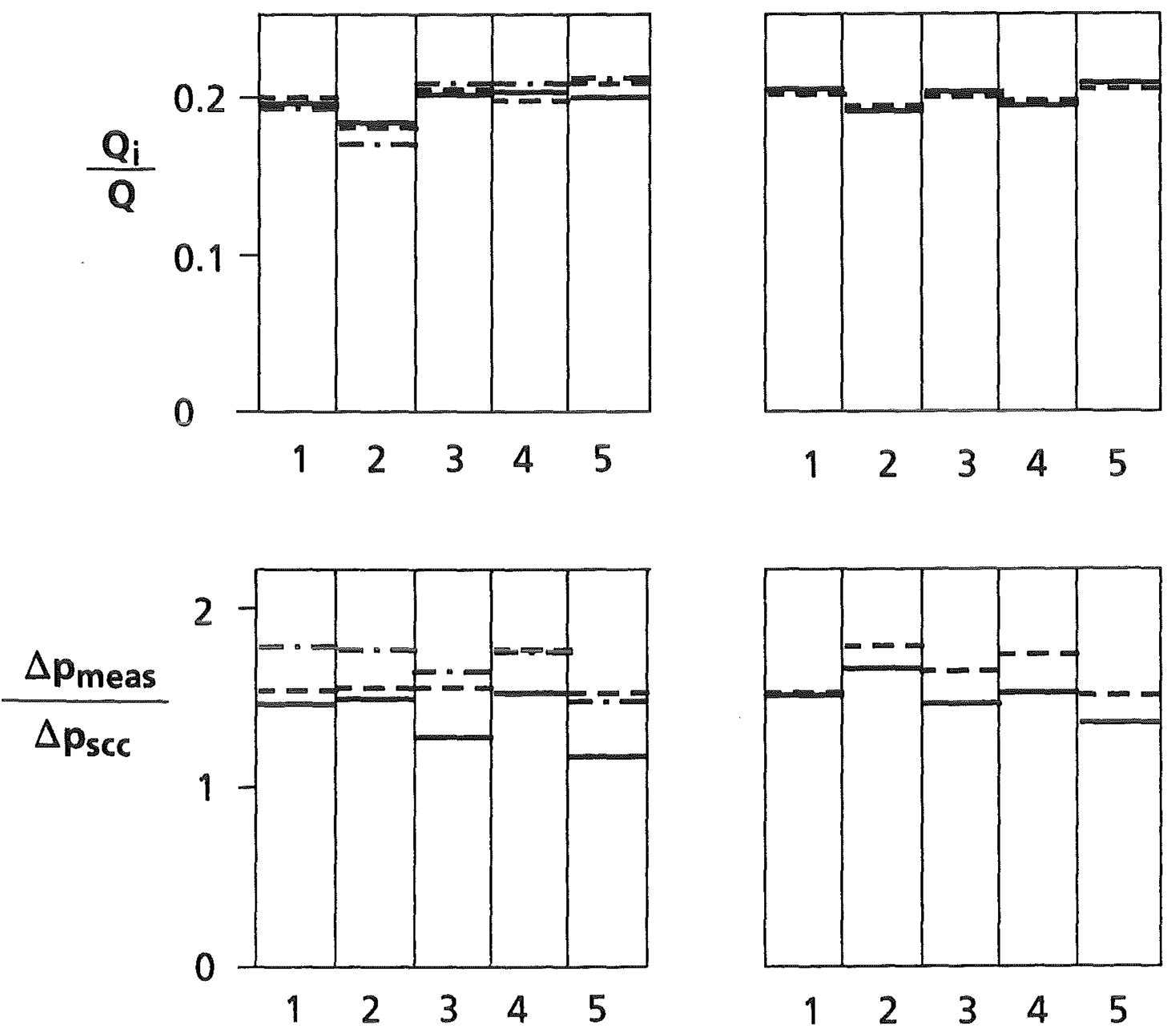
a) $M=1600, N=6340$
b) $M=1600, N=1860$

$$
\begin{aligned}
-\beta & =0^{\circ} \\
--\beta & =+12^{\circ} \\
--\beta & =-12^{\circ}
\end{aligned}
$$

Figure 5.23 Influence of the magnetic field inclination for electrically separated channels (Channel Geometry III) 
Figure 5.24 contains the experimental results. Again it shows that the volume flow rate distribution does not change significantly. The pressure drop distributions for nonconducting outside walls (Channel Geometries I and IV) are also very similar for $\beta=0$ and $12^{\circ}$. The surprising result is that the values are rather lower for $\beta=12^{\circ}$ than higher as perhaps assumed.

For conducting outside walls (Geometry II) there is a characteristic tendency that the pressure drop is higher in the channels 4 and 5. (A similar tendency can be also observed in Fig. 5.23). It would have been advantageous to perform some experiments with $\beta=-12^{\circ}$ to see if the tendency reverses. The reason for this asymmetric distribution is not clear yet.

To summarize the results it can be said that a slight inclination of the magnetic field does not change remarkably both the volume flow rates and pressure drops in the single channels. However, the inclination might change significantly the velocity distribution especially in the toroidal channels where the heat has to be removed.

More theoretical and experimental work is required to evaluate the influence of the magnetic field inclination on pressure drop and velocity distributions in multichannel bends. 

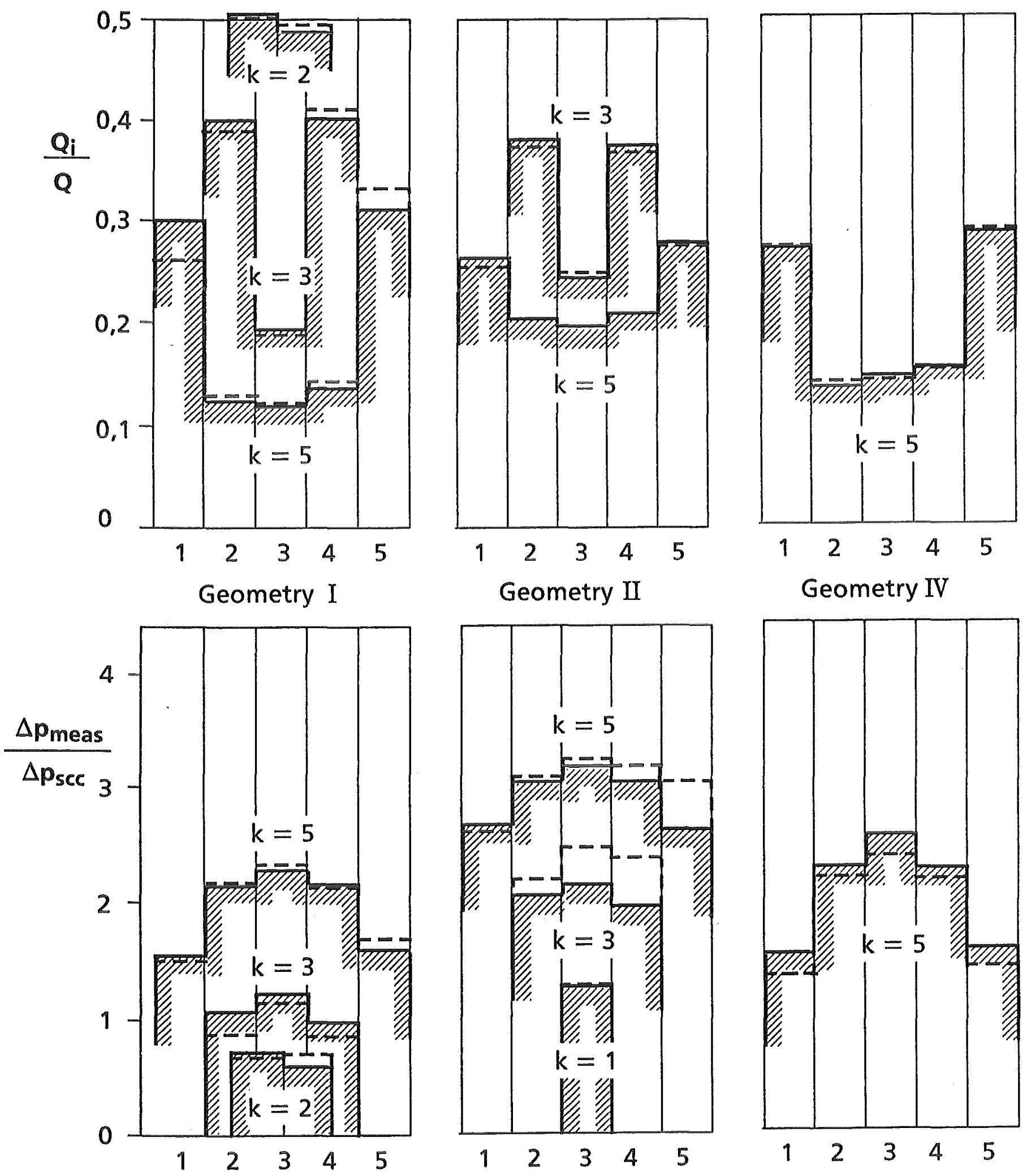

$-\beta=0^{\circ} \quad--\beta=12^{\circ}$

Figure 5.24 Experimental results on the influence of the magnetic field inclination for multichannel ducts $\left(\Delta \mathrm{p}_{\mathrm{i}} \approx\right.$ const) 


\section{CONCLUUSIONS}

The aim of the screening tests was to obtain basic information on the influence of the main parameters on the non-uniform distribution of individual flow rates and pressure drops. These multichannel effects are dependent on the duct dimensions, the wall conductance ratio, the number of channels and the MHD flow parameters: the Hartmann Number and the Interaction parameter.

For electrically coupled channels the number of parallel channels is an important parameter. The multichannel effects are also significantly dependent on the Interaction Parameter, whereas no marked influence of the Hartmann Number was observed.

A theoretical analysis for electrically coupled channels with conducting outside walls was performed, based on the Core Flow Approximation. The prediction of the ratios of the pressure drops in the individual channels agrees with the experimental results. The predicted pressure drops are lower since this analysis are based on inviscid and inertialess assumptions which are not fulfilled in the experimentally investigated parameter range.

For the multichannel duct with electrically decoupled radial channels, relevant for the KfK self-cooled $\mathrm{Pb}$-17Li blanket, no marked multichannel effects were observed in the whole parameter range. Here, the pressure drops of the individual channels are approximately equal to that one of a single channel. Although this pressure drop also increases with decreasing Interaction Parameter, this increase is much smaller than for electrically coupled channels. Therefore, these results are very favourable compared with previous assessments (based on a non-MHD specific model). 


\section{ACKNOWLEDGEMENT}

This work has been performed in the framework of the nuclear Fusion Project of the Kernforschungszentrum Karlsruhe and is supported by the European Communities within the European Fusion Technology Program.

\section{REFERENCES}

1/ S. Malang, H. Deckers, U. Fischer, H. John, R. Meyder, P. Norajitra, J. Reimann, H. Reiser and K. Rust, "Self-cooled blanket concepts using Pb-17Li as liquid breeder and coolant", Fusion Eng. \& Design 14 (1991), p. 373-399

12/ S. Malang, J. Reimann, and H. Sebening, (Eds.) with contributions from: L. Barleon, E. Bogusch, E. Bojarsky, H.U. Borgstedt, L. Bühler, V. Casal, H. Deckers, H. Feuerstein, U. Fischer, G. Frees, H. Graebner, H. John, Th. Jordan, W. Kramer, R. Krieg, L. Lenhart, S. Malang, R. Meyder, P. Norajitra, J. Reimann, A. Schwenk-Ferrero, H. Schnauder, R. Stieglitz, J. Oschinski, E. Wiegner: "Status report KfK contribution to the development of DEMOrelevant test blankets for NET/ITER. Part 1: Self-cooled liquid metal breeder blanket. Vol. 1: Summary." KfK-4907 (Dezember 91).

/3/ H. John, S. Malang, H. Sebening (Eds.); L. Barleon, E. Bogusch, E. Bojarsky, H.U. Borgstedt, L. Bühler, V. Casal, H. Deckers, H. Feuerstein, U. Fischer, G. Frees, H. Graebner, H. John, Th. Jordan, W. Kramer, R. Krieg, L. Lenhart, S. Malang, R. Meyder, P. Norajitra, H. Reiser, J. Reimann, A. Schwenk-Ferrero, H. Schnauder, R. Stieglitz, J. Oschinski, E. Wiegner: Status report $\mathrm{KfK}$ contribution to the development of DEMO-relevant test blankets for NET/ITER. Part 1: Self cooled liquid metal breeder blanket. Vol. 2: Detailed version". KfK-4908 (Dezember 91).

14/ H. Madarame, "MHD Fluid Fluid and Pressure Drop", FINESSE Interim Report, Vol. III, ed. by M. Abdou, pp. pp G-821 UCLA-ENG-84-30 (Oct. (1984), pp. 6.9. - 6.109

/5/ S. Molokov, "Fully developed liquid-metal flow in multiple rectangular ducts in a strong uniform magnetif field", KfK 5075 (Januar 1993) 
16/ T.Q. Hua and B.F. Picologlou, "Magnetohydrodynamic flow in a manifold and multiple rectangular coolant ducts of self-cooled blankets", Fusion Technologie, Vol. 19, pp. 102-112 (1991)

/7/ S. Molokov and L. Bühler, "Numerical simulation of liquid-metal flows in radial-toroidal-radial ducts", KfK 5103 (1992)

18/ J.S. Walker, "Magnetohydrodynamic Flows in Rectangular Ducts with Thin Conducting Walls", J. de Méchanique, Vol. 20, No. 1, 1981, pp. 79-112

19/ K. Miyazaki, S. Inone and N. Yamoaka, "MHD pressure drop of liquid metal flow in circular and rectangular ducts under transverse magnetic field", Liquid Metal Magnetohydrodynamics ed. by L. Lielpetris and R. Moreau, Kluwer Academic Publishers, Dordrecht/Boston/London (1989) pp. 29-36.

110/ Lavrentiev, I.V., Molokov, S.Yu., Sidorenkov, S.I., Shishico, A.Ya., 1990, "Stoke flow in a rectangular magnetohydrodynamic channel with nonconducting walls within a nonuniform magnetic field at large Hartmann numbers", Magnetohydrodynamics, vol. 26, no. 3, pp. 328-338.

11/ O. Lielausis, personal communication (1992)

112/ L. Bühler, "Liquid metal flow in arbitrary thin-walled channels under a strong transverse variable magnetic field", Sec. Int. Symp. on Fusion Nuclear Techn., ed. by D. Vollath, North Holland, Amsterdam-London-New York-Tokio (1991), Part B, pp. 215-220

/13/ L. Bühler, personal communication (1992)

14/ S. Molokov, "Magnetohydrodynamic flow in a rectangular channel in a strong suewed magnetic field", In: Proc. 13th Riga Conference on Magnetohydrodynamics, Riga 1990, Pt. 1, pp. 23-24 (In Russia). 


\section{APPENDIX}

Table A1: Test Section Configuration I

(Channel.Geometry $1 ; k=1$, Channel Geometry $11 ; k=1$ and 3 )

Date: 5.11 .91

\begin{tabular}{|c|c|c|c|c|c|}
\hline $\begin{array}{c}\text { Test Point } \\
\text { Nr. }\end{array}$ & $\underset{\text { Current }}{\text { Pump }}$ & $\begin{array}{l}\text { Magn. } \\
\text { Field } \\
\text { B(T) }\end{array}$ & $\begin{array}{c}\text { Flow } \\
\text { Direction }\end{array}$ & $\begin{array}{l}\text { Incl. } \\
\text { Angle } \\
\beta\left(^{\circ}\right)\end{array}$ & $\begin{array}{c}\text { Position } \\
\text { of } \\
\text { Throttles }\end{array}$ \\
\hline $\begin{array}{l}1-3 \\
4-8\end{array}$ & $\begin{array}{c}10 \\
0\end{array}$ & \multirow{2}{*}{$\begin{array}{c}0 \\
\text { (outside } \\
\text { magnet) }\end{array}$} & $w$ & \multirow[t]{5}{*}{0} & \multirow[t]{2}{*}{ open } \\
\hline $\begin{array}{c}9-11 \\
12-17\end{array}$ & $\begin{array}{l}20 \\
20\end{array}$ & & \multirow[t]{8}{*}{$\mathrm{e}$} & & \\
\hline $\begin{array}{l}18-48 \\
49-57 \\
53-57 \\
58-60\end{array}$ & $\begin{array}{c}20 \\
13 \\
8 \\
20\end{array}$ & $\underset{\mathrm{B}}{\text { increasing }}$ & & & $\begin{array}{l}Q_{i} \approx \text { const } \\
\text { for } B=0\end{array}$ \\
\hline \multicolumn{3}{|l|}{ new file } & & & \\
\hline $\begin{array}{c}1 \\
2-5 \\
6-11 \\
12 \\
13-16\end{array}$ & $\begin{array}{l}11 \\
21 \\
11 \\
28 \\
22\end{array}$ & \multirow[t]{4}{*}{$\approx 4$} & & & \multirow[t]{2}{*}{ open } \\
\hline $17-18$ & 22 & & & 12 & \\
\hline $\begin{array}{l}19-22 \\
24-29\end{array}$ & $\begin{array}{l}22 \\
11\end{array}$ & & & \multirow[t]{3}{*}{0} & $\mathrm{Q}_{\mathrm{i}} \approx$ const \\
\hline $30-32$ & 11 & & & & \multirow[t]{2}{*}{ open } \\
\hline $33-77$ & 16 & $\begin{array}{c}\text { decreasing } \\
\mathrm{B}\end{array}$ & & & \\
\hline
\end{tabular}


Table A2: Test Section Configuration II (Channel Geometry II ; $k=5$ )

Date: 5.11 .91

\begin{tabular}{|c|c|c|c|c|c|}
\hline $\begin{array}{l}\text { Test Point } \\
\text { Nr. }\end{array}$ & $\underset{\substack{\text { Purrent } \\
\text { Ip(A) }}}{\text { Purrenp }}$ & $\begin{array}{l}\text { Magn. } \\
\text { Field } \\
B(T)\end{array}$ & $\begin{array}{c}\text { Flow } \\
\text { Direction }\end{array}$ & $\begin{array}{l}\text { Incl. } \\
\text { Angle } \\
\beta\left(^{\circ}\right)\end{array}$ & $\begin{array}{c}\text { Position } \\
\text { of } \\
\text { Throttles }\end{array}$ \\
\hline $1-4$ & 20 & 0 & \multirow[t]{7}{*}{$\mathrm{e}$} & \multirow[t]{3}{*}{0} & \multirow[t]{4}{*}{ open } \\
\hline $\begin{array}{c}5-14 \\
15-18 \\
20-23 \\
24-27 \\
28-32 \\
33-36 \\
37-45 \\
46-51\end{array}$ & $\begin{array}{c}20 \\
10 \\
16 \\
20 \\
16 \\
21 \\
9 \\
16\end{array}$ & $\begin{array}{c}\text { increasing } \\
\mathrm{B}\end{array}$ & & & \\
\hline $\begin{array}{l}52-56 \\
57-60\end{array}$ & $\begin{array}{l}16 \\
21\end{array}$ & \multirow{6}{*}{$\approx 4$} & & & \\
\hline $61-64$ & 21 & & & 12 & \\
\hline $65-68$ & 21 & & & \multirow[t]{6}{*}{0} & $\mathrm{Q}_{\mathrm{i}} \approx$ const \\
\hline $69-71$ & 21 & & & & $\mathrm{E}_{\mathrm{i}} \approx$ const* \\
\hline $72-80$ & 11 & & & & $\mathrm{Q}_{\mathrm{i}} \approx \mathrm{const}$ \\
\hline $\begin{array}{l}81-86 \\
87-91\end{array}$ & $\begin{array}{l}21 \\
10\end{array}$ & & \multirow[t]{3}{*}{$\mathrm{w}$} & & \multirow[t]{3}{*}{ open } \\
\hline $\begin{array}{c}92-98 \\
99-103 \\
104-108 \\
109-112 \\
113-121 \\
122-126\end{array}$ & $\begin{array}{l}10 \\
22 \\
15 \\
10 \\
8 \\
21\end{array}$ & $\begin{array}{c}\text { decreasing } \\
\text { B }\end{array}$ & & & \\
\hline $127-131$ & 21 & 0 & & & \\
\hline
\end{tabular}

* $E_{\mathrm{i}}$ : measured voltages from electrodes in radial channels 
Table A3: Test Section Configuration III (Channel Geometry III ; $k=5$ )

Date: $5 .-6.11 .91$

\begin{tabular}{|c|c|c|c|c|c|}
\hline $\begin{array}{c}\text { Test Point } \\
\text { Nr. }\end{array}$ & $\begin{array}{c}\text { Pump } \\
\text { Current } \\
\text { Ip(A) }\end{array}$ & $\begin{array}{l}\text { Magn. } \\
\text { Field } \\
B(T)\end{array}$ & $\begin{array}{c}\text { Flow } \\
\text { Direction }\end{array}$ & $\begin{array}{c}\text { Incl. } \\
\text { Angle } \\
\beta\left(\left(^{\circ}\right)\right.\end{array}$ & $\begin{array}{c}\text { Position } \\
\text { of } \\
\text { Throttles }\end{array}$ \\
\hline $1-4$ & 20 & 0.6 & e & \multirow[t]{3}{*}{0} & \multirow[t]{8}{*}{ open } \\
\hline $\begin{array}{c}5-11 \\
12-18 \\
19-23 \\
24-28 \\
29-33 \\
34-39 \\
40-44 \\
45-49\end{array}$ & $\begin{array}{c}20 \\
10 \\
16 \\
20 \\
16 \\
21 \\
9 \\
16\end{array}$ & $\begin{array}{c}\text { increasing } \\
B\end{array}$ & w & & \\
\hline $\begin{array}{l}50-54 \\
55-59\end{array}$ & $\begin{array}{l}16 \\
21\end{array}$ & \multirow{4}{*}{4} & & & \\
\hline $\begin{array}{l}60-63 \\
64-67\end{array}$ & $\begin{array}{l}20 \\
11\end{array}$ & & & +12 & \\
\hline $68-71$ & 11 & & & -12 & \\
\hline $72-76$ & 23 & & \multirow[t]{3}{*}{ e } & \multirow[t]{3}{*}{0} & \\
\hline $\begin{array}{c}77-83 \\
84-88 \\
89-93 \\
99-120\end{array}$ & $\begin{array}{c}13 \\
8 \\
23 \\
5\end{array}$ & $\begin{array}{c}\text { decreasing } \\
\text { B }\end{array}$ & & & \\
\hline $121-125$ & 23 & 0 & & & \\
\hline
\end{tabular}


Table A5: Test Section Configuration V

(Channel Geometry $1 ; k=2$ and 3 )

Date: 9.11 .91

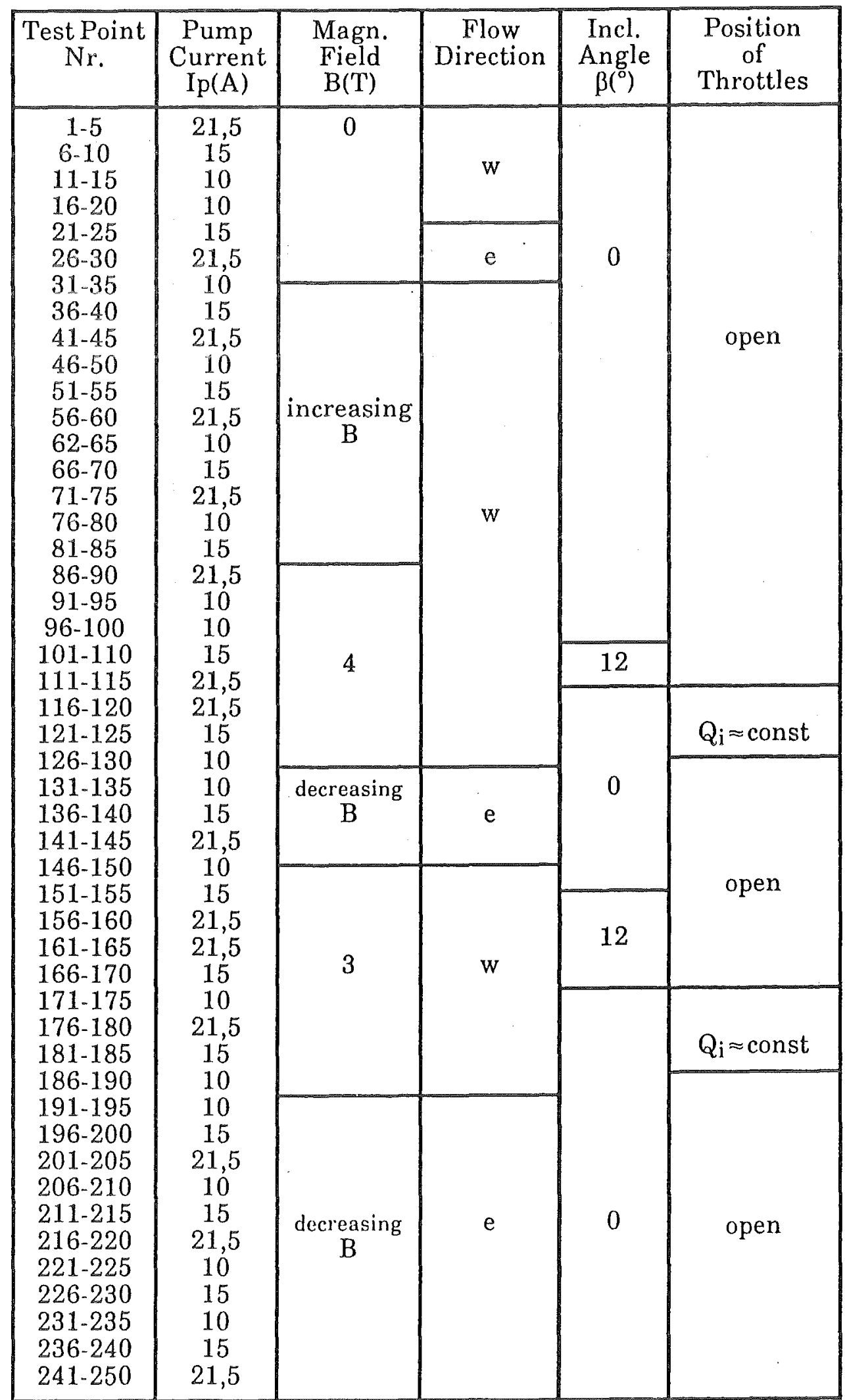


Table A6: Test Section Configuration VI

(Channel Geometry IV; $k=5$ )

Date: 9.11 .91

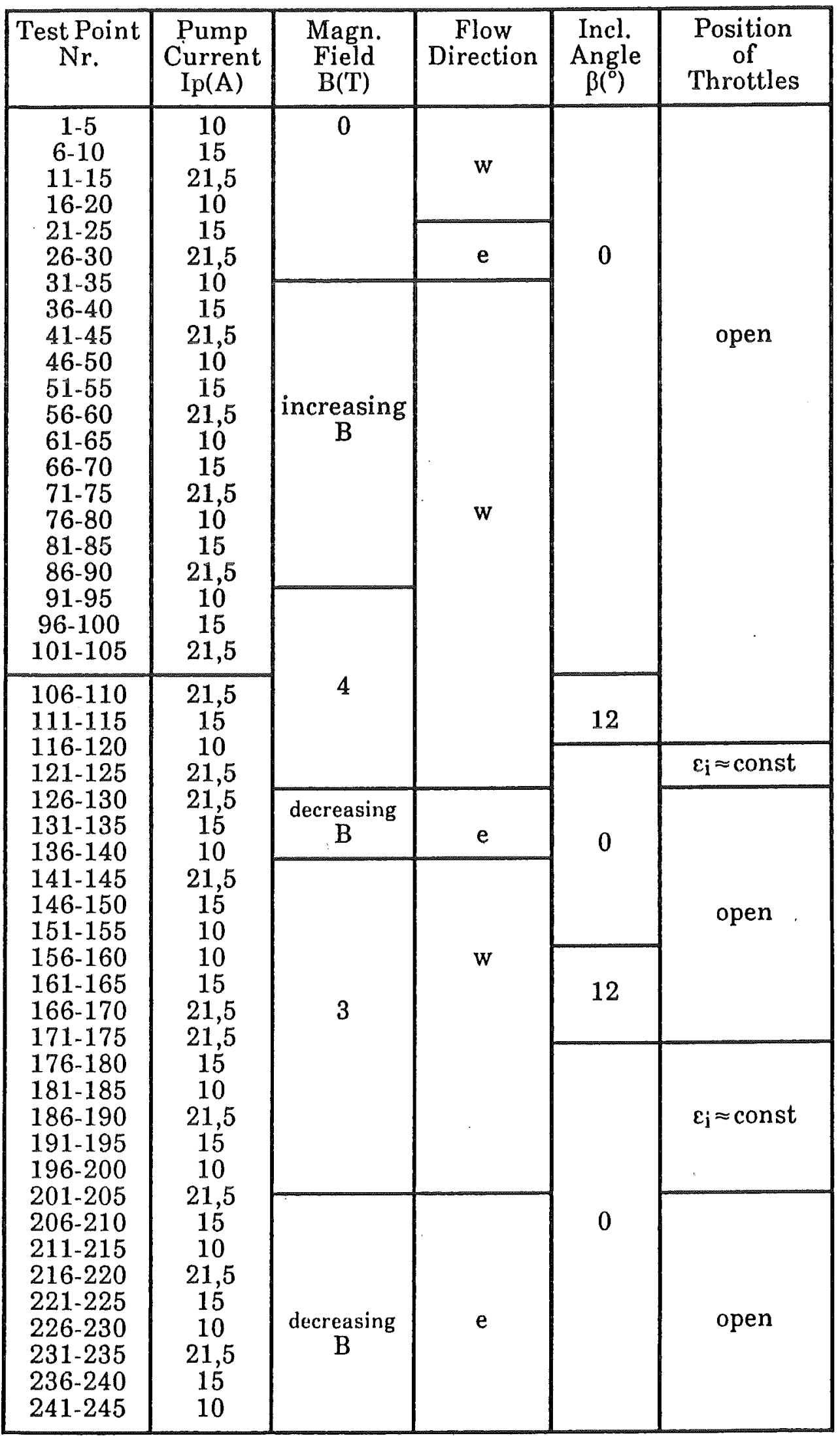

